Copies of NMR Spectra

For

\title{
Hydroxyalkylation of Conjugated Nitroalkenes with Activated Non-enolizable Carbonyl Compounds
}

Indubhusan Deb, ${ }^{\mathrm{a}}$ Mamta Dadwal, ${ }^{\mathrm{a}}$ Shaikh M. Mobin, ${ }^{\mathrm{b}}$ Irishi N. N. Namboothiri ${ }^{\text {a* }}$

\section{Table of Contents}

\begin{tabular}{|c|c|c|}
\hline & & Page \\
\hline 1 & Figure S1. ${ }^{1}$ H NMR Spectrum of $\mathbf{3 a}$ & 3 \\
\hline 2 & Figure S2. ${ }^{13} \mathrm{C}$ NMR Spectrum of $\mathbf{3 a}$ & 4 \\
\hline 3 & Figure S3. 1H NMR Spectrum of $\mathbf{3 b}$ & 5 \\
\hline 4 & Figure S4. ${ }^{13}$ C NMR Spectrum of $\mathbf{3 b}$ & 6 \\
\hline 5 & Figure S5. ${ }^{1} \mathrm{H}$ NMR Spectrum of $\mathbf{3 c}$ & 7 \\
\hline 6 & Figure S6. ${ }^{13} \mathrm{HC}$ NMR Spectrum of $\mathbf{3 c}$ & 8 \\
\hline 7 & Figure S7. ${ }^{1} \mathrm{H}$ NMR Spectrum of $\mathbf{3 d}$ & 9 \\
\hline 8 & Figure S8. ${ }^{13} \mathrm{C}$ NMR Spectrum of $\mathbf{3 d}$ & 10 \\
\hline 9 & Figure S9. ${ }^{1} \mathrm{H}-{ }^{1} \mathrm{H}$ NOESY Spectrum of $\mathbf{3 d}$ & 11 \\
\hline 10 & Figure S10. ${ }^{1} \mathrm{H}$ NMR Spectrum of $\mathbf{3 e}$ & 12 \\
\hline 11 & Figure S11. ${ }^{13}$ C NMR Spectrum of $\mathbf{3 e}$ & 13 \\
\hline 12 & Figure S12. ${ }^{1} \mathrm{H}$ NMR Spectrum of $\mathbf{3 f}$ & 14 \\
\hline 13 & Figure S13. ${ }^{13} \mathrm{C}$ NMR Spectrum of $\mathbf{3 f}$ & 15 \\
\hline 14 & Figure S14. ${ }^{1} \mathrm{H}$ NMR Spectrum of $\mathbf{3 g}$ & 16 \\
\hline 15 & Figure S15. ${ }^{13} \mathrm{C}$ NMR Spectrum of $\mathbf{3 g}$ & 17 \\
\hline 16 & Figure S16. ${ }^{1} \mathrm{H}$ NMR Spectrum of $\mathbf{3 h}$ & 18 \\
\hline 17 & Figure S17. ${ }^{13} \mathrm{C}$ NMR Spectrum of $\mathbf{3 h}$ & 19 \\
\hline 18 & Figure S18. ${ }^{1} \mathrm{H}$ NMR Spectrum of $\mathbf{3 i}$ & 20 \\
\hline 19 & Figure S19. ${ }^{13} \mathrm{C}$ NMR Spectrum of $\mathbf{3 i}$ & 21 \\
\hline 20 & Figure $S 20 .{ }^{1} \mathrm{H}$ NMR Spectrum of $\mathbf{3 j}$ & 22 \\
\hline 21 & Figure $S 21 .{ }^{13} \mathrm{C}$ NMR Spectrum of $\mathbf{3} \mathbf{j}$ & 23 \\
\hline 22 & Figure S22. ${ }^{1} \mathrm{H}$ NMR Spectrum of $\mathbf{3 k}$ & 24 \\
\hline 23 & Figure S23. ${ }^{13} \mathrm{C}$ NMR Spectrum of $\mathbf{3 k}$ & 25 \\
\hline 24 & Figure S24. ${ }^{1} \mathrm{H}$ NMR Spectrum of $\mathbf{3 l}$ & 26 \\
\hline 25 & Figure S25. ${ }^{13} \mathrm{C}$ NMR Spectrum of $\mathbf{3 1}$ & 27 \\
\hline 26 & Figure S26. ${ }^{1} \mathrm{H}$ NMR Spectrum of $\mathbf{3 m}$ & 28 \\
\hline 27 & Figure S27. ${ }^{13} \mathrm{C}$ NMR Spectrum of $\mathbf{3 m}$ & 29 \\
\hline 28 & Figure S28. ${ }^{1} \mathrm{H}$ NMR Spectrum of $\mathbf{4 c}$ & 30 \\
\hline 29 & Figure S29. ${ }^{13} \mathrm{C}$ NMR Spectrum of $\mathbf{4 c}$ & 31 \\
\hline 30 & Figure S30. ${ }^{19}$ FNMR Spectrum of $\mathbf{4 c}$ & 32 \\
\hline 31 & Figure S31. ${ }^{1} \mathrm{H}$ NMR Spectrum of $\mathbf{4 d}$ & 33 \\
\hline 32 & Figure S32. ${ }^{13} \mathrm{C}$ NMR Spectrum of $\mathbf{4 d}$ & 34 \\
\hline 33 & Figure S33. ${ }^{19}$ FNMR Spectrum of $\mathbf{4 d}$ & 35 \\
\hline 34 & Figure S34. ${ }^{1}$ H NMR Spectrum of $\mathbf{4 e}$ & 36 \\
\hline 35 & Figure S35. ${ }^{13} \mathrm{C}$ NMR Spectrum of $\mathbf{4 e}$ & 37 \\
\hline 36 & Figure S36. ${ }^{19}$ FNMR Spectrum of $\mathbf{4 e}$ & 38 \\
\hline 37 & Figure S37. ${ }^{1} \mathrm{H}$ NMR Spectrum of $\mathbf{4 f}$ & 39 \\
\hline 38 & Figure S38. ${ }^{13} \mathrm{C}$ NMR Spectrum of $\mathbf{4 f}$ & 40 \\
\hline 39 & Figure S39. ${ }^{19}$ FNMR Spectrum of $\mathbf{4 f}$ & 41 \\
\hline
\end{tabular}


40 Figure S40. ${ }^{1} \mathrm{H}$ NMR Spectrum of $\mathbf{5} \mathbf{b}$

41 Figure S41. ${ }^{13} \mathrm{C}$ NMR Spectrum of $\mathbf{5 b}$

42 Figure S42. ${ }^{1} \mathrm{H}$ NMR Spectrum of $\mathbf{5 c}$

43 Figure S43. ${ }^{13} \mathrm{C}$ NMR Spectrum of $\mathbf{5 c}$

44 Figure S44. ${ }^{1} \mathrm{H}$ NMR Spectrum of $\mathbf{5 d}$

45 Figure $\mathrm{S} 45 .{ }^{13} \mathrm{C}$ NMR Spectrum of $\mathbf{5 d}$

46 Figure S46. ${ }^{1} \mathrm{H}$ NMR Spectrum of $\mathbf{5 e}$

47 Figure S47. ${ }^{13} \mathrm{C}$ NMR Spectrum of $\mathbf{5 e}$

48 Figure S48. ${ }^{1} \mathrm{H}$ NMR Spectrum of $\mathbf{5 f}$

49 Figure S49. ${ }^{13} \mathrm{C}$ NMR Spectrum of $\mathbf{5 f}$

50 Figure S50. ${ }^{1} \mathrm{H}$ NMR Spectrum of $\mathbf{6 c}+\mathbf{7 c}$

51 Figure S51. ${ }^{13} \mathrm{C}$ NMR Spectrum of $\mathbf{6 c}+\mathbf{7 c}$

52 Figure S52. ${ }^{1} \mathrm{H}$ NMR Spectrum of $\mathbf{6 d}+\mathbf{7 d}$

53 Figure S53. ${ }^{13}$ C NMR Spectrum of $\mathbf{6 d}+\mathbf{7 d}$

54 Figure S54. ${ }^{1} \mathrm{H}$ NMR Spectrum of $6 \mathbf{e}$

55 Figure S55. ${ }^{13} \mathrm{HC}$ NMR Spectrum of $6 \mathbf{e}$

56 Figure S56. ${ }^{1} \mathrm{H}$ NMR Spectrum of $\mathbf{6} \mathbf{f}$

57 Figure S57. ${ }^{13} \mathrm{C}$ NMR Spectrum of $\mathbf{6 f}$

58 Figure S58. ${ }^{1} \mathrm{H}$ NMR Spectrum of $\mathbf{6 g}$

59 Figure S59. ${ }^{13} \mathrm{C}$ NMR Spectrum of $\mathbf{6 g}$

60 Figure S60. ${ }^{1} \mathrm{H}$ NMR Spectrum of $\mathbf{7 g}$

61 Figure S61. ${ }^{13} \mathrm{C}$ NMR Spectrum of $\mathbf{7 g}$ 


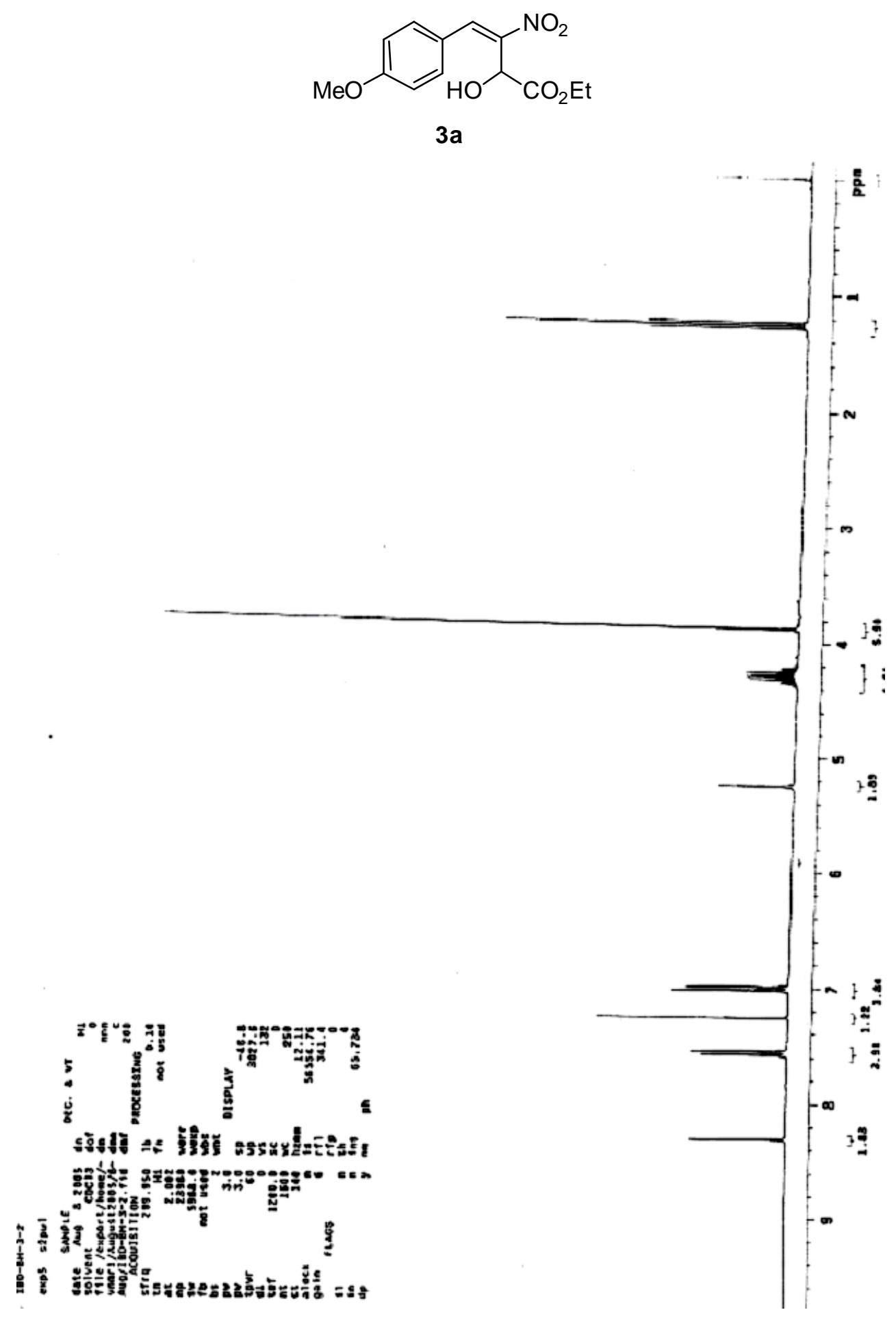

Figure S1. ${ }^{1} \mathrm{H}$ NMR Spectrum of $\mathbf{3 a}$ 

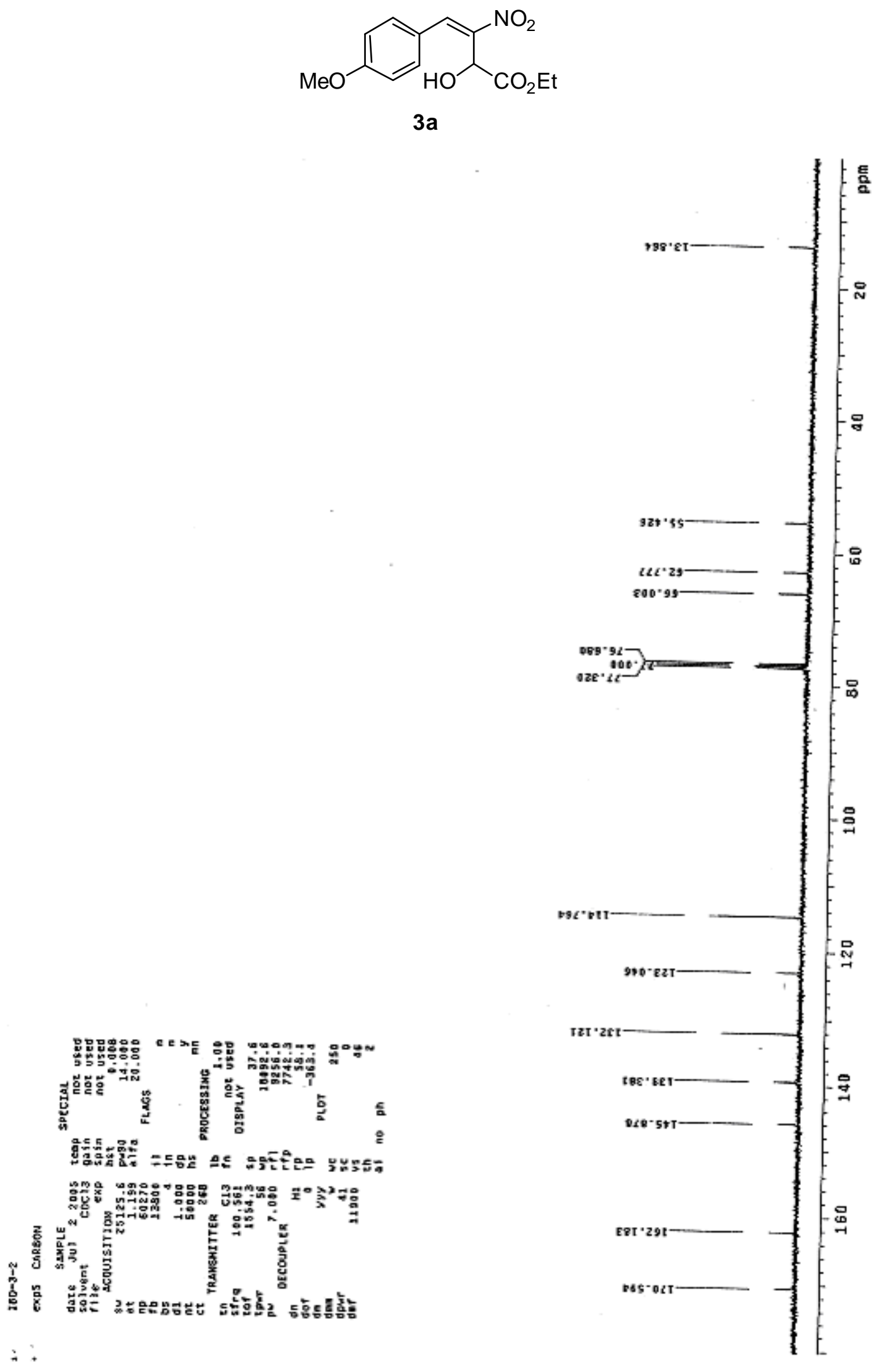

Figure S2. ${ }^{13} \mathrm{C}$ NMR Spectrum of $\mathbf{3 a}$ 


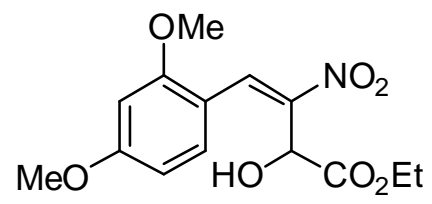

$3 b$

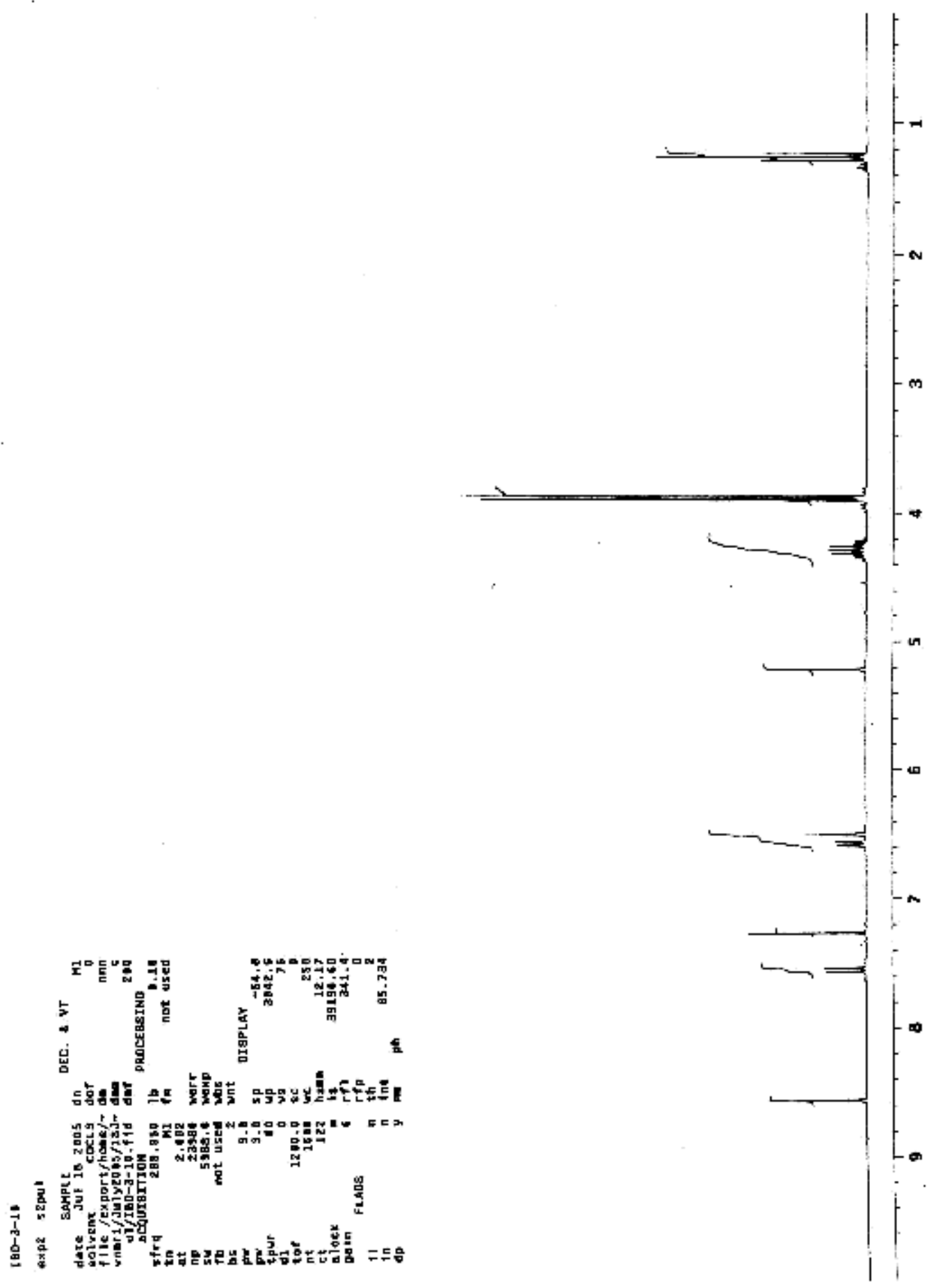

Figure S3. ${ }^{1} \mathrm{H}$ NMR Spectrum of $\mathbf{3 b}$ 


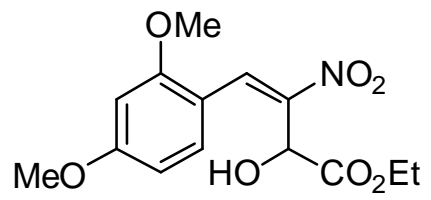

3b

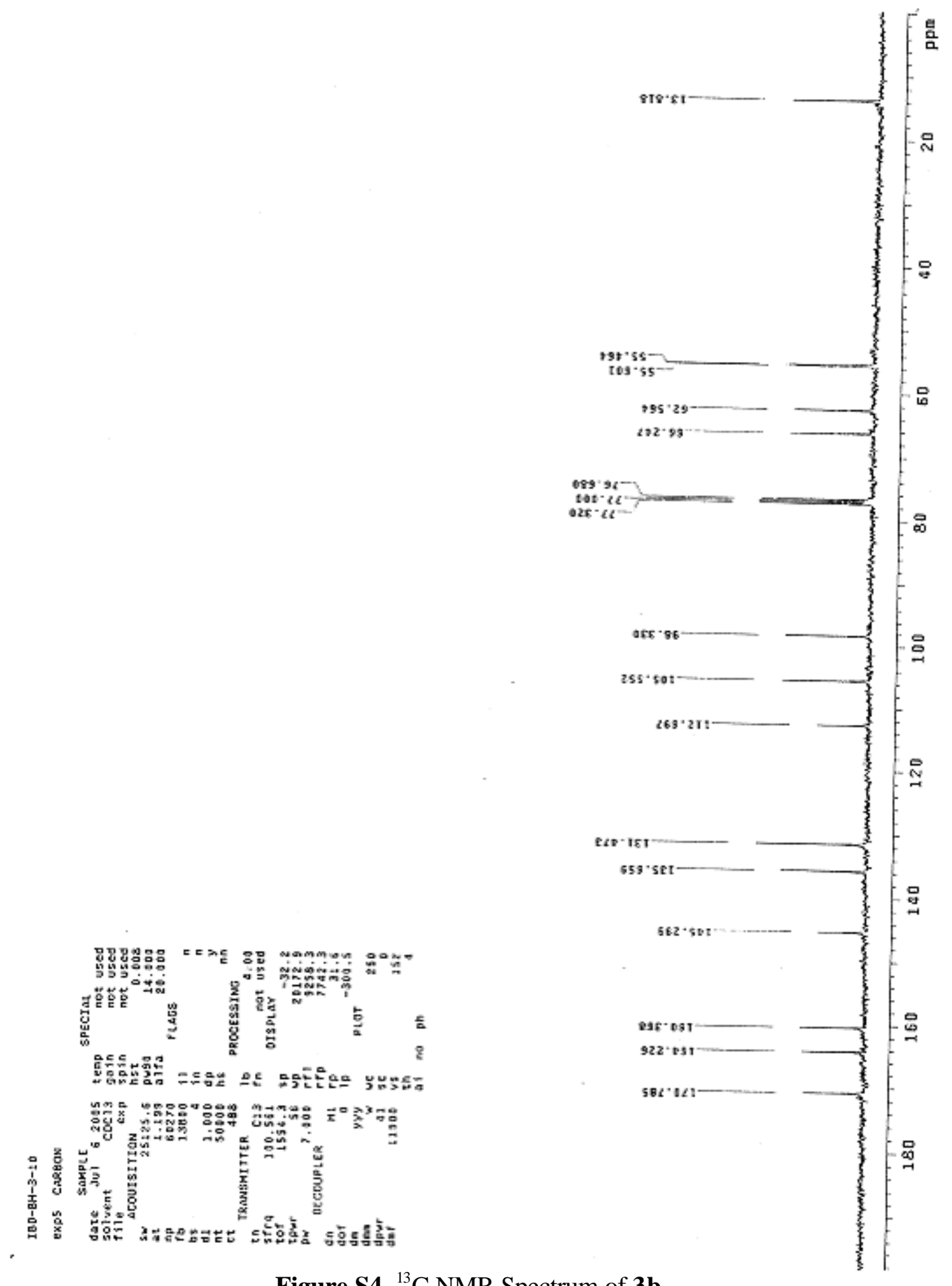

Figure S4. ${ }^{13} \mathrm{C}$ NMR Spectrum of $\mathbf{3 b}$ 


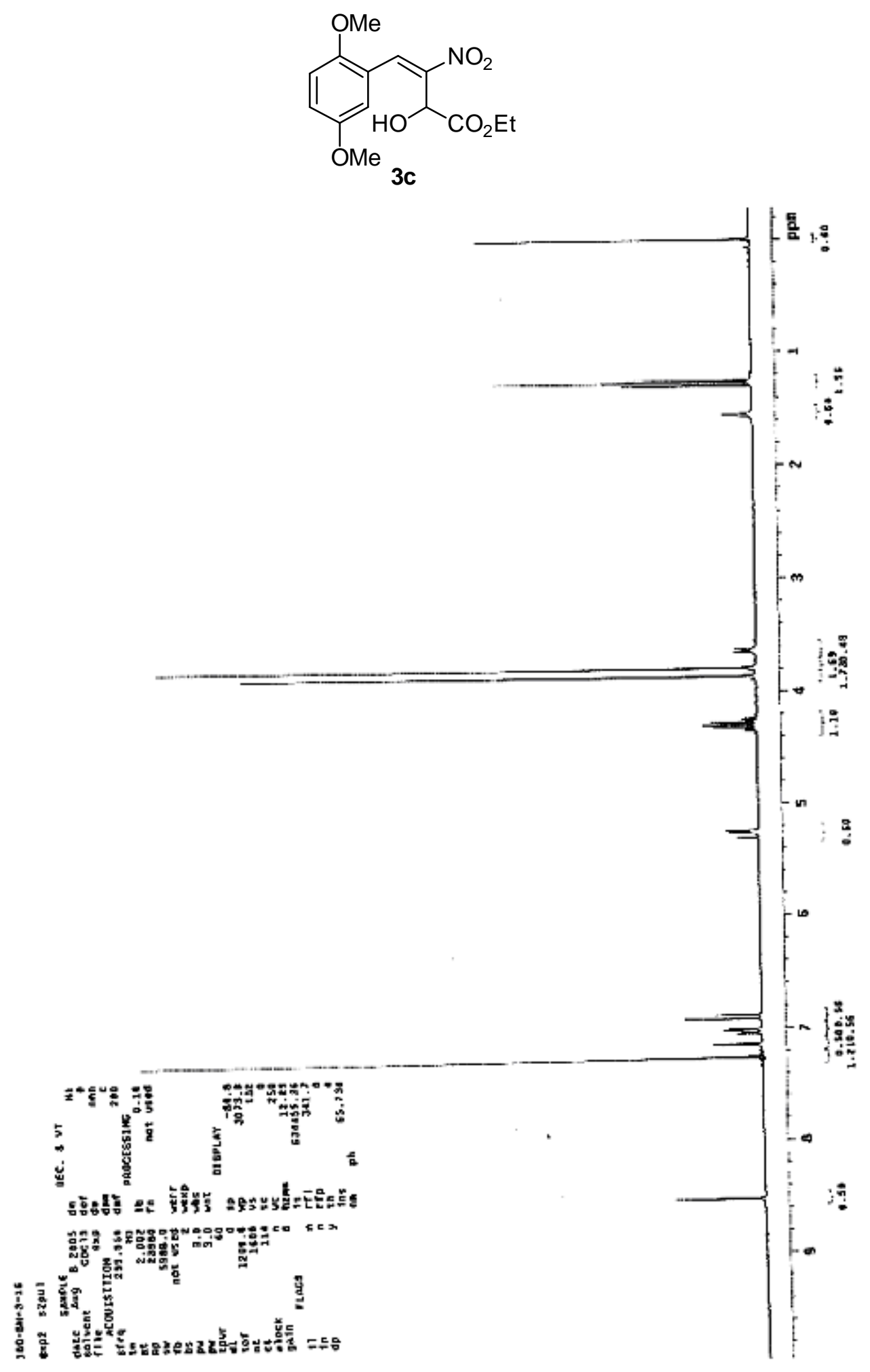

Figure S5. ${ }^{1}$ H NMR Spectrum of $\mathbf{3 c}$ 
<smiles>CCOC(O)C(=Cc1cc(OC)ccc1OC)[N+](=O)[O-]</smiles>

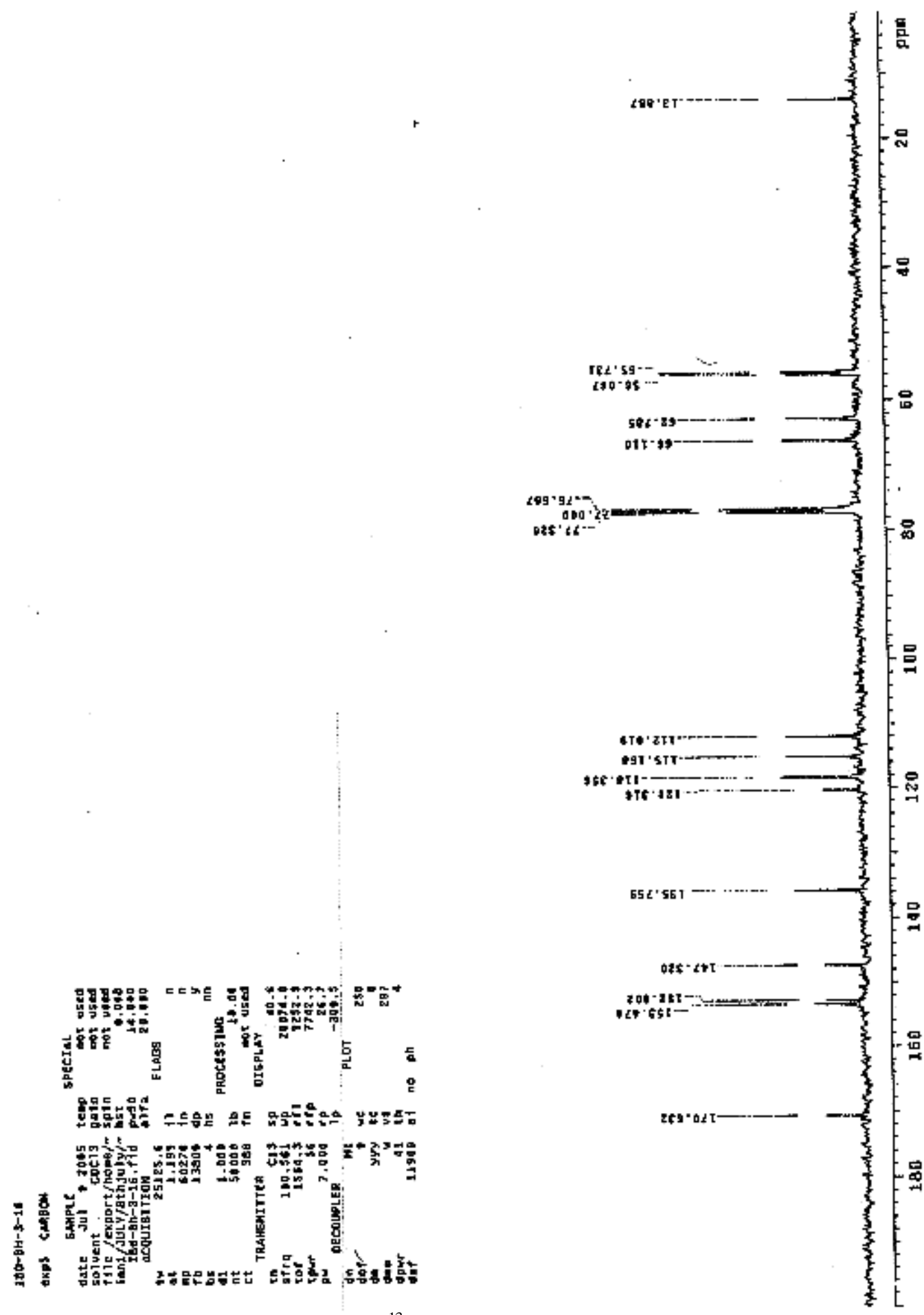

Figure S6. ${ }^{13} \mathrm{C}$ NMR Spectrum of $\mathbf{3 c}$ 


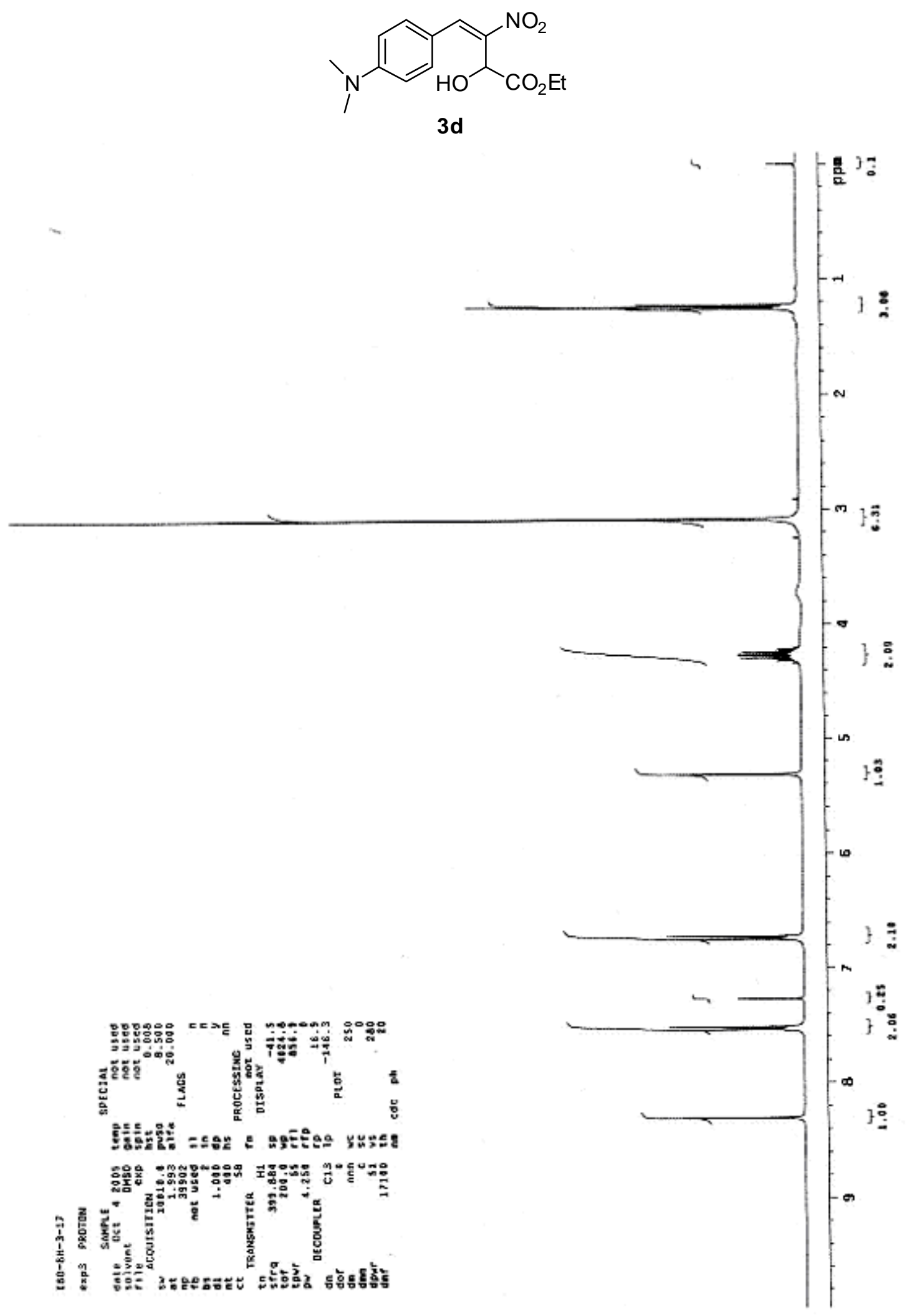

Figure S6. ${ }^{1} \mathrm{H}$ NMR Spectrum of $\mathbf{3 d}$ 
<smiles>CCOC(=O)C(O)/C(=C\c1ccc(N(C)C)cc1)[N+](=O)[O-]</smiles>

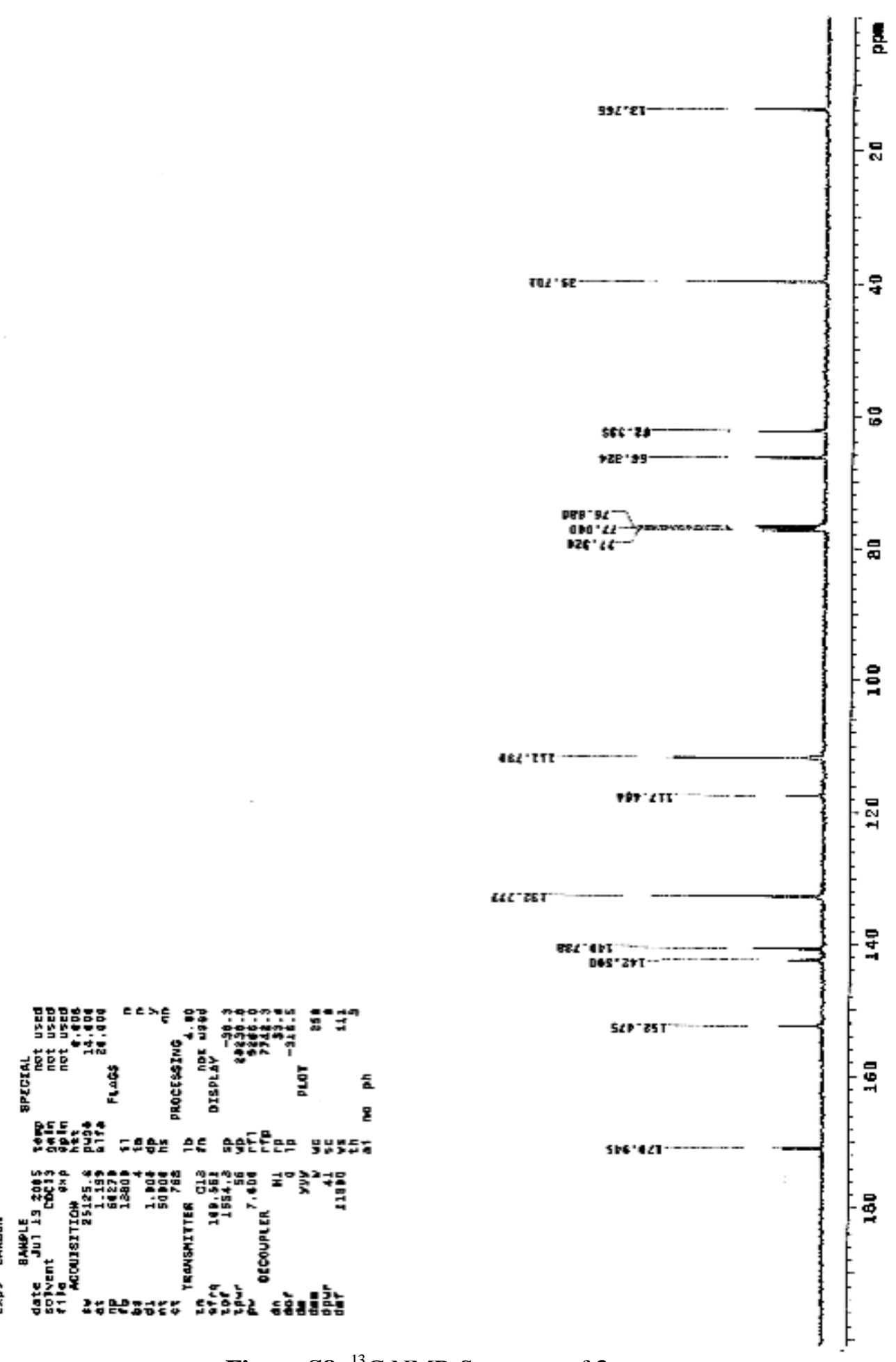

Figure S8. ${ }^{13} \mathrm{C}$ NMR Spectrum of $\mathbf{3 c}$ 

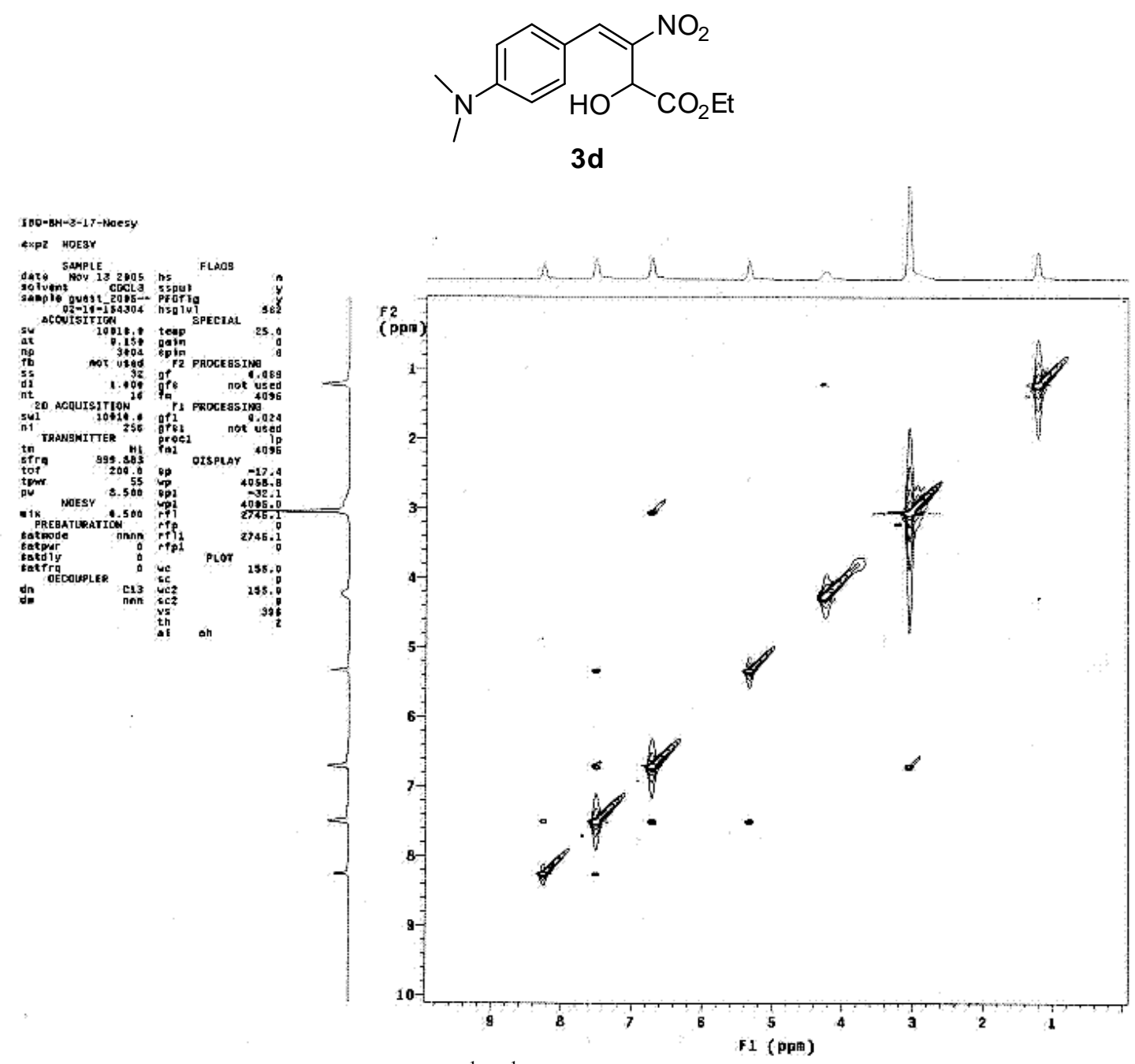

Figure S9. ${ }^{1} \mathrm{H}-{ }^{1} \mathrm{H}$ NOESY Spectrum of $\mathbf{3 d}$ 


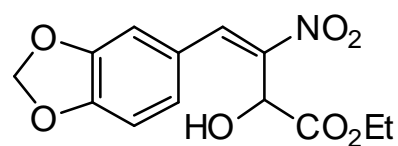

$3 e$

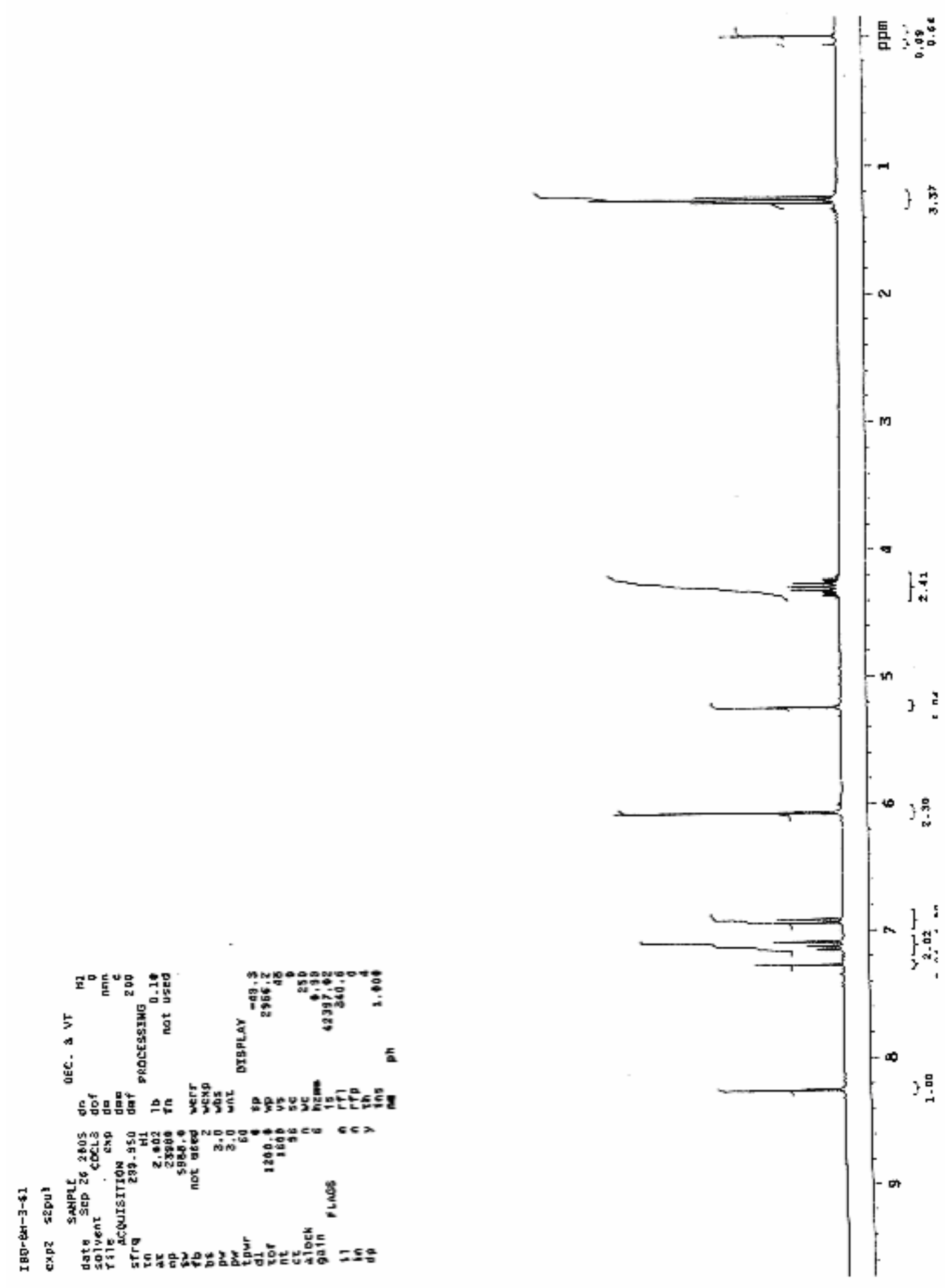

Figure S10. ${ }^{1} \mathrm{H}$ NMR Spectrum of $\mathbf{3 e}$ 


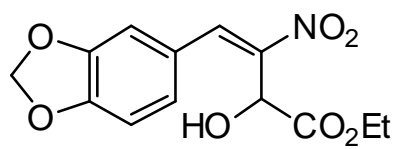

$3 e$

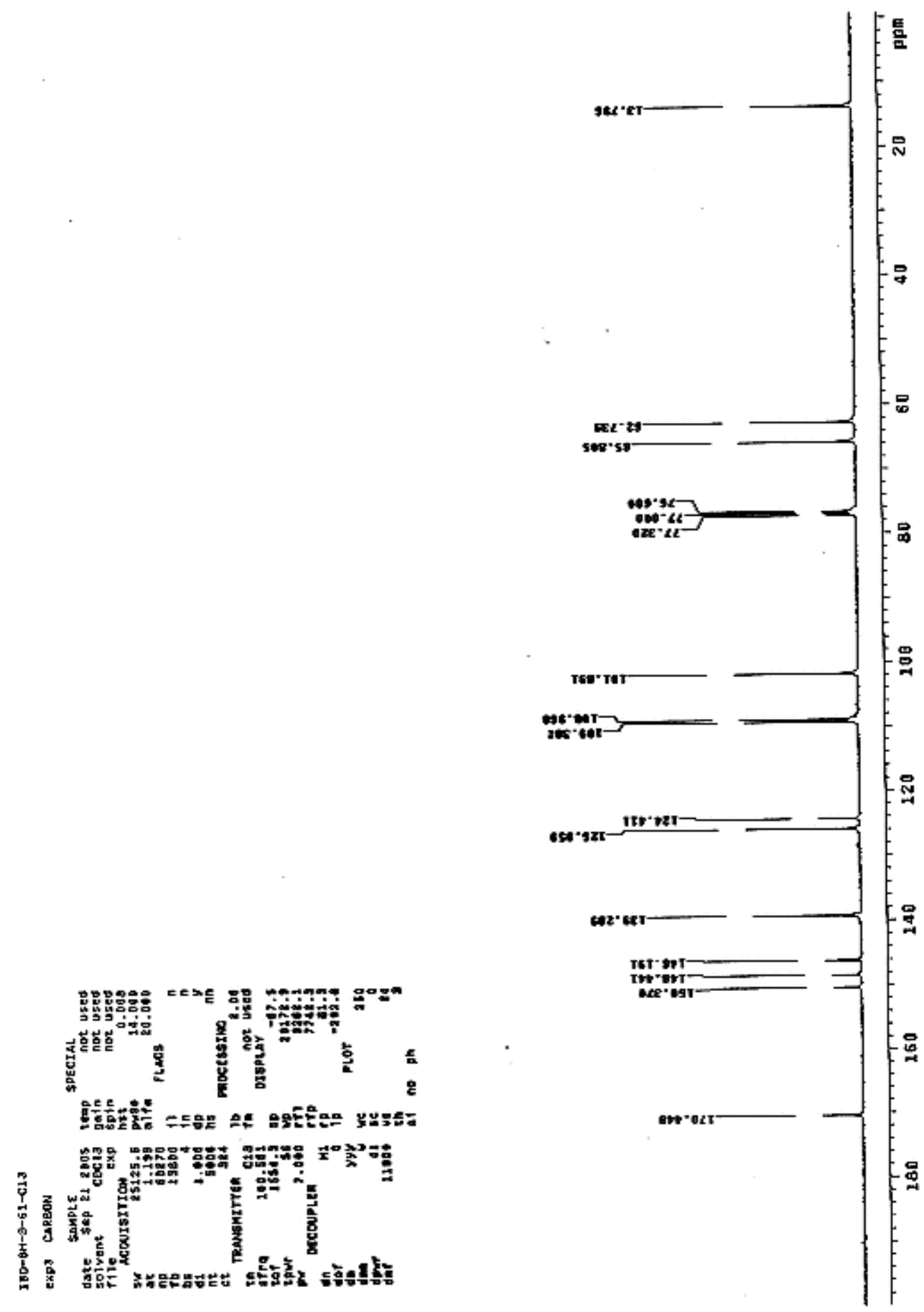

Figure S11. ${ }^{13} \mathrm{C}$ NMR Spectrum of $\mathbf{3 e}$ 


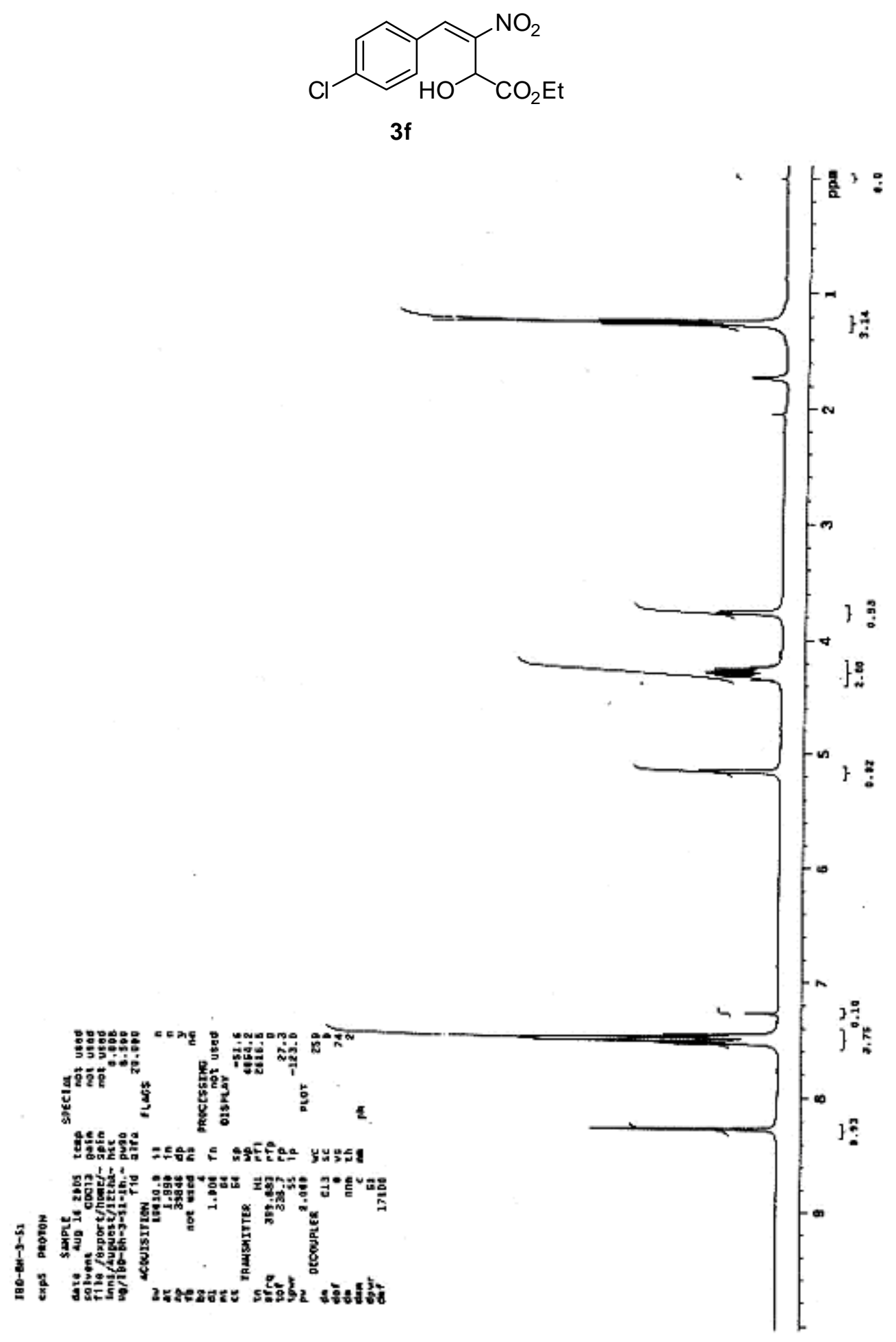

Figure S12. ${ }^{1} \mathrm{H}$ NMR Spectrum of $\mathbf{3 f}$ 


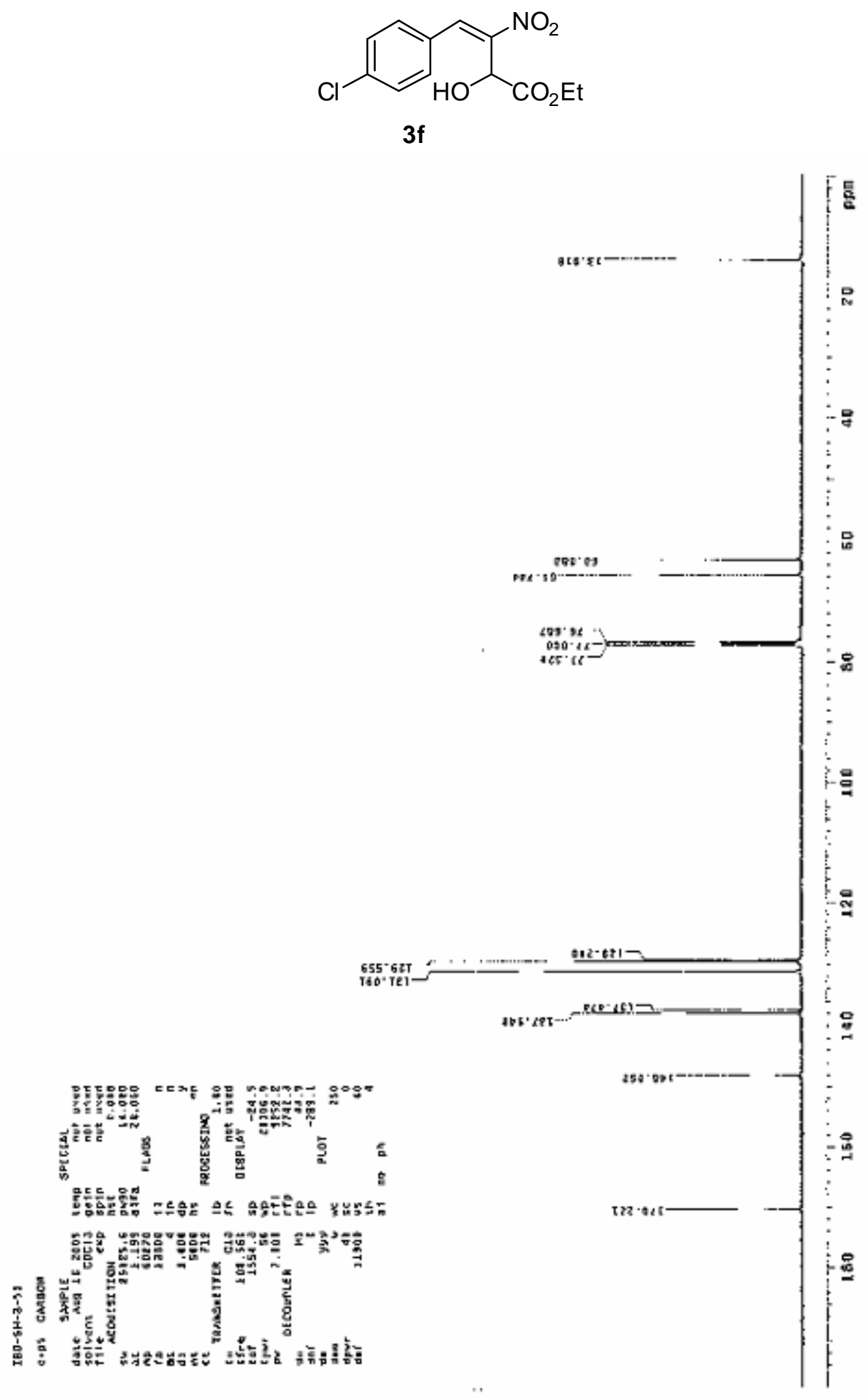

Figure S13. ${ }^{13} \mathrm{C}$ NMR Spectrum of $\mathbf{3 f}$ 


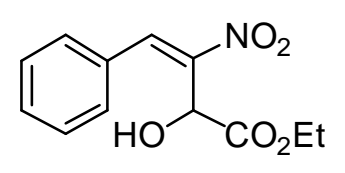

$3 g$

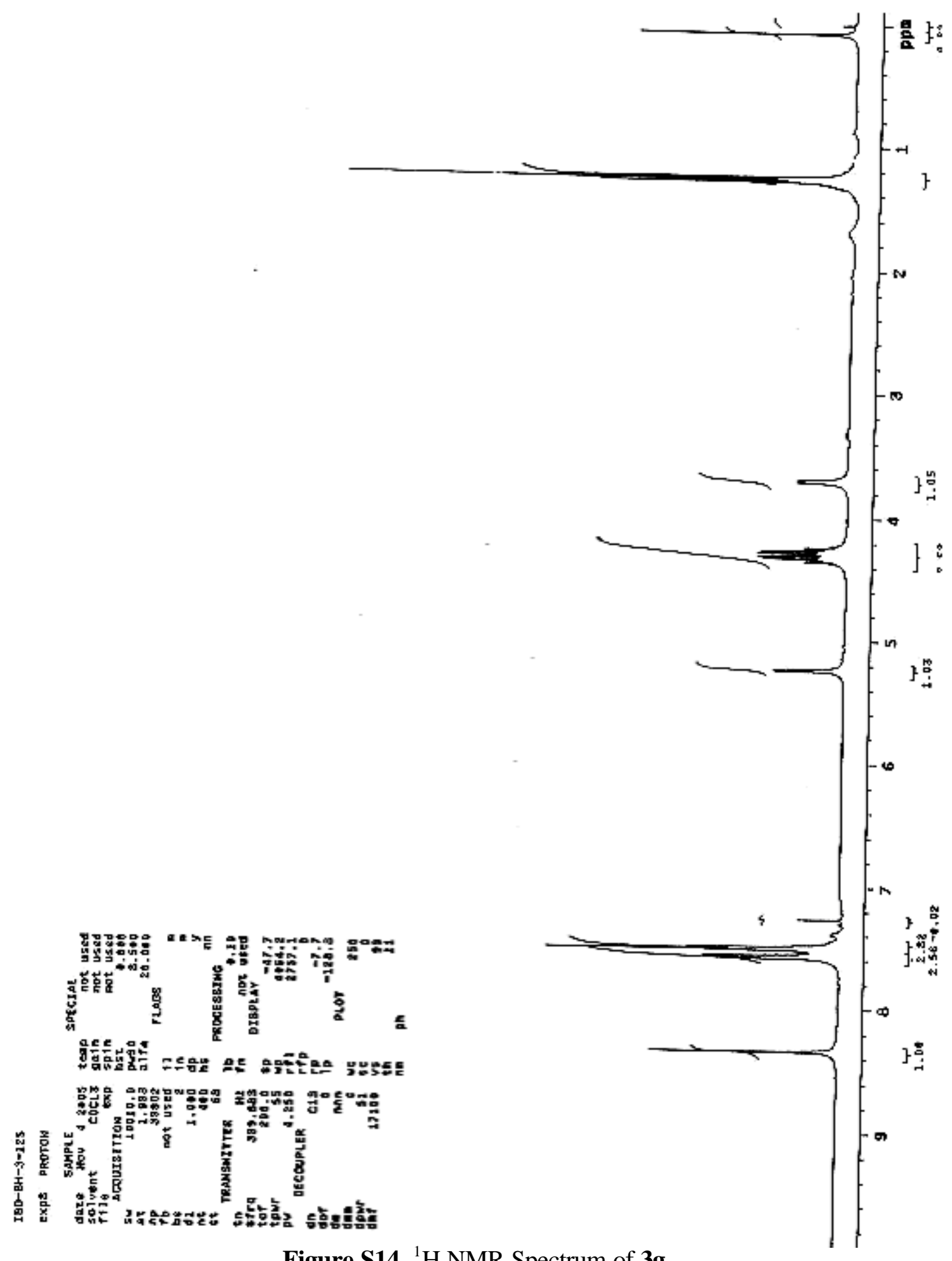

Figure S14. ${ }^{1} \mathrm{H}$ NMR Spectrum of $\mathbf{3 g}$ 


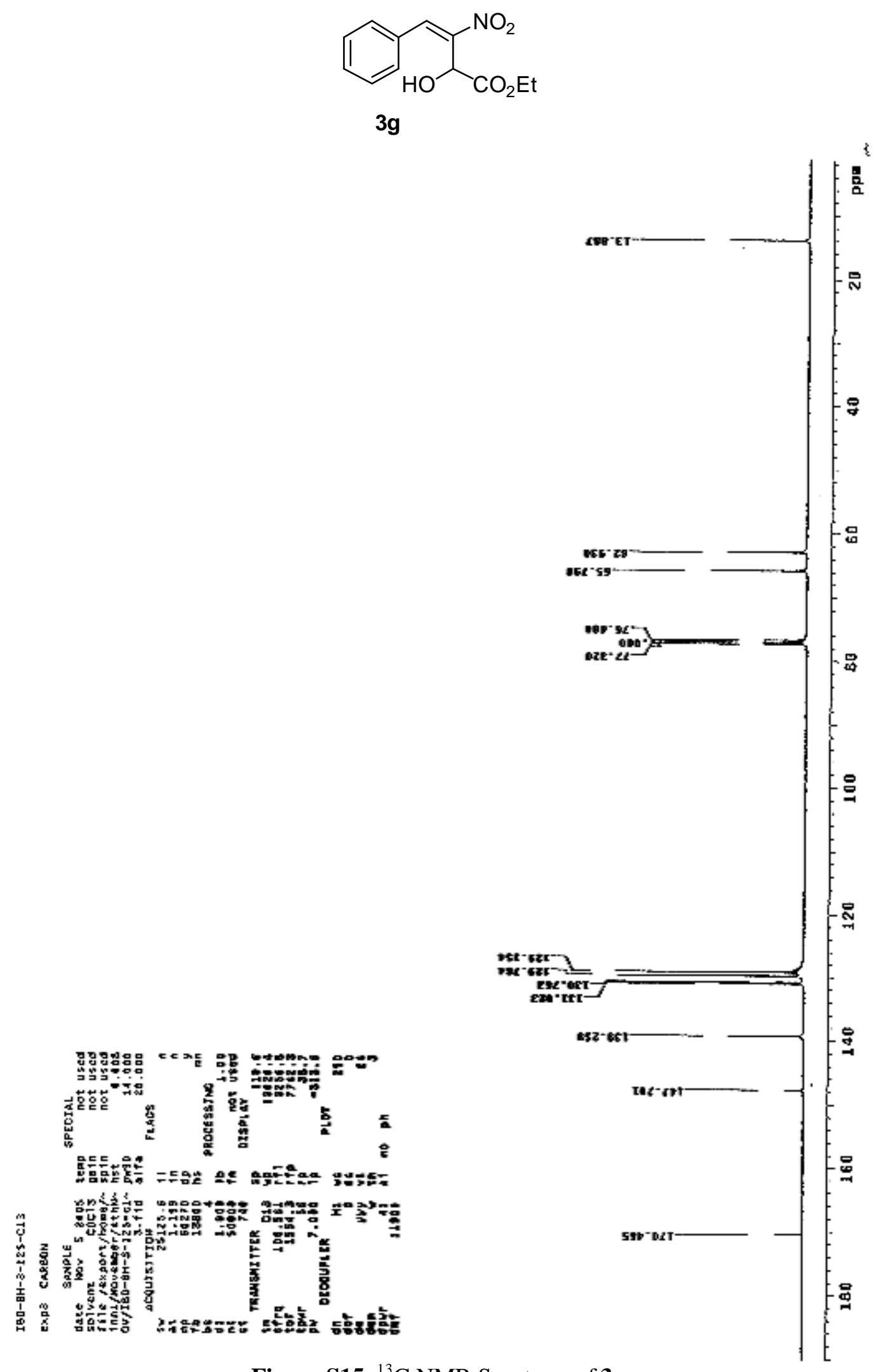

Figure S15. ${ }^{13} \mathrm{C}$ NMR Spectrum of $\mathbf{3 g}$ 

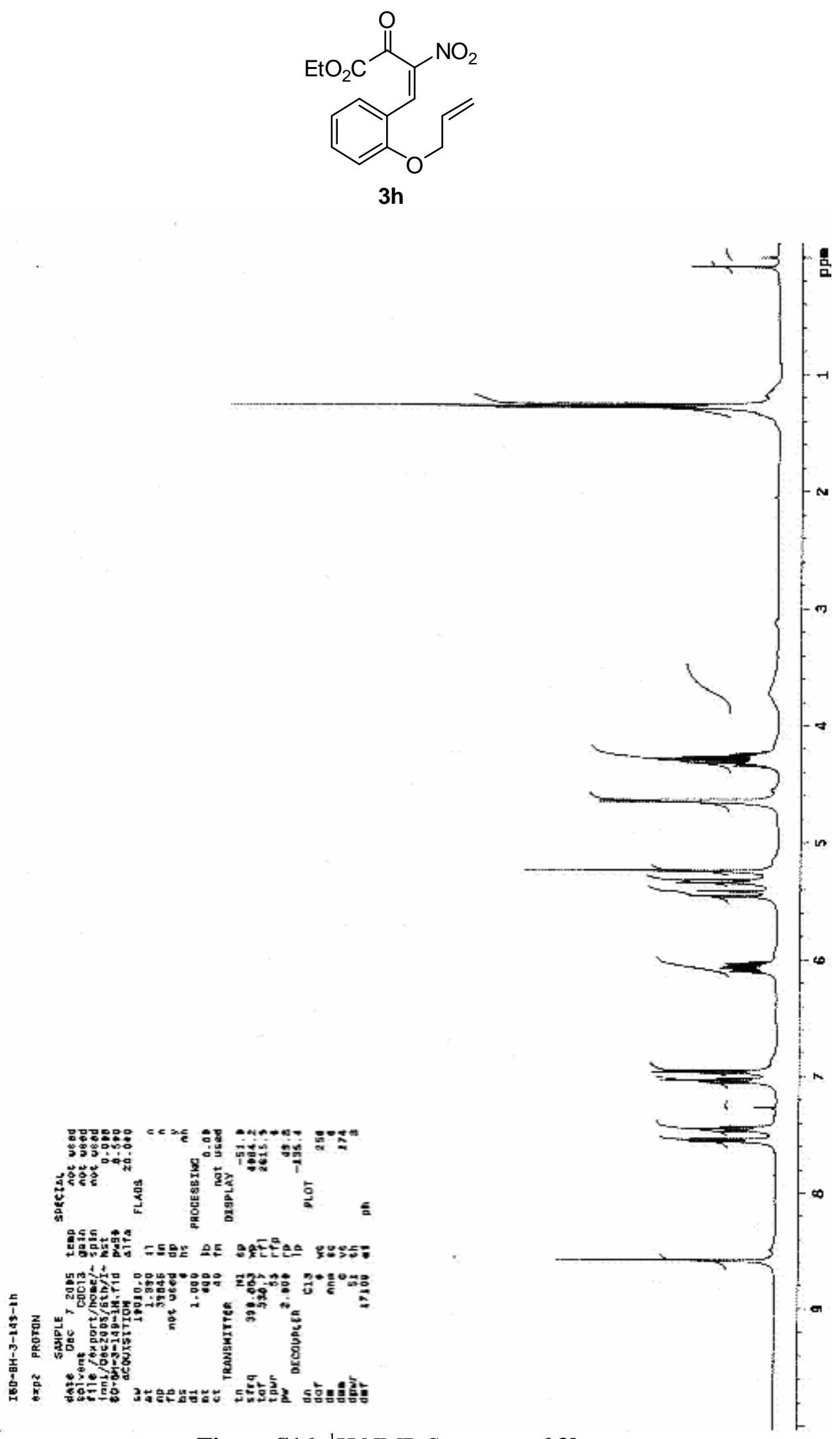

Figure S16. ${ }^{1} \mathrm{H}$ NMR Spectrum of $\mathbf{3 h}$ 

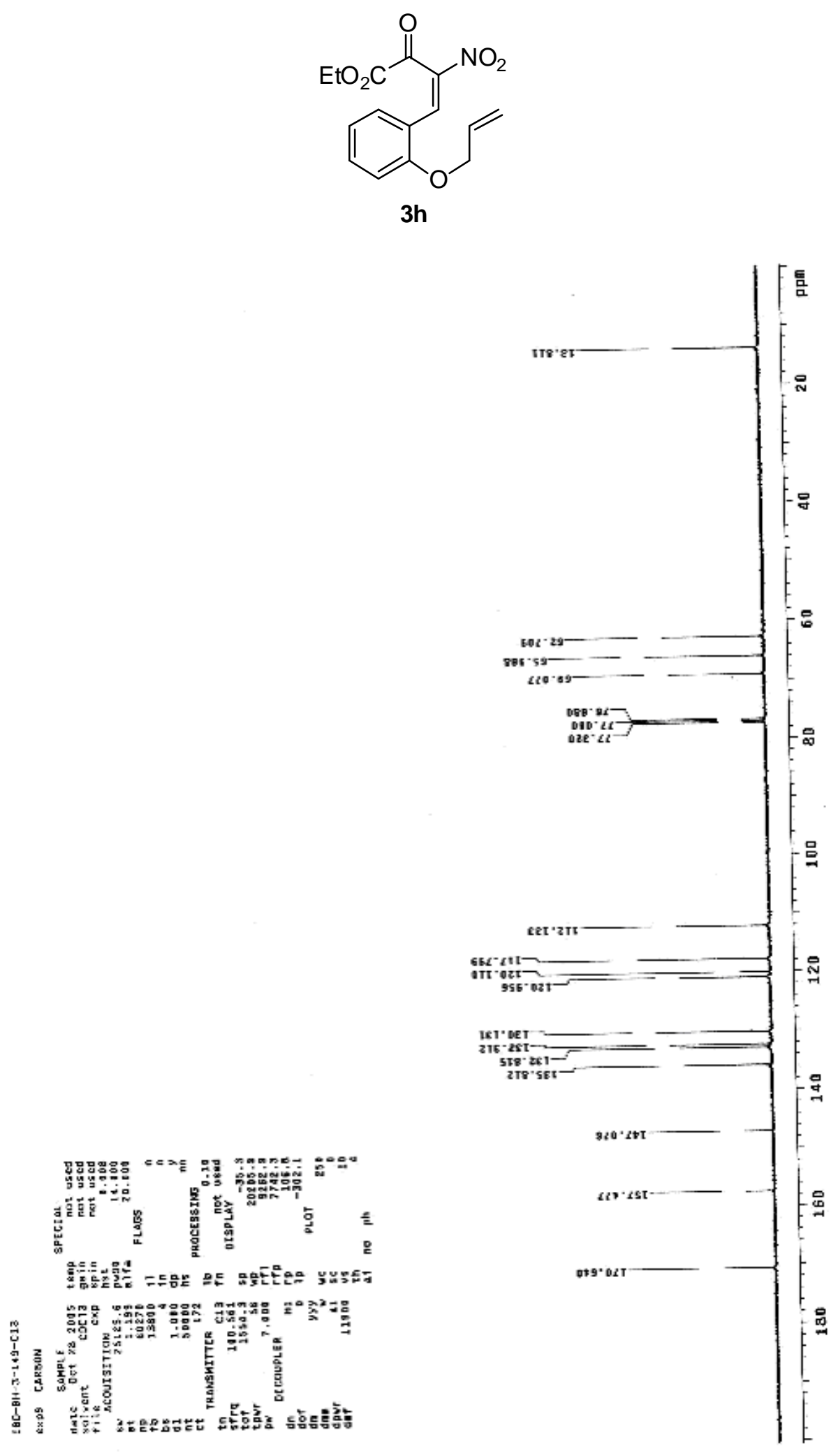

Figure S17. ${ }^{13} \mathrm{C}$ NMR Spectrum of $\mathbf{3 h}$ 


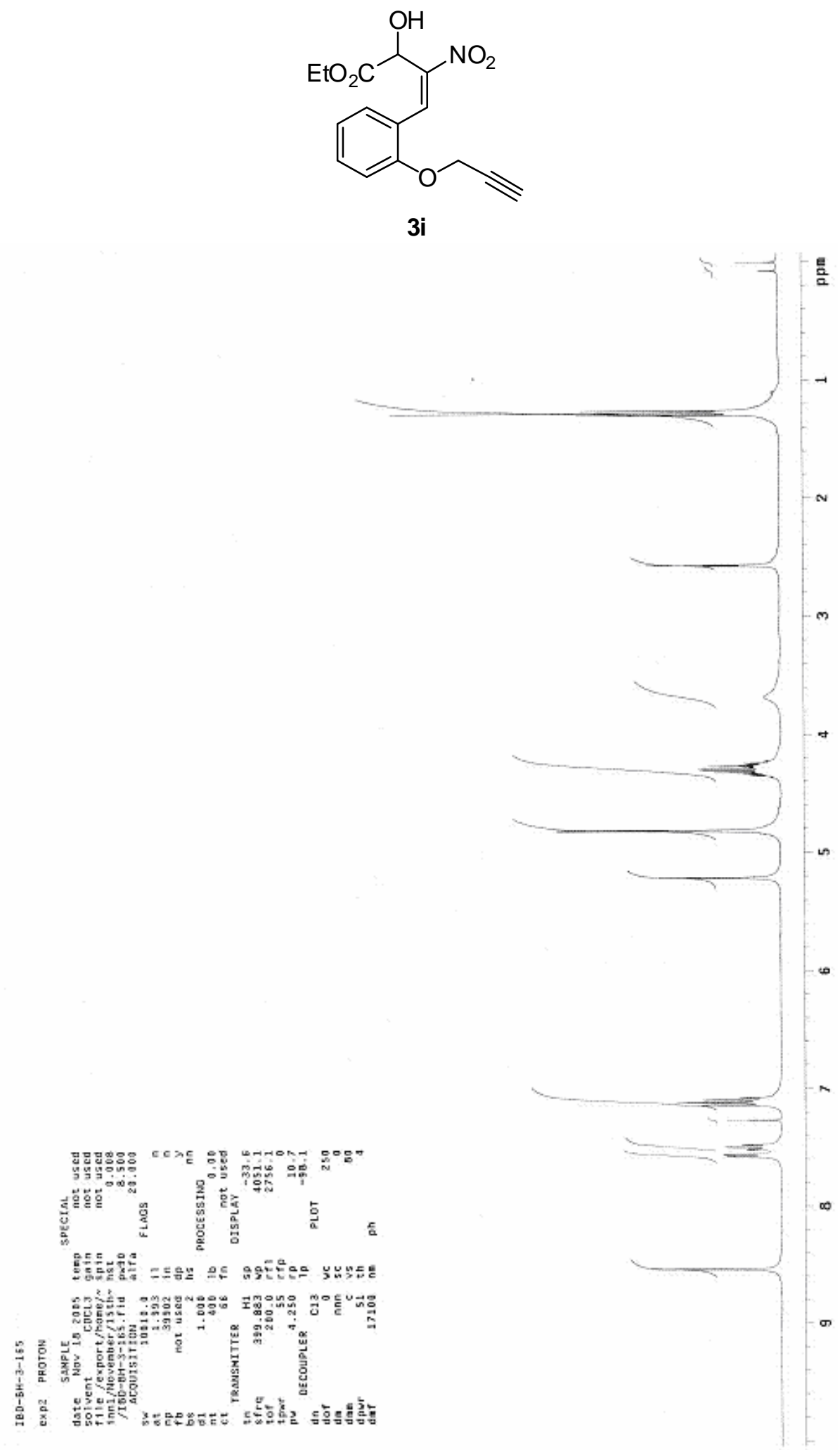

Figure S18. ${ }^{1}$ H NMR Spectrum of $\mathbf{3 i}$ 


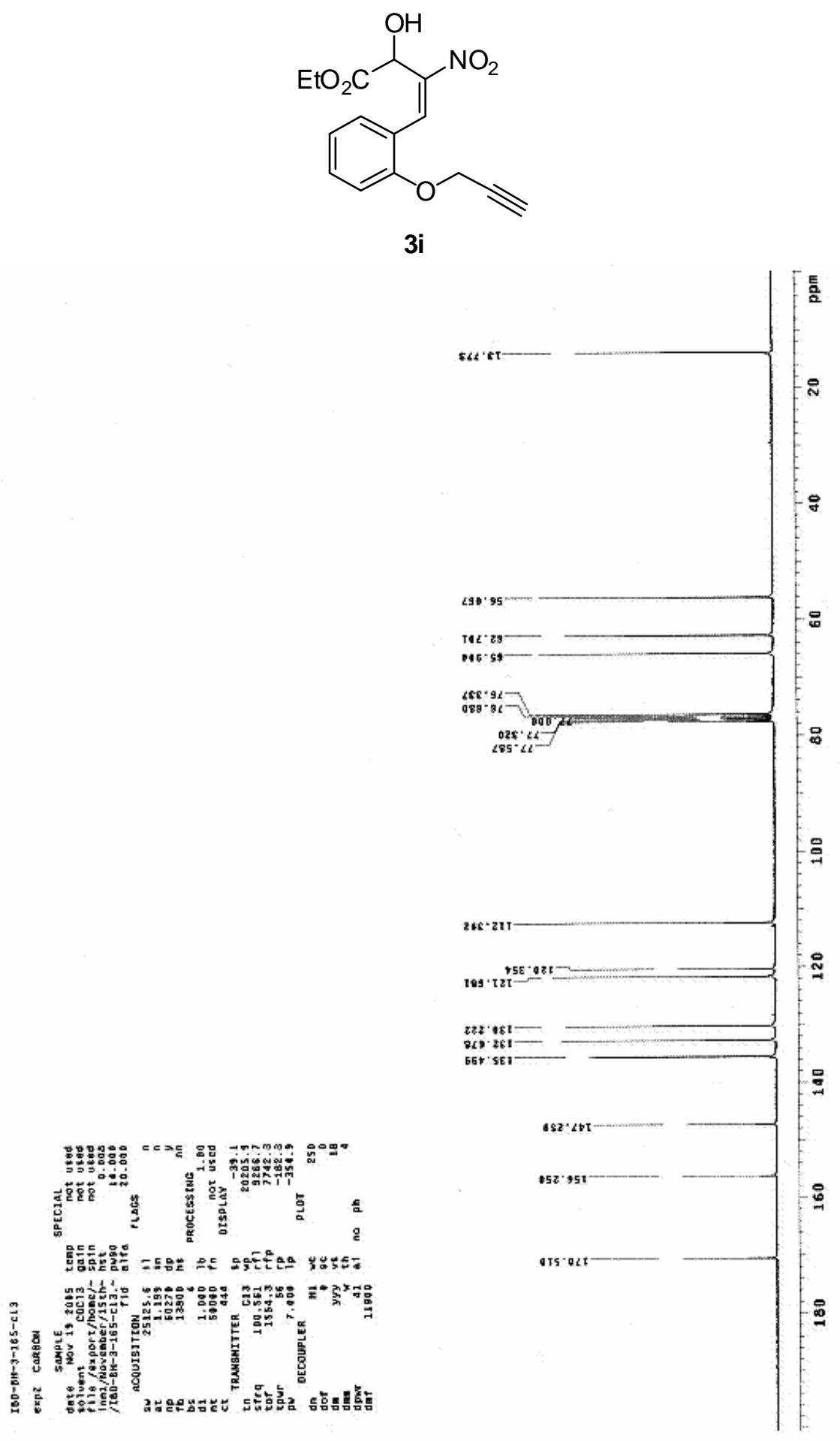

Figure S19. ${ }^{13} \mathrm{C}$ NMR Spectrum of $\mathbf{3 i}$ 


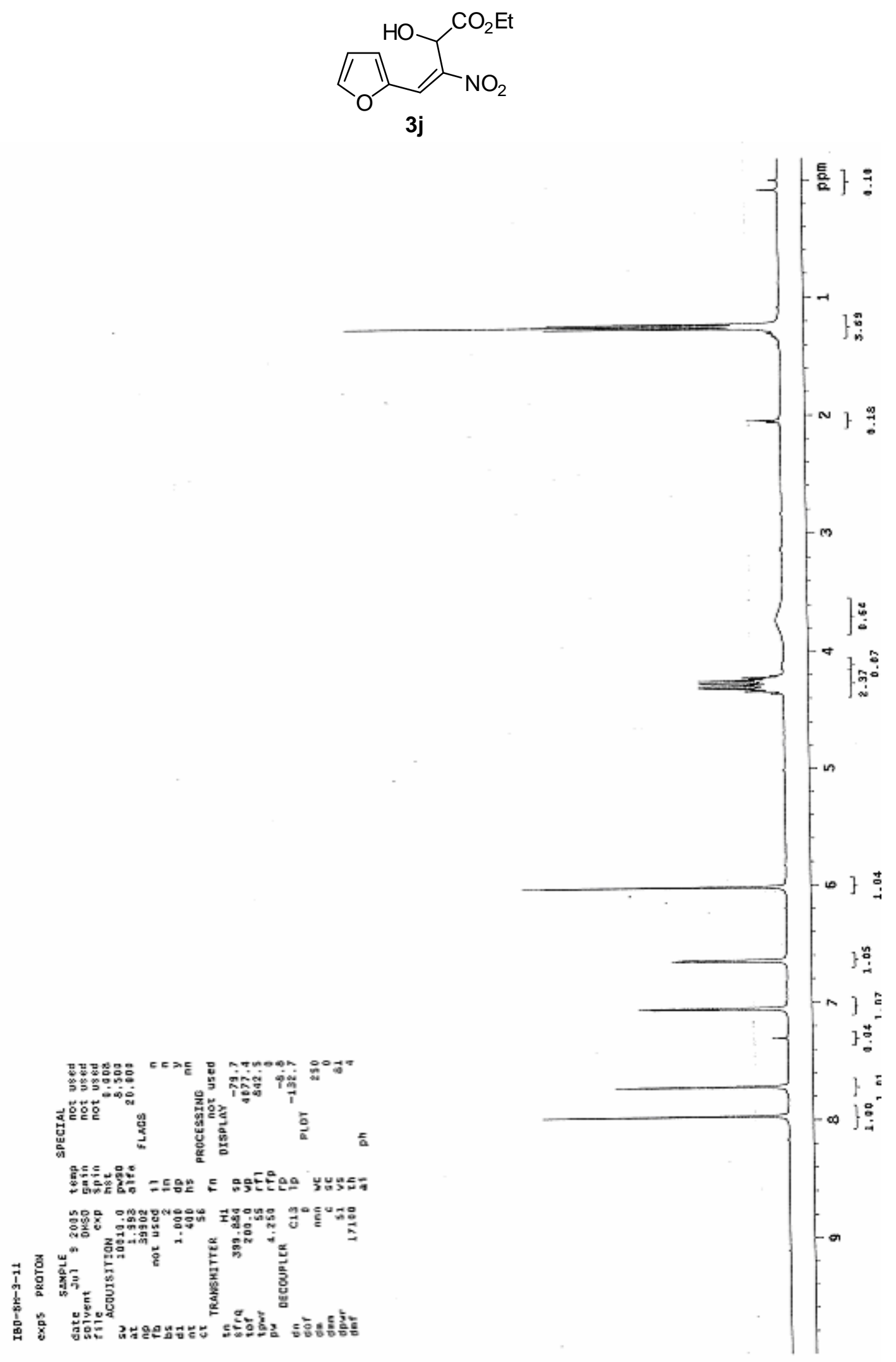

Figure S20. ${ }^{1}$ H NMR Spectrum of $\mathbf{3 j}$ 


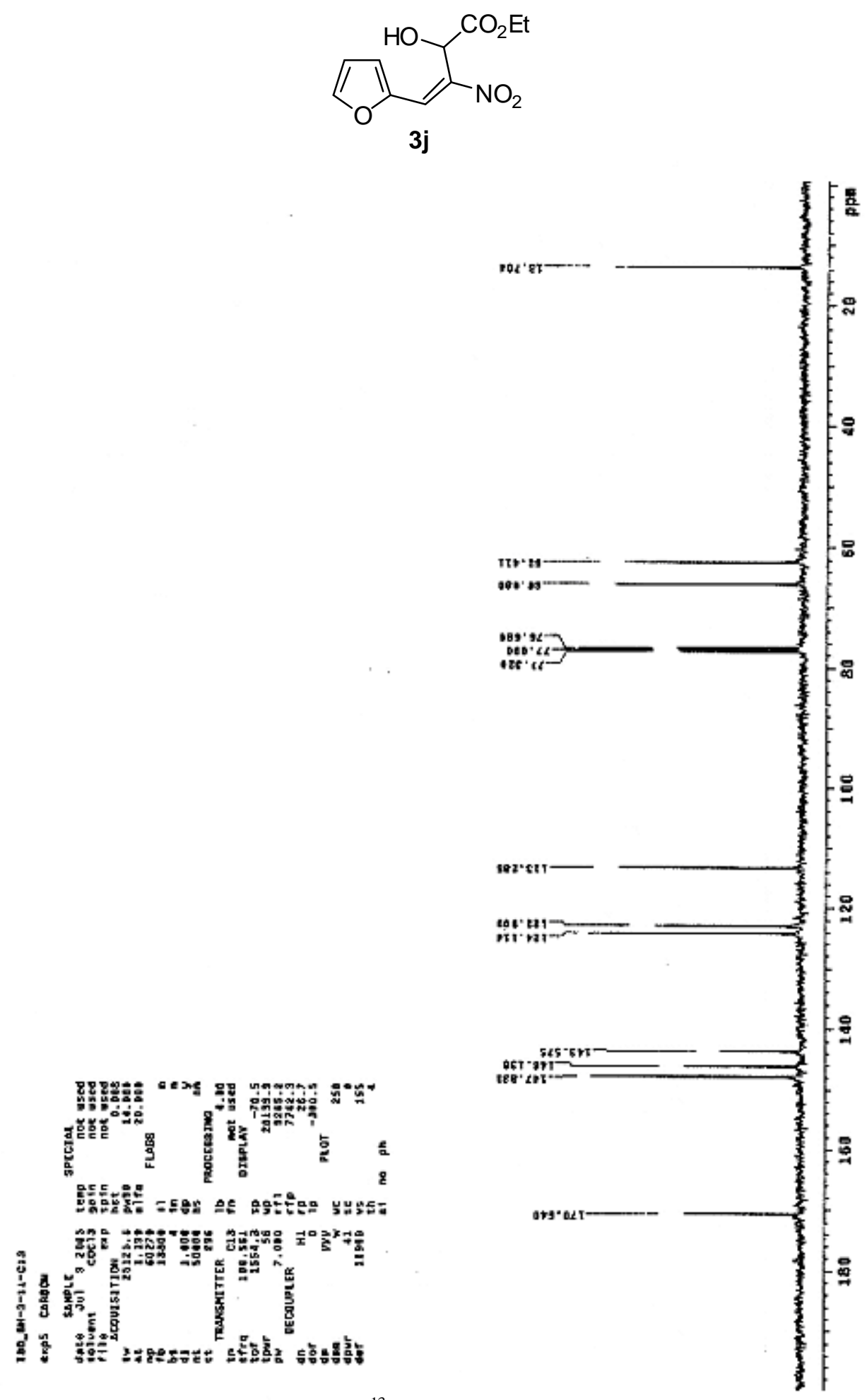

Figure S21. ${ }^{13} \mathrm{C}$ NMR Spectrum of $\mathbf{3 j}$ 


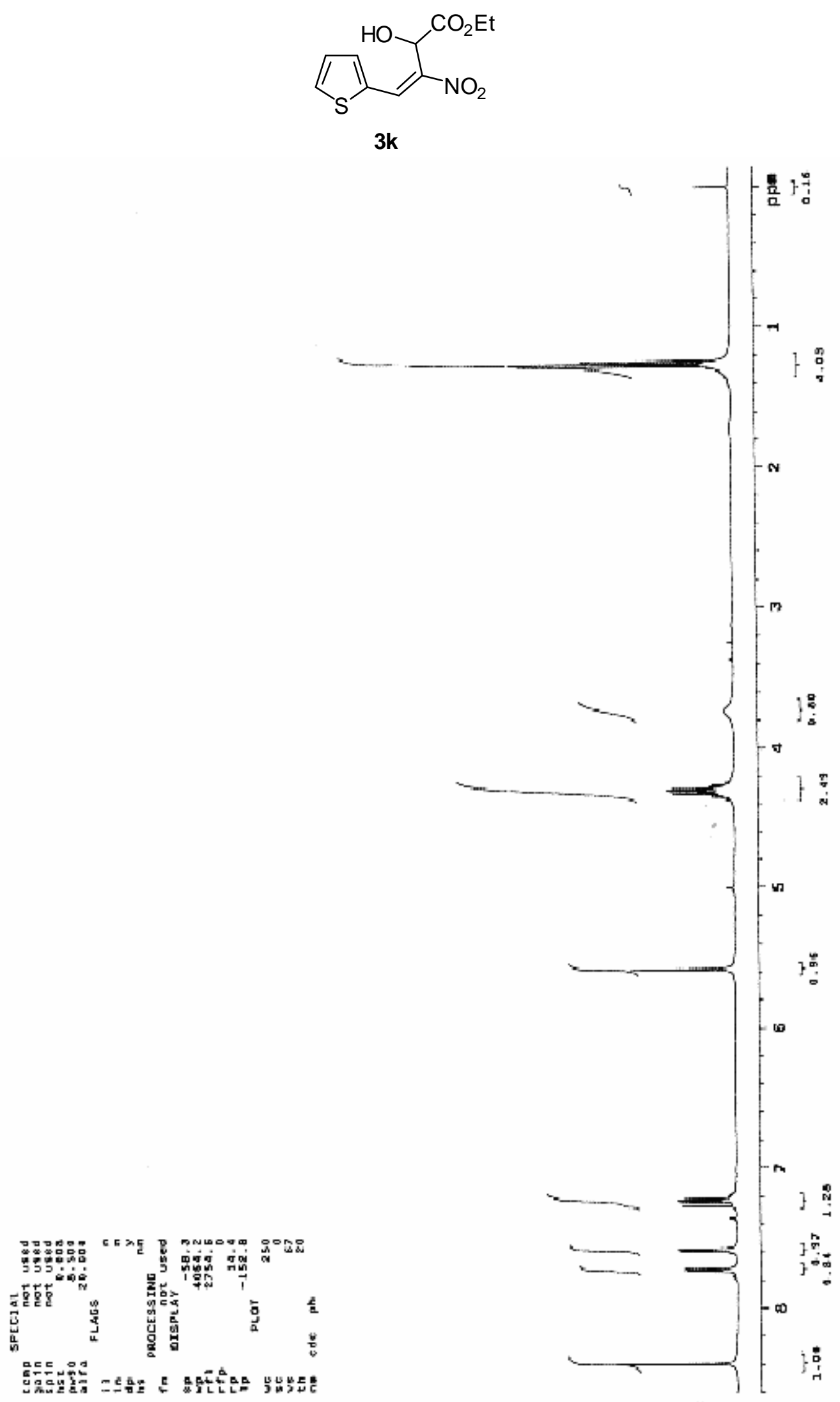

Figure S22. ${ }^{1} \mathrm{H}$ NMR Spectrum of $\mathbf{3 k}$ 


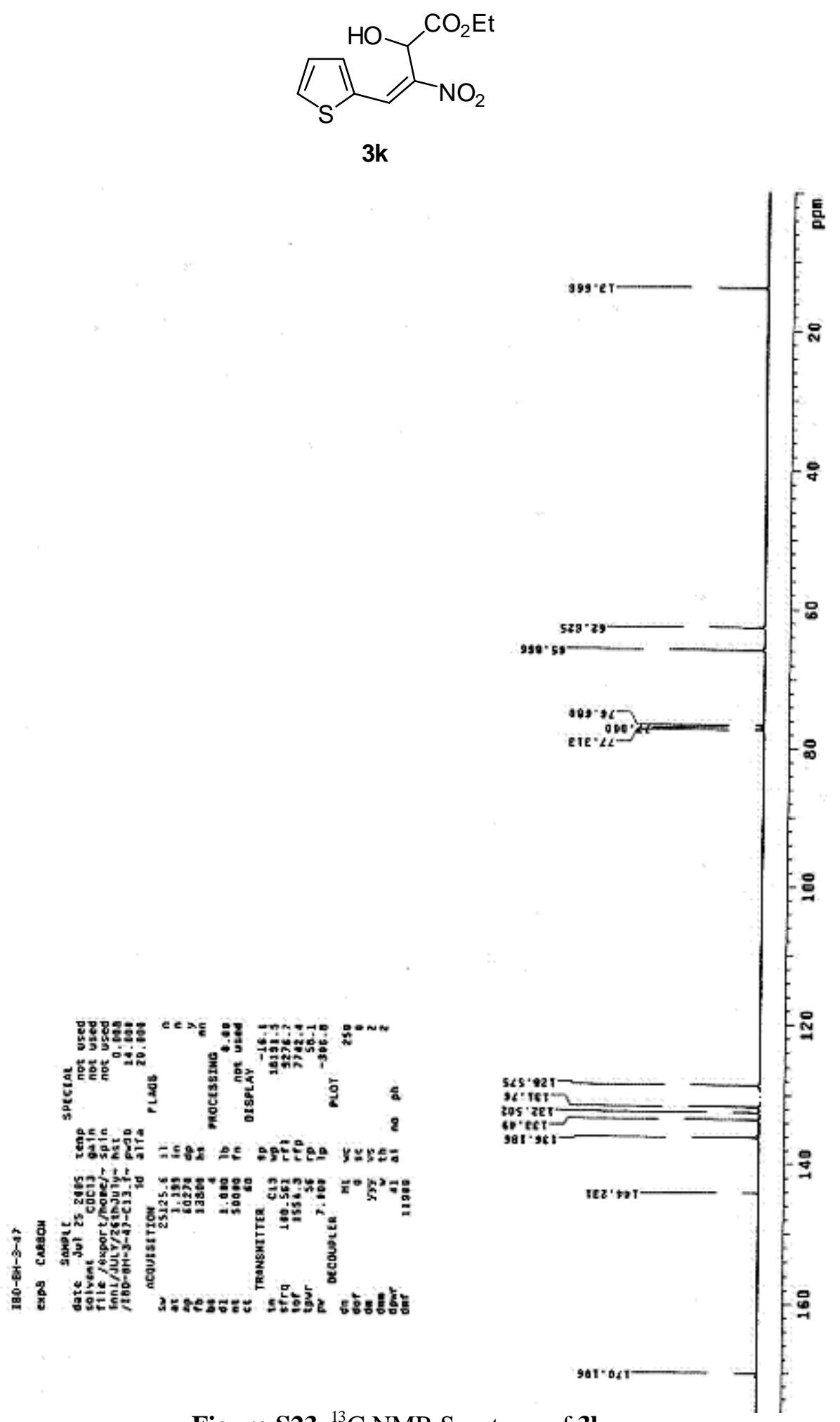

Figure S23. ${ }^{13} \mathrm{C}$ NMR Spectrum of $\mathbf{3 k}$ 


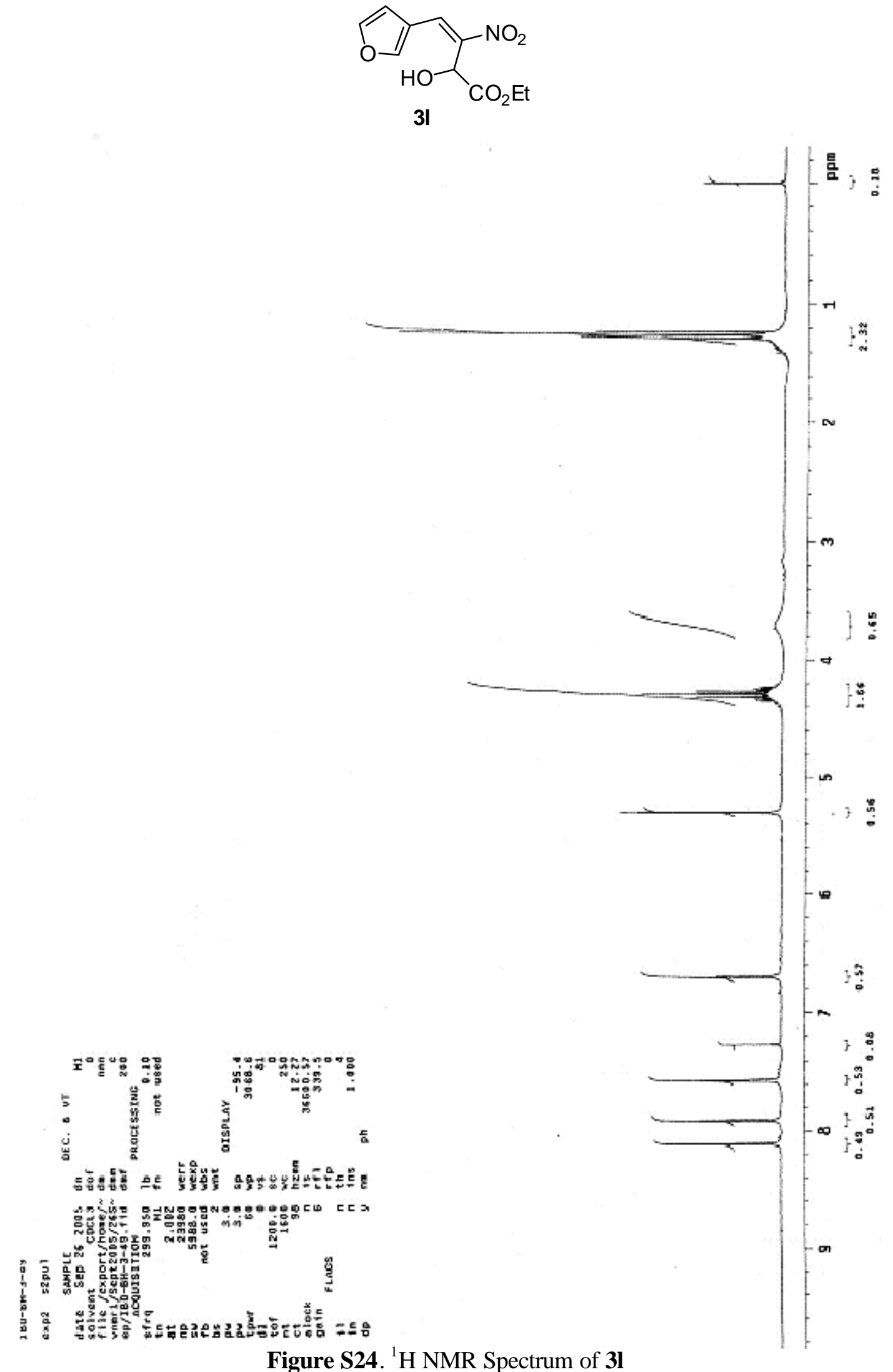



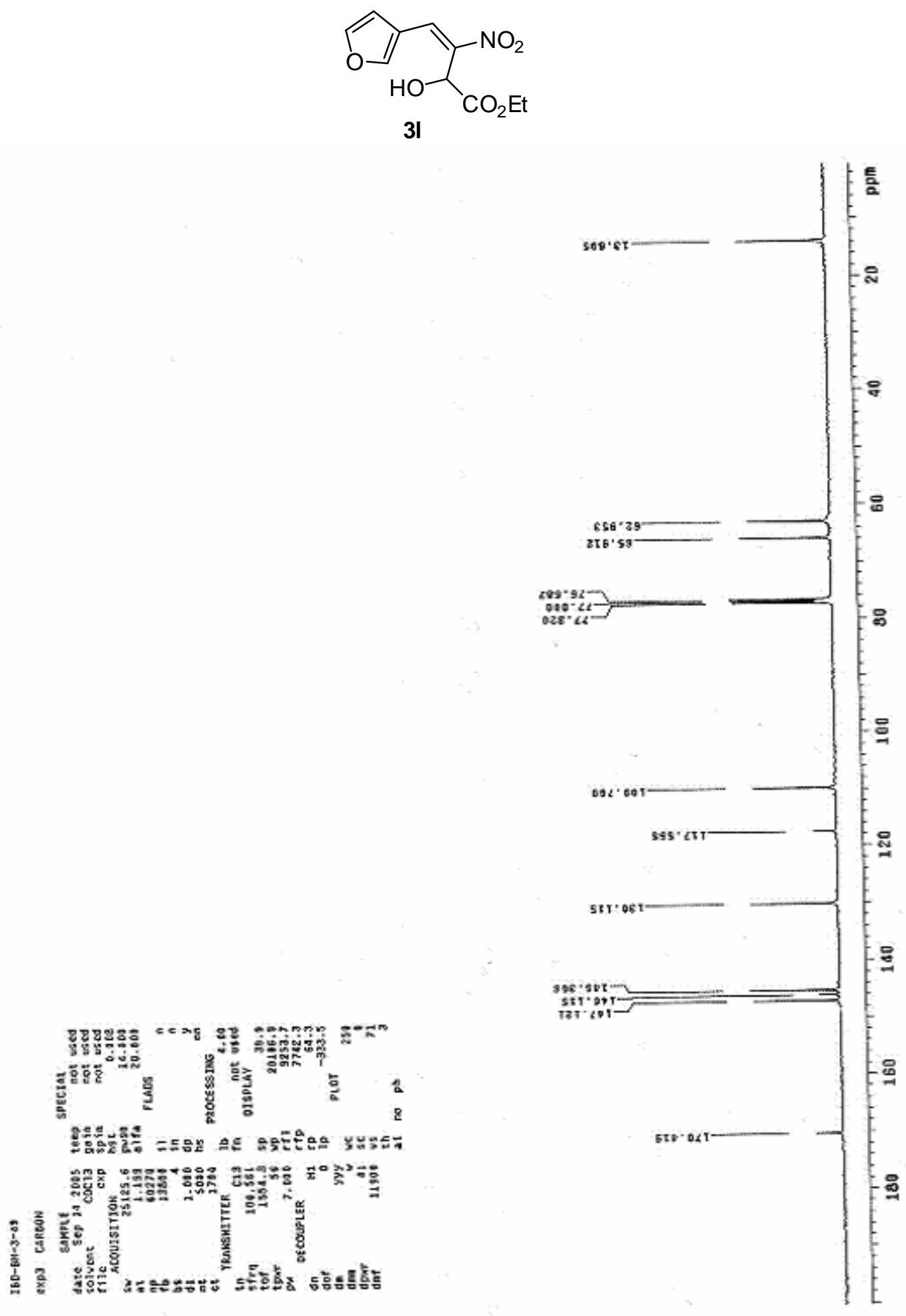

Figure S25. ${ }^{13} \mathrm{C}$ NMR Spectrum of $\mathbf{3 l}$ 


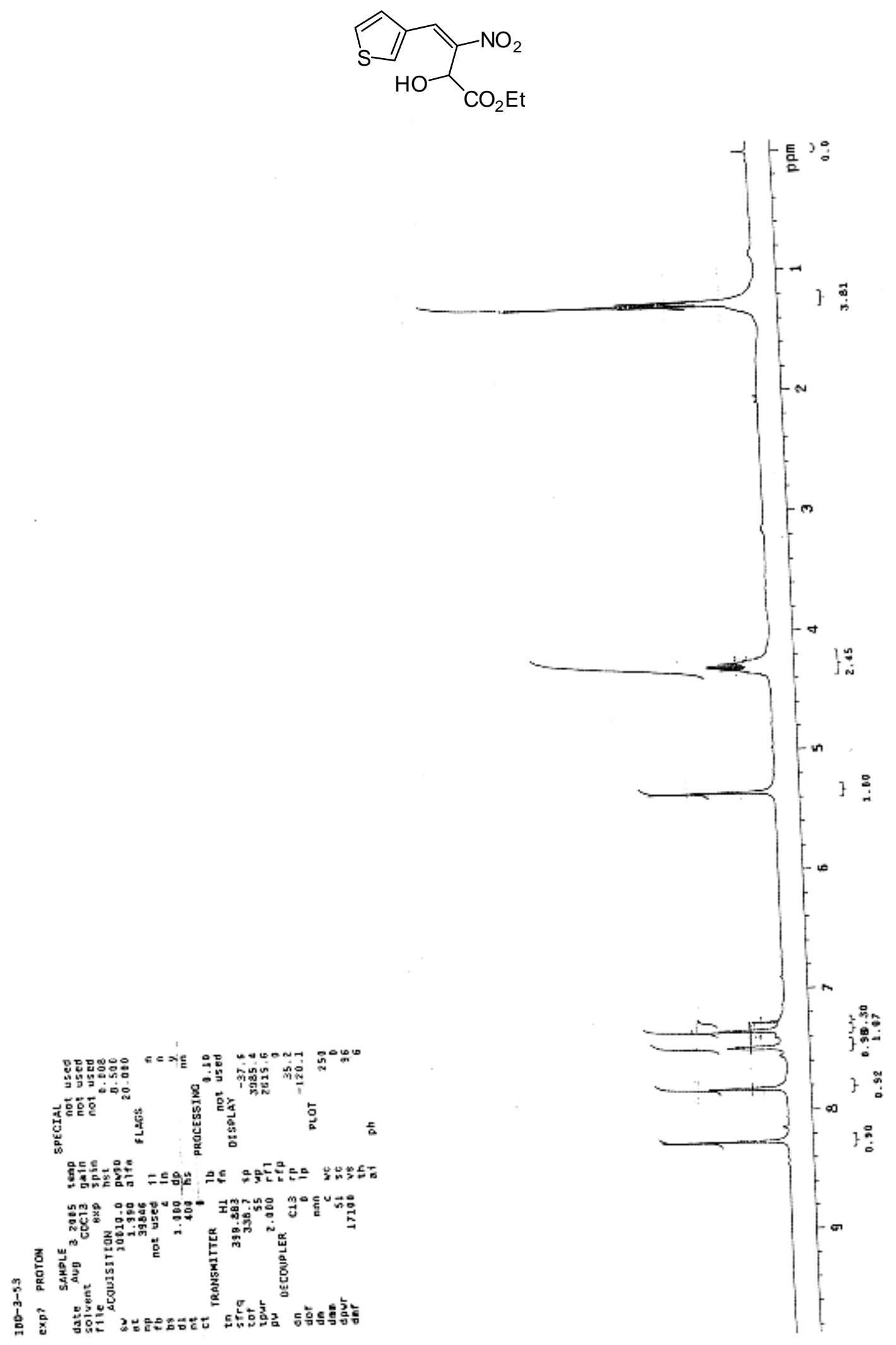

Figure S26. ${ }^{1} \mathrm{H}$ NMR Spectrum of $\mathbf{3 m}$ 


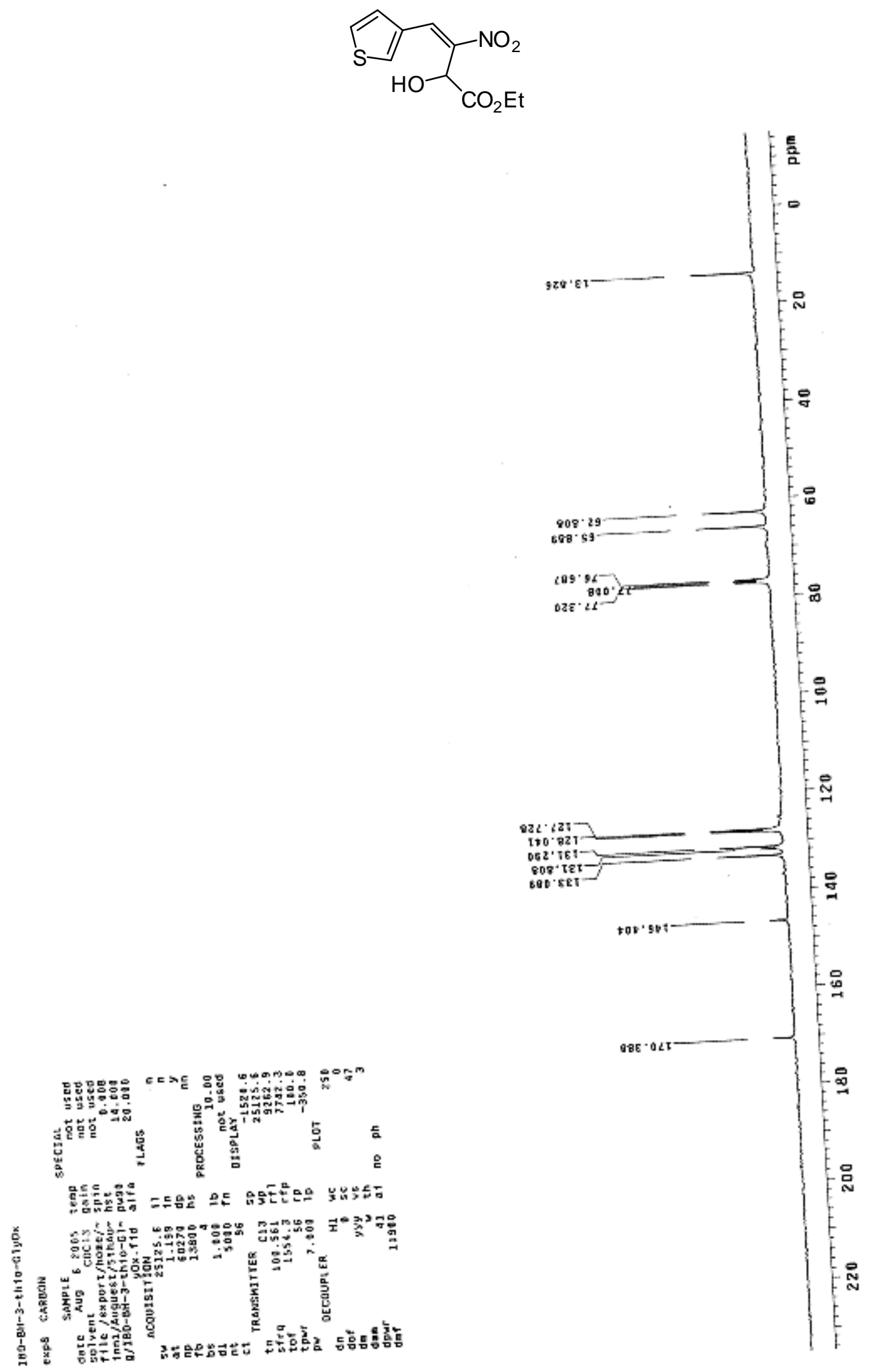

Figure S27. ${ }^{13} \mathrm{C}$ NMR Spectrum of $\mathbf{3 m}$ 


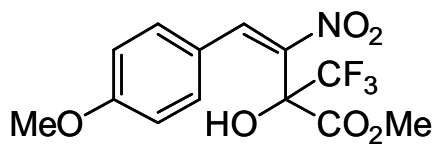

$4 c$

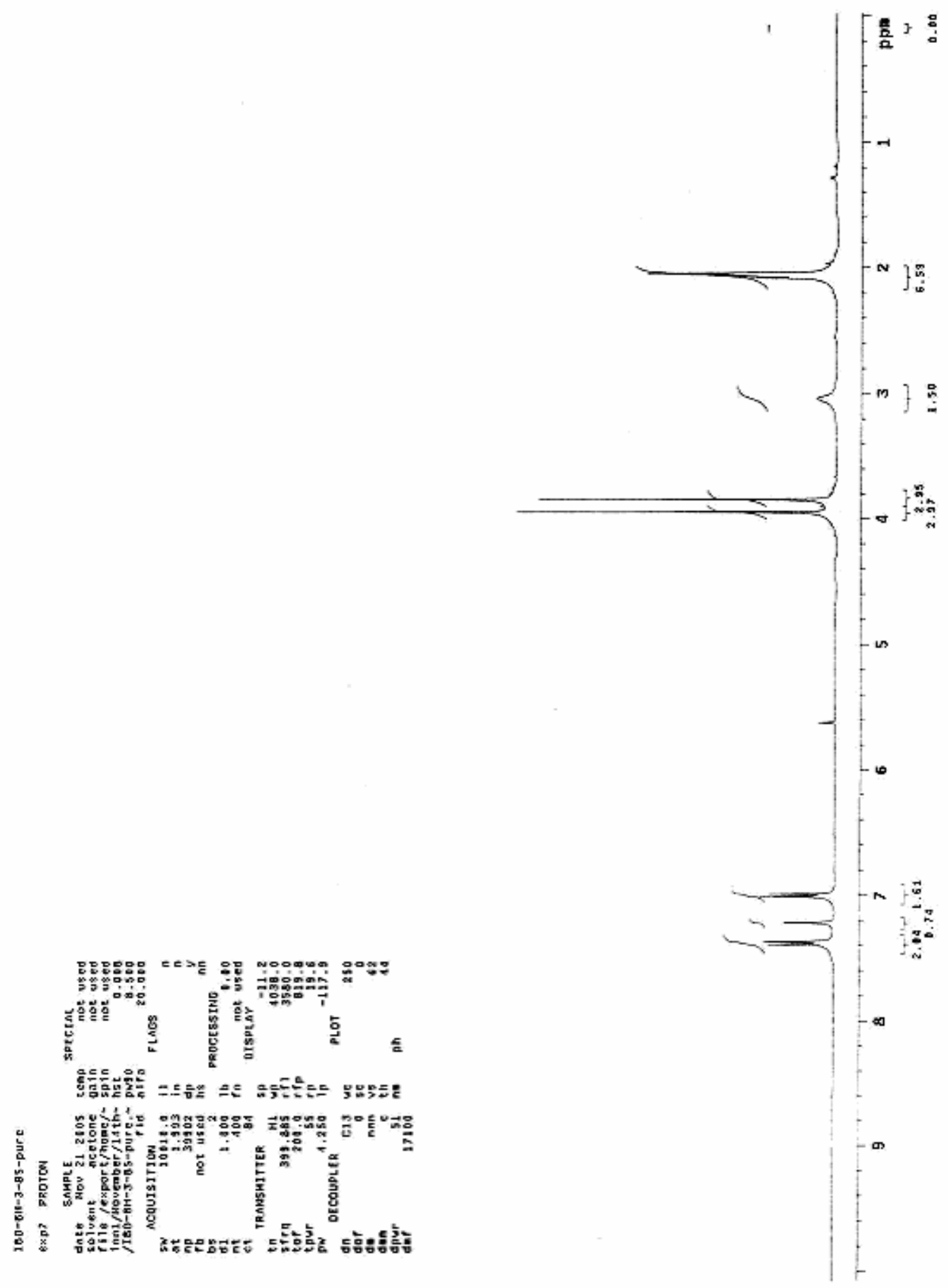

Figure S28. ${ }^{1} \mathrm{H}$ NMR Spectrum of $\mathbf{4 c}$ 


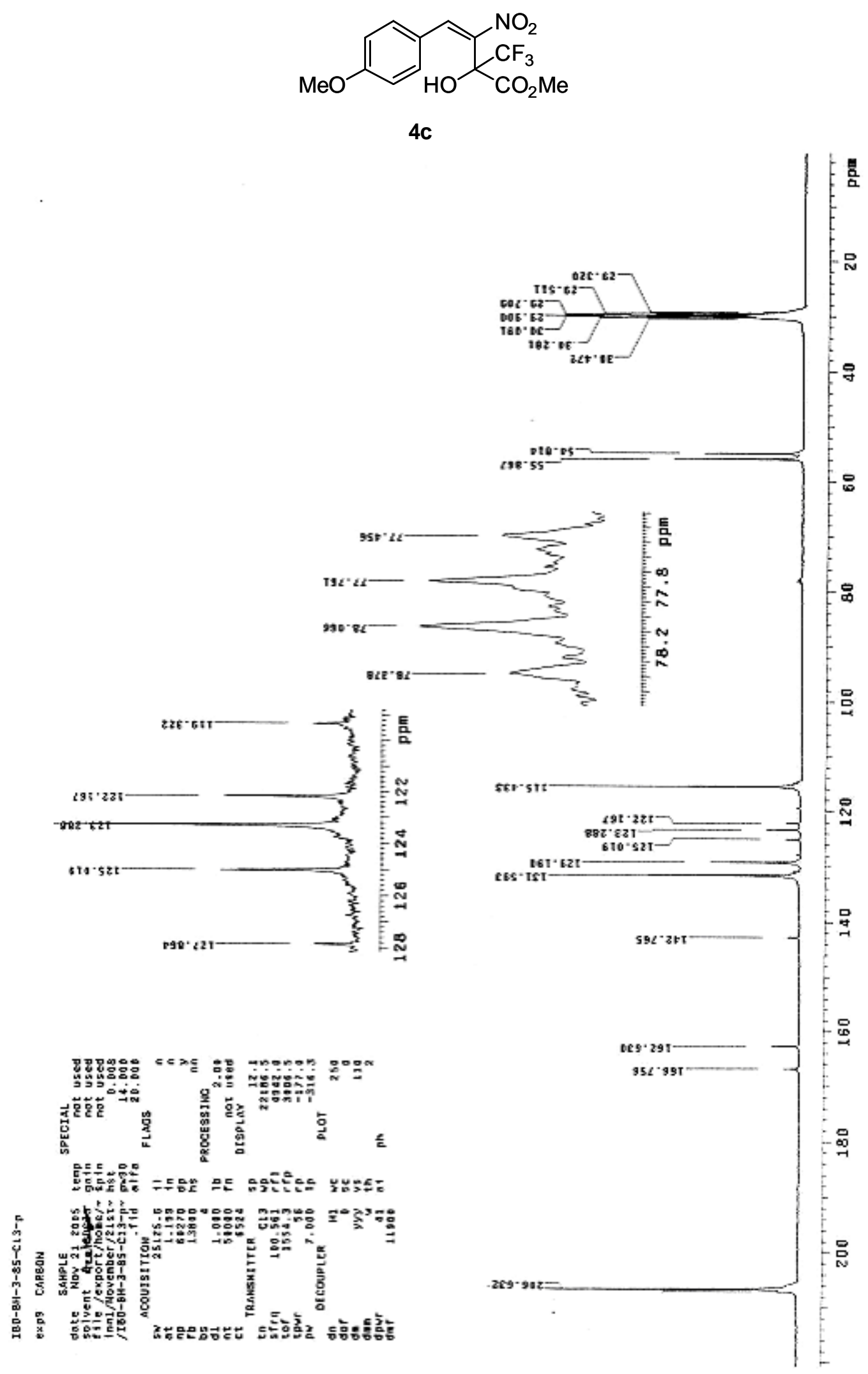

Figure S29. ${ }^{13} \mathrm{C}$ NMR Spectrum of $\mathbf{4 c}$ 


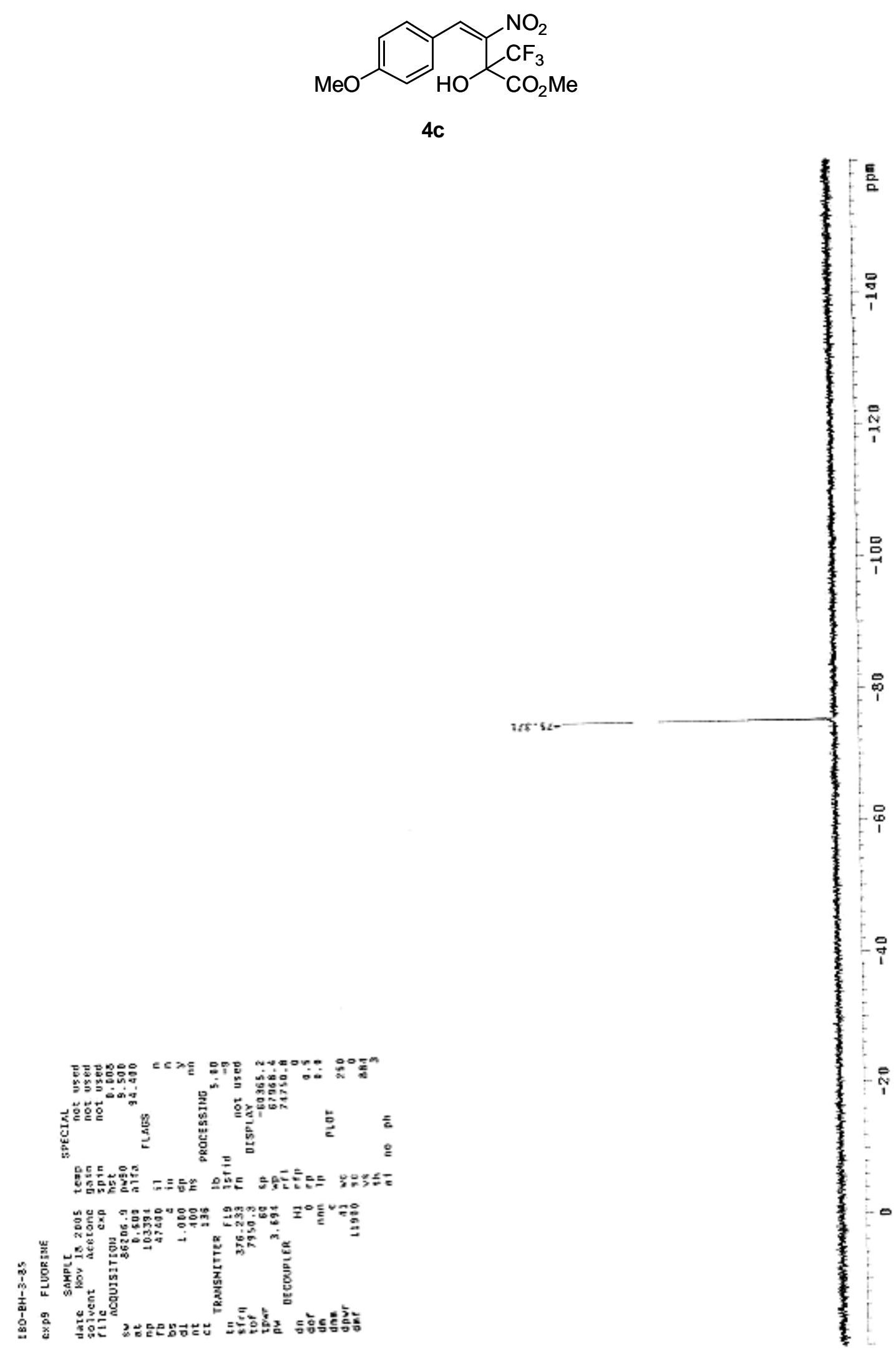

Figure S30. ${ }^{19}$ FNMR Spectrum of $\mathbf{4 c}$ 

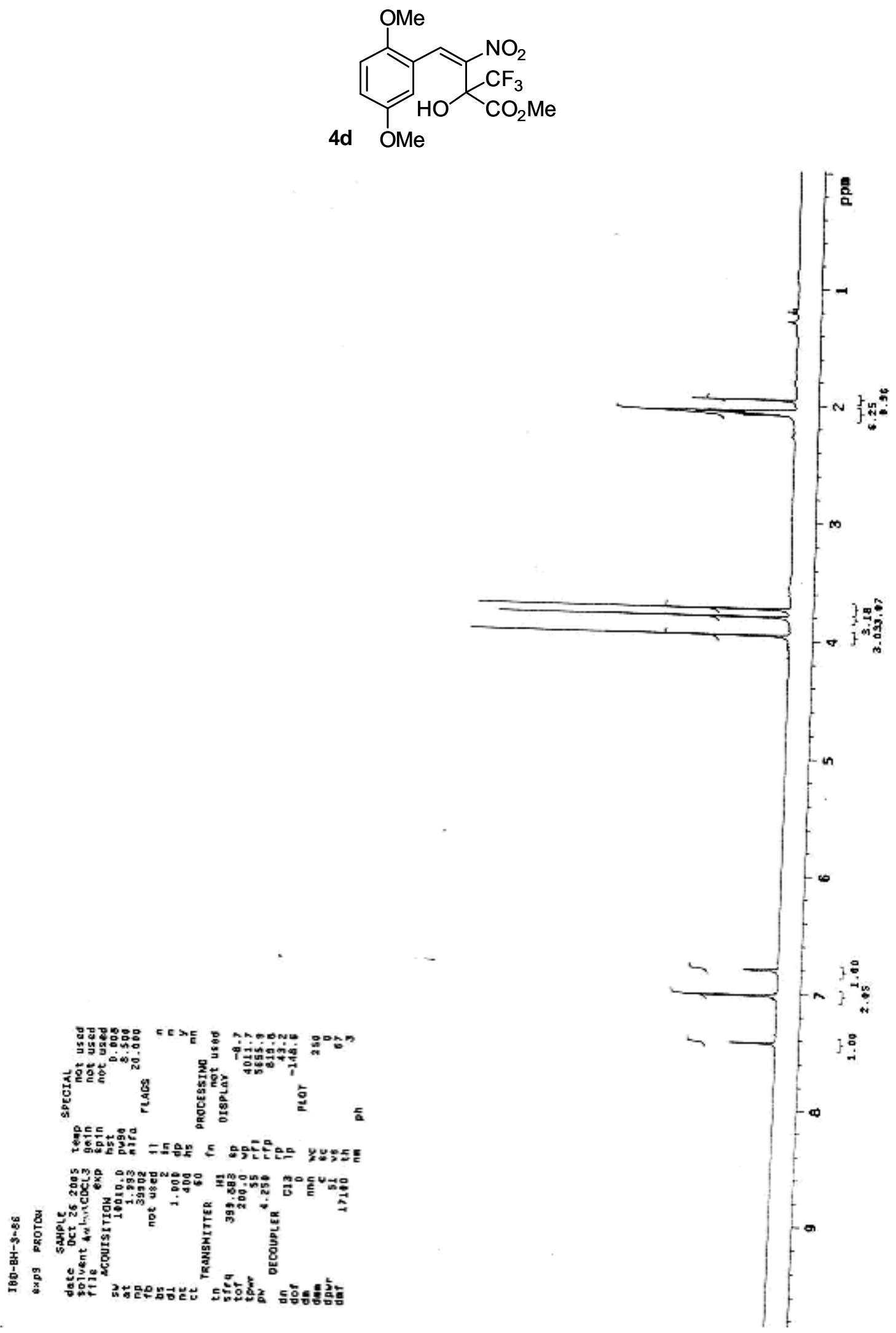

Figure S31 . ${ }^{1} \mathrm{H}$ NMR Spectrum of $\mathbf{4 d}$ 


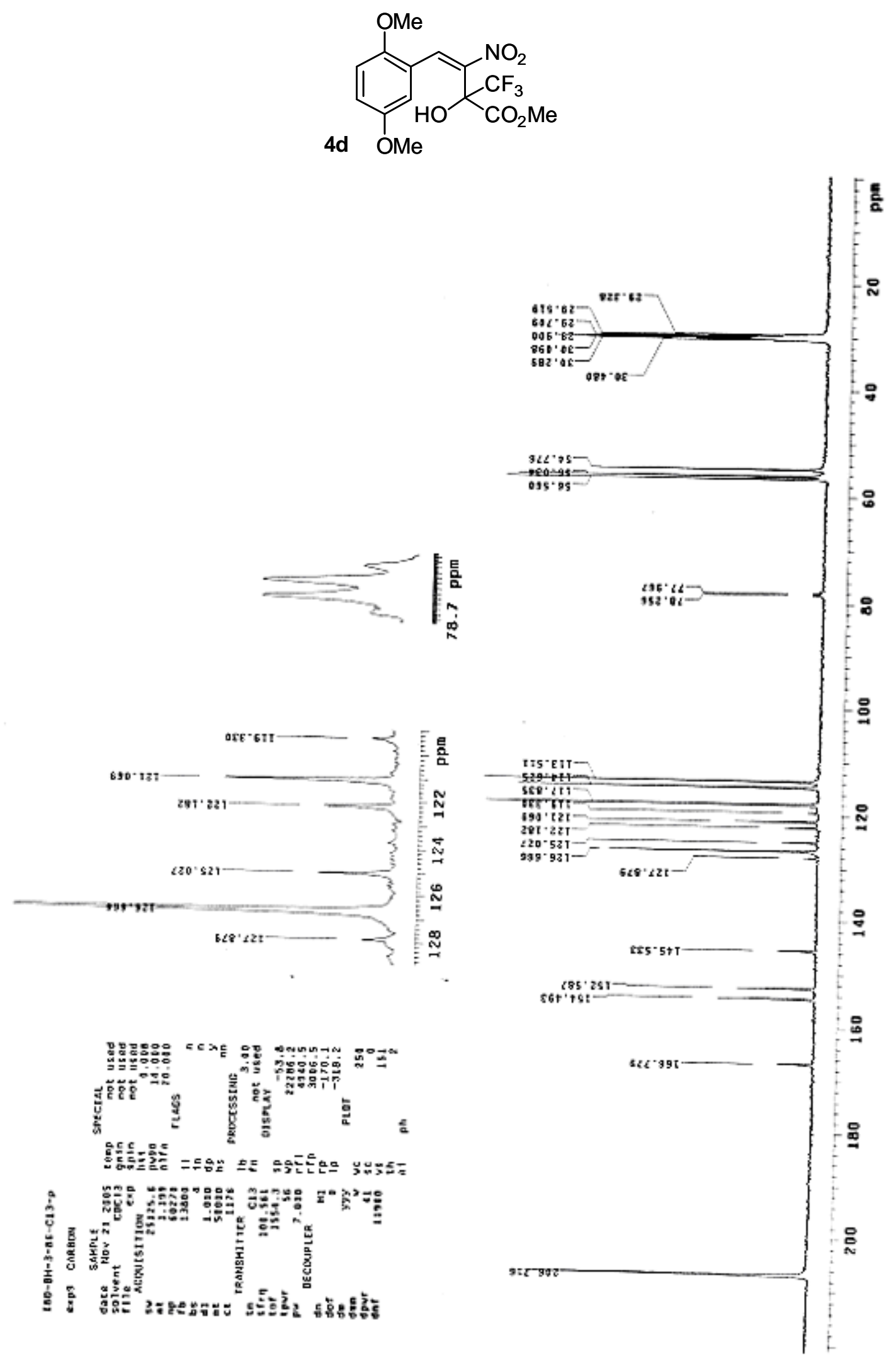

Figure S32. ${ }^{13} \mathrm{C}$ NMR Spectrum of $\mathbf{4 d}$ 

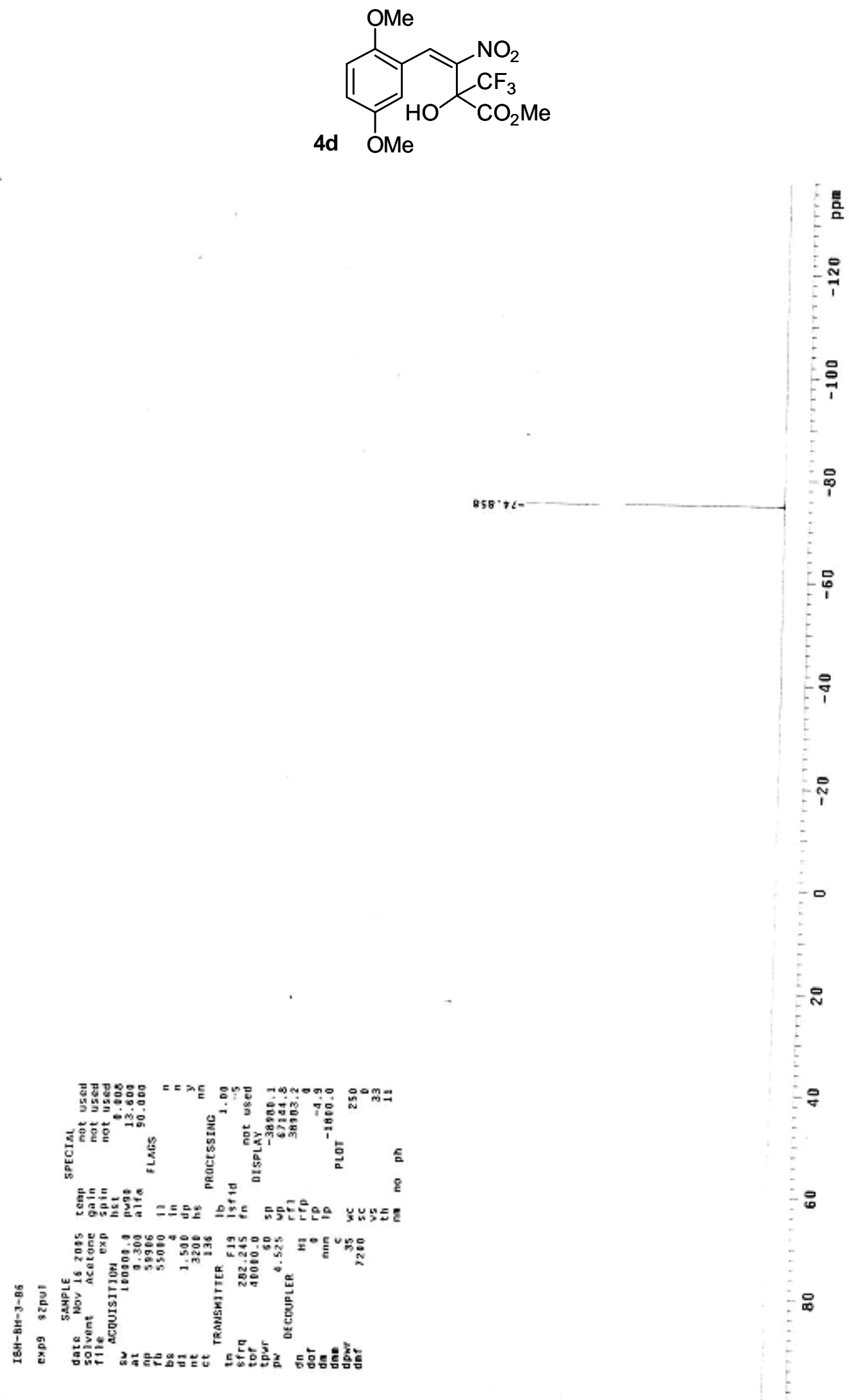

Figure S33. ${ }^{19}$ FNMR Spectrum of $4 \mathbf{d}$ 

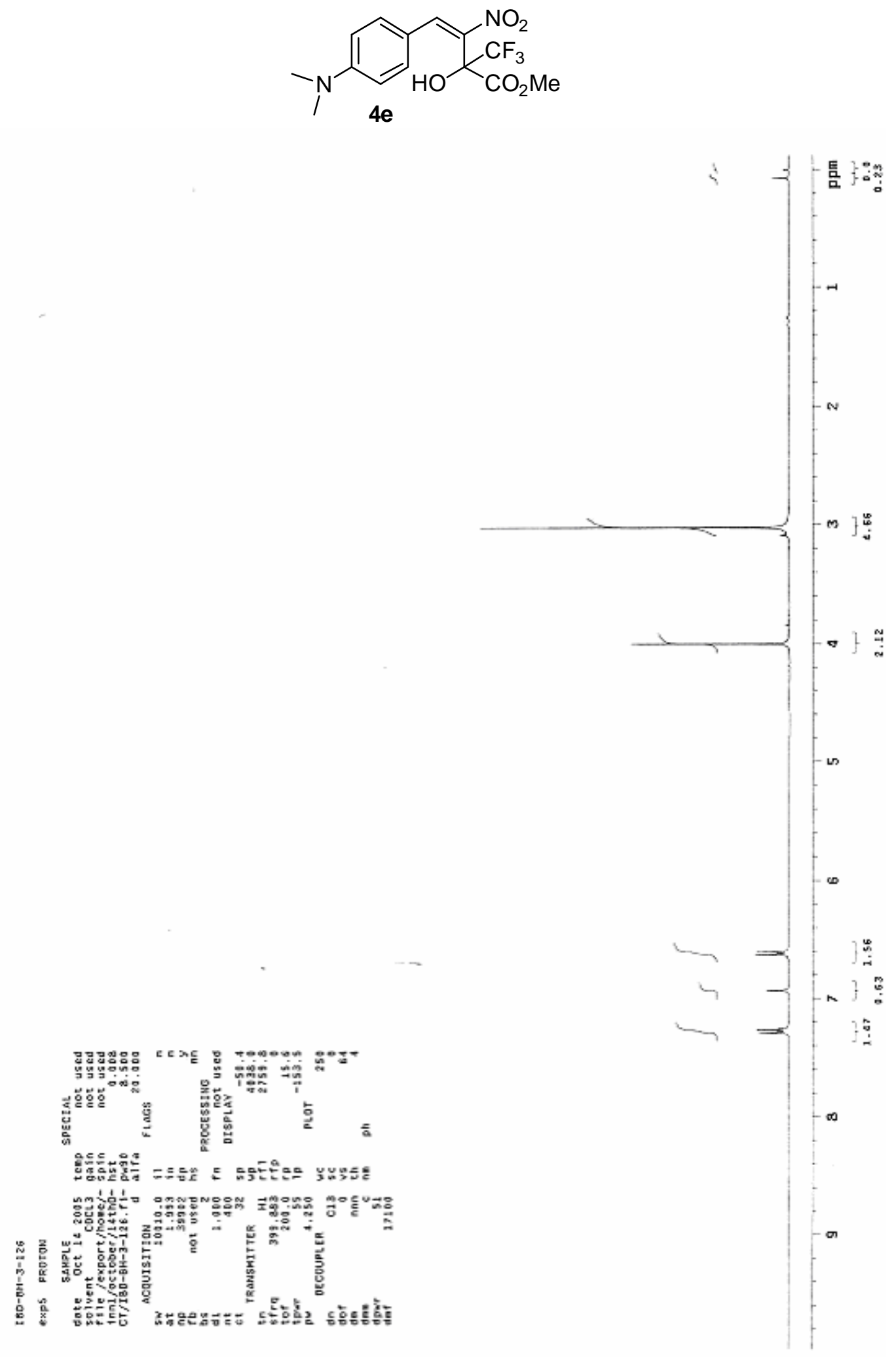

Figure S34. ${ }^{1}$ H NMR Spectrum of $4 \mathbf{e}$ 

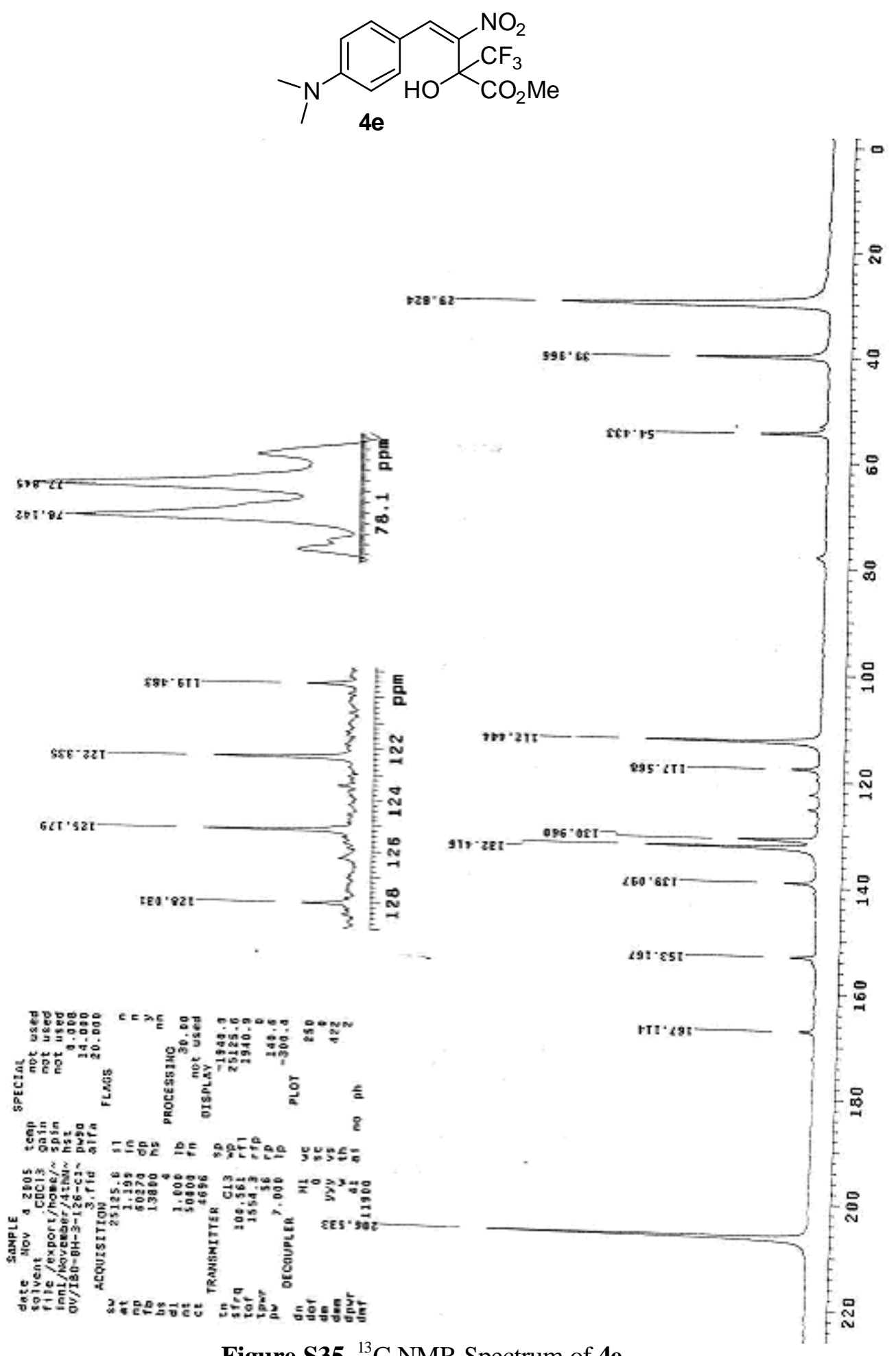

Figure S35. ${ }^{13} \mathrm{C}$ NMR Spectrum of $4 \mathrm{e}$ 

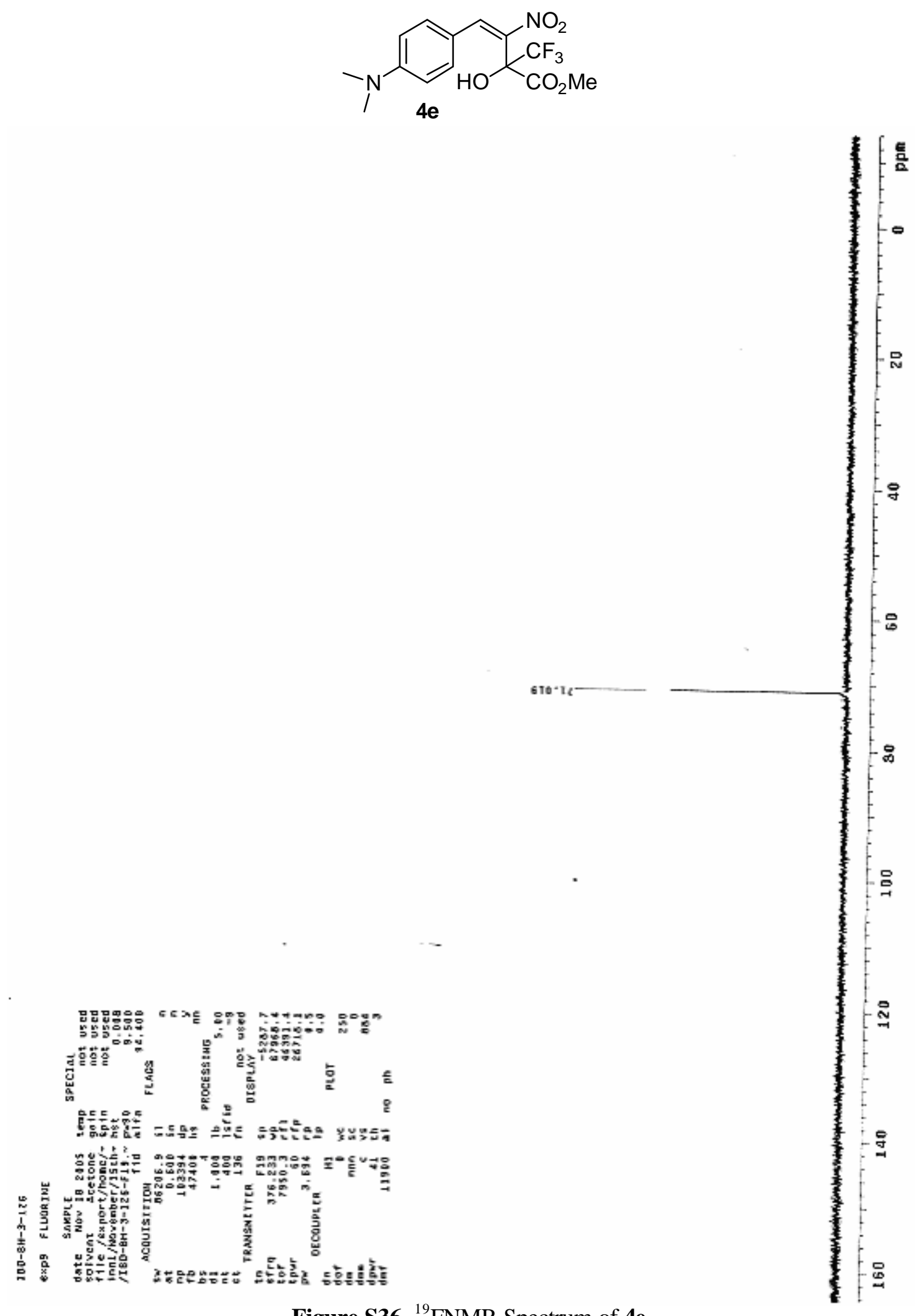

Figure S36. ${ }^{19}$ FNMR Spectrum of $4 \mathbf{e}$ 

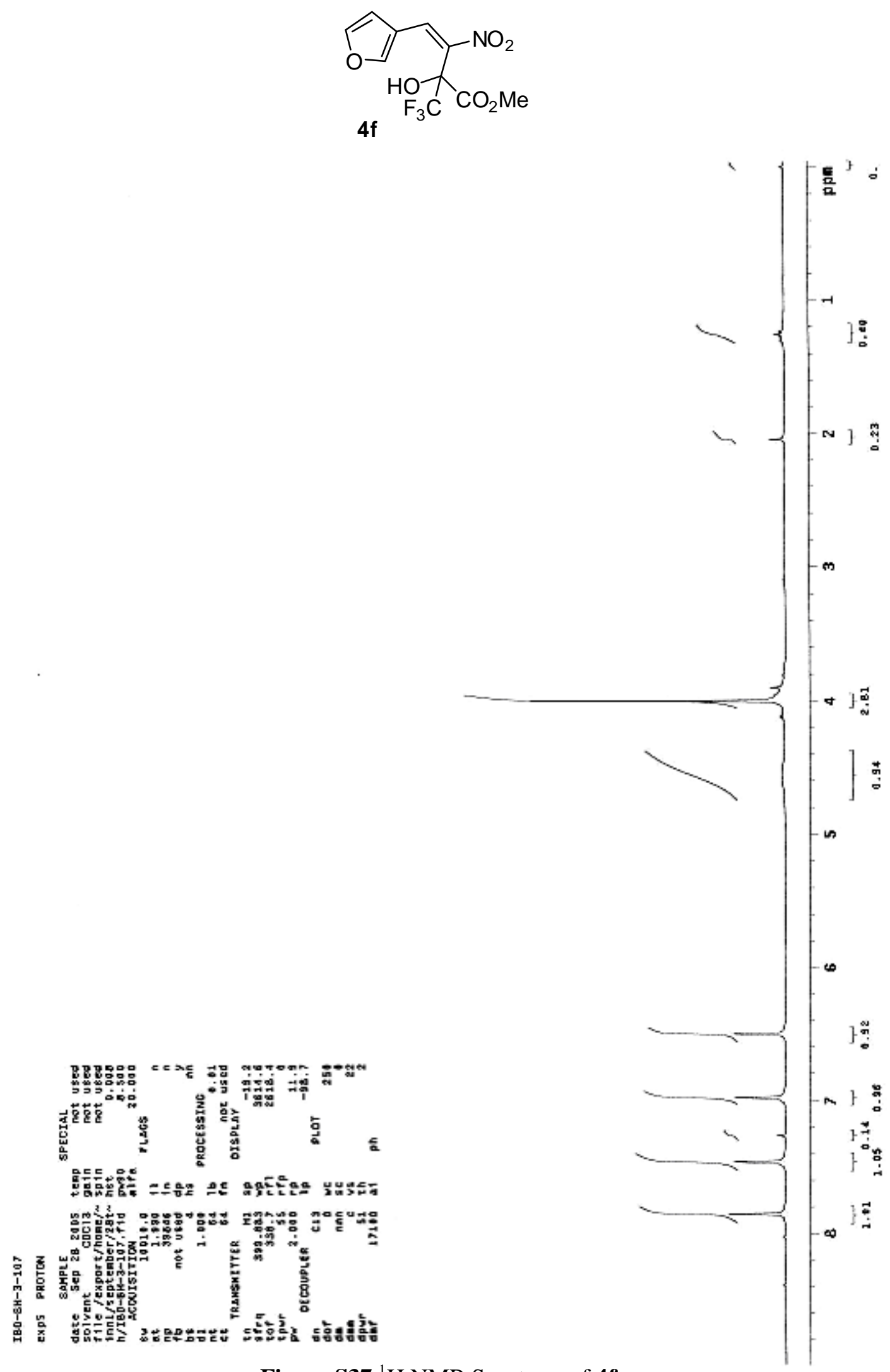

Figure S37 ${ }^{1} \mathrm{H}$ NMR Spectrum of $\mathbf{4 f}$ 


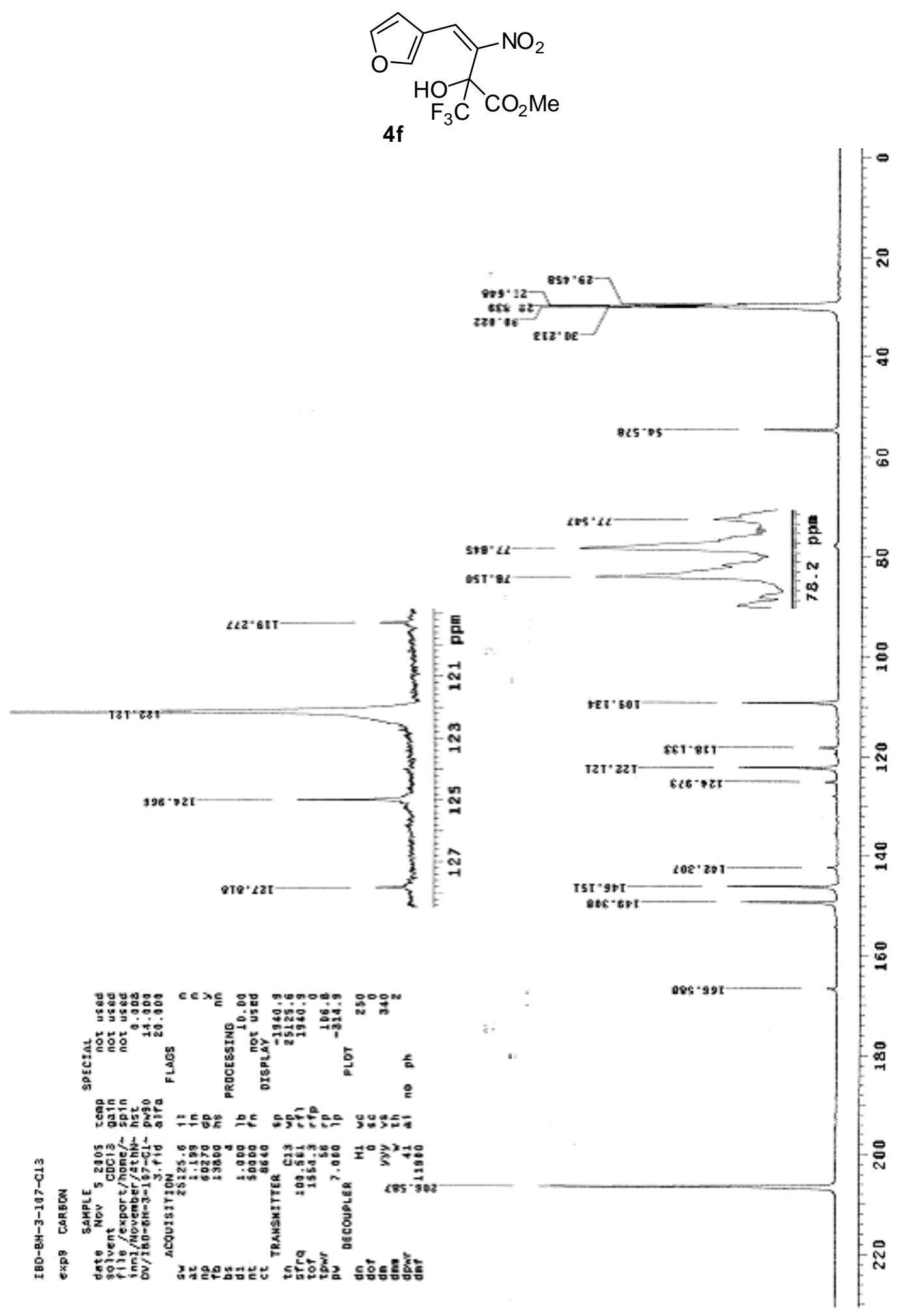

Figure S38. ${ }^{13} \mathrm{C}$ NMR Spectrum of $\mathbf{4 f}$ 


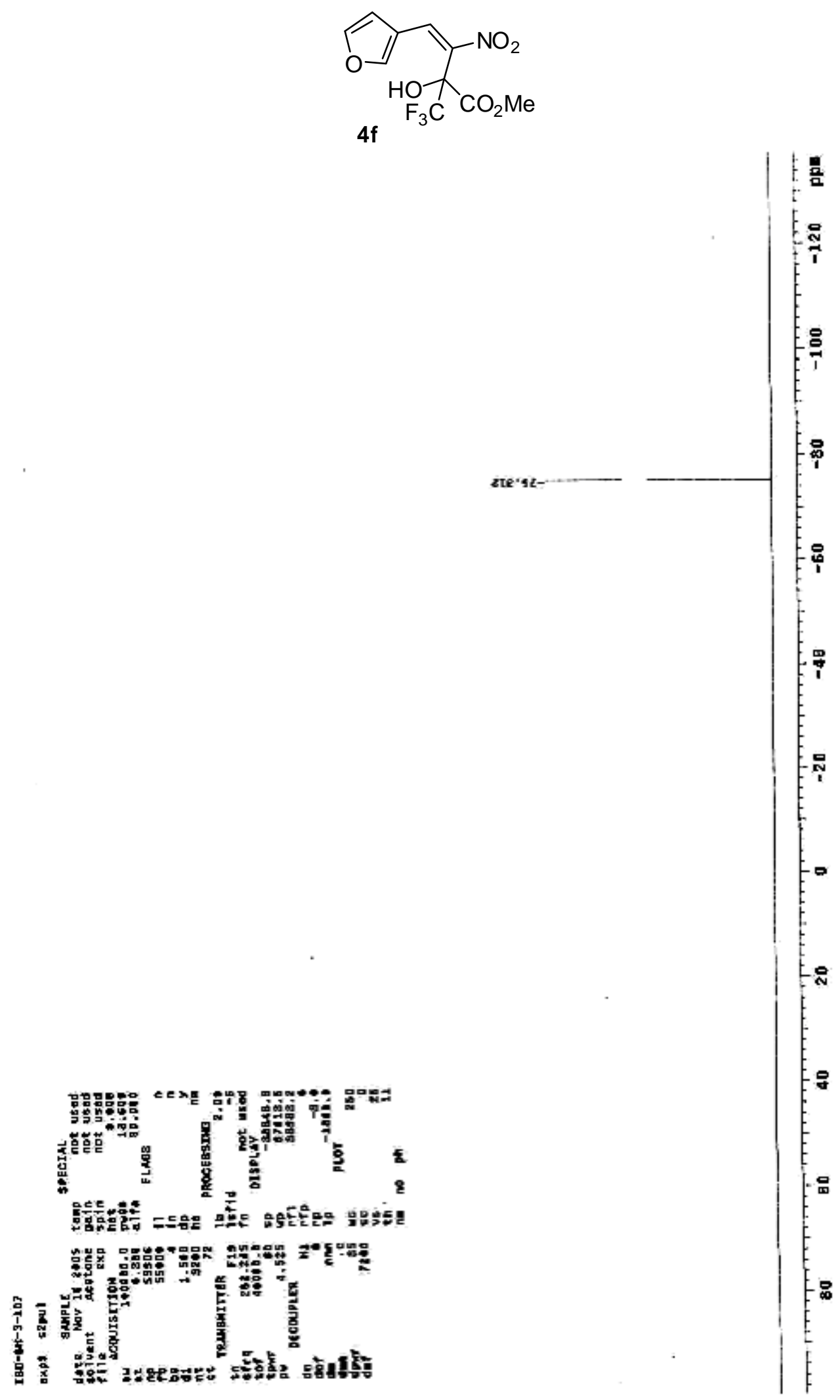

Figure S39. ${ }^{19}$ FNMR Spectrum of $\mathbf{4 f}$ 
<smiles>COc1ccc(/C=C(\C(O)C(C)=O)[N+](=O)[O-])cc1</smiles>

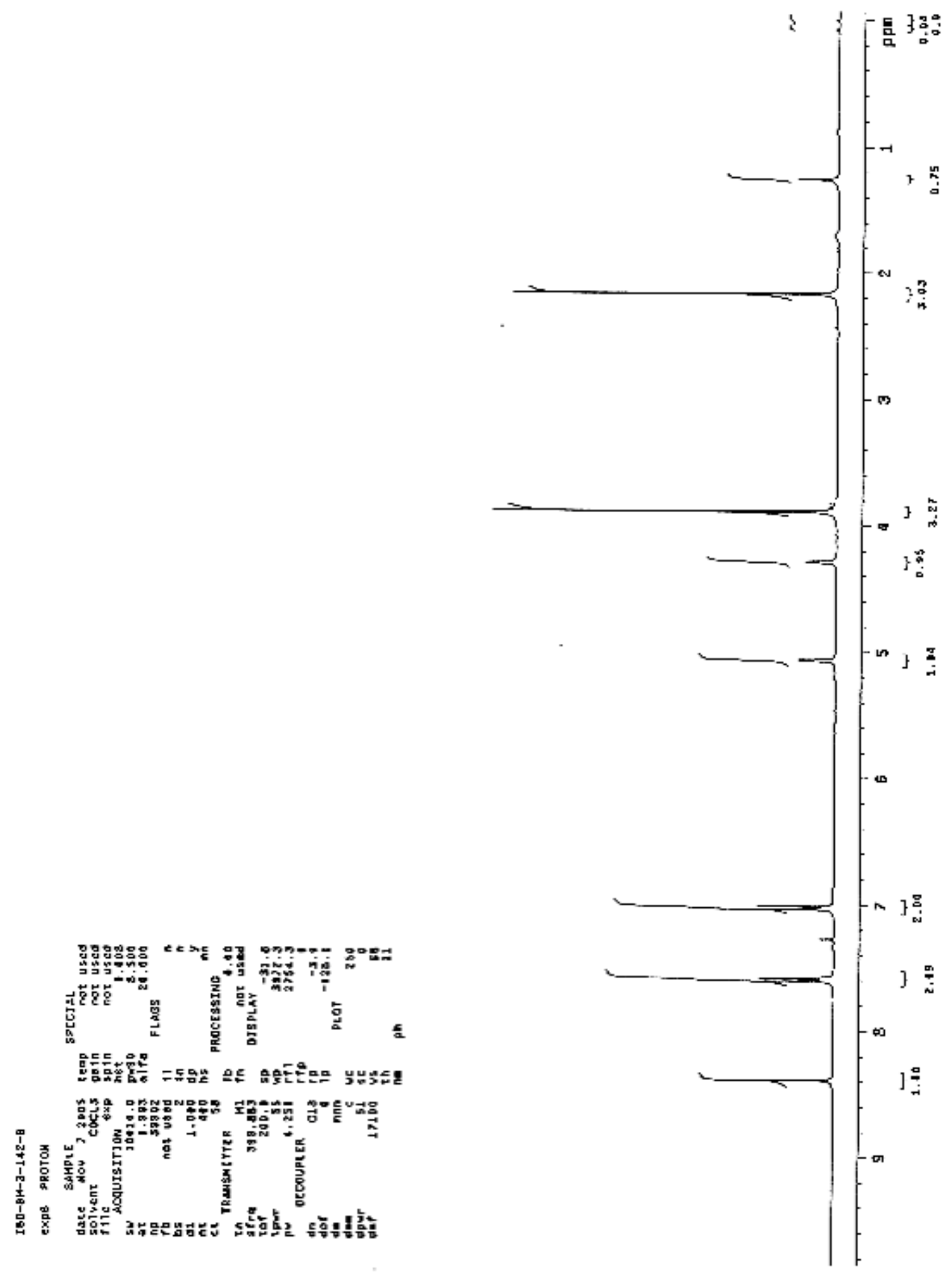

Figure S40. ${ }^{1} \mathrm{H}$ NMR Spectrum of $\mathbf{5 b}$ 
<smiles>COc1ccc(/C=C(\C(O)C(C)=O)[N+](=O)[O-])cc1</smiles>

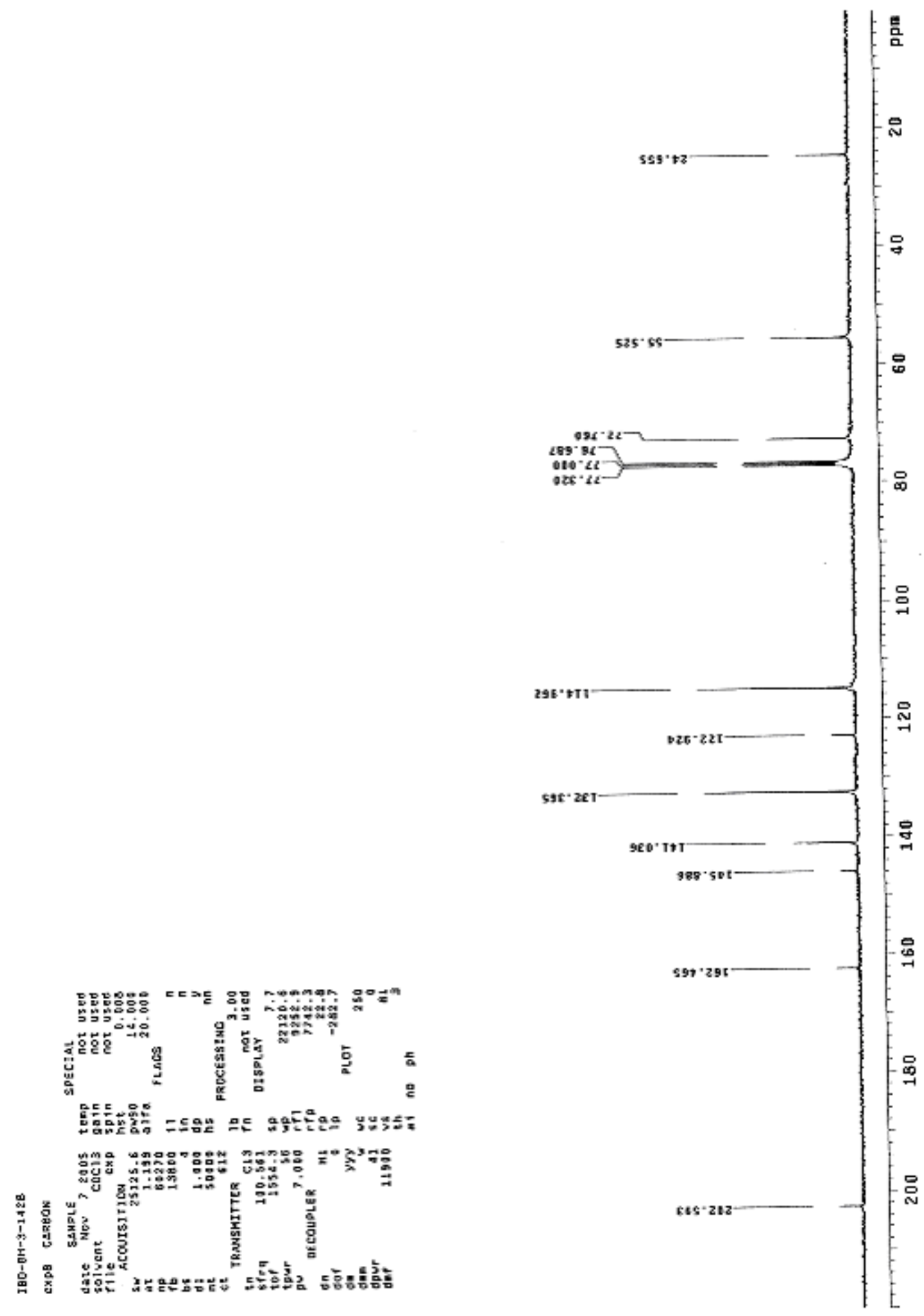

Figure S41. ${ }^{13} \mathrm{C}$ NMR Spectrum of $\mathbf{5 b}$ 


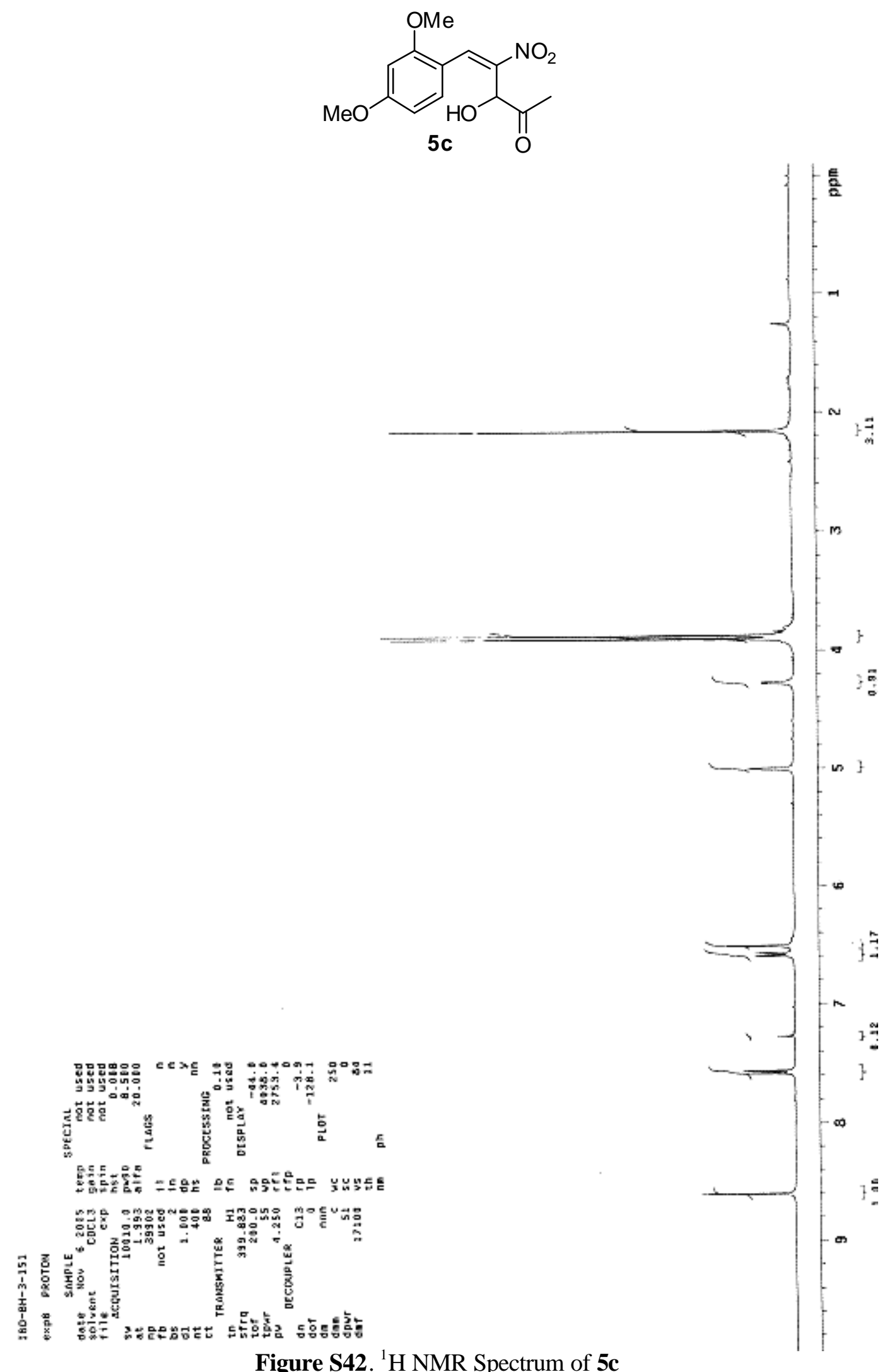

Figure S42. ${ }^{1} \mathrm{H}$ NMR Spectrum of $\mathbf{5 c}$ 
<smiles>COc1ccc(/C=C(\C(O)C(C)=O)[N+](=O)[O-])c(OC)c1</smiles>

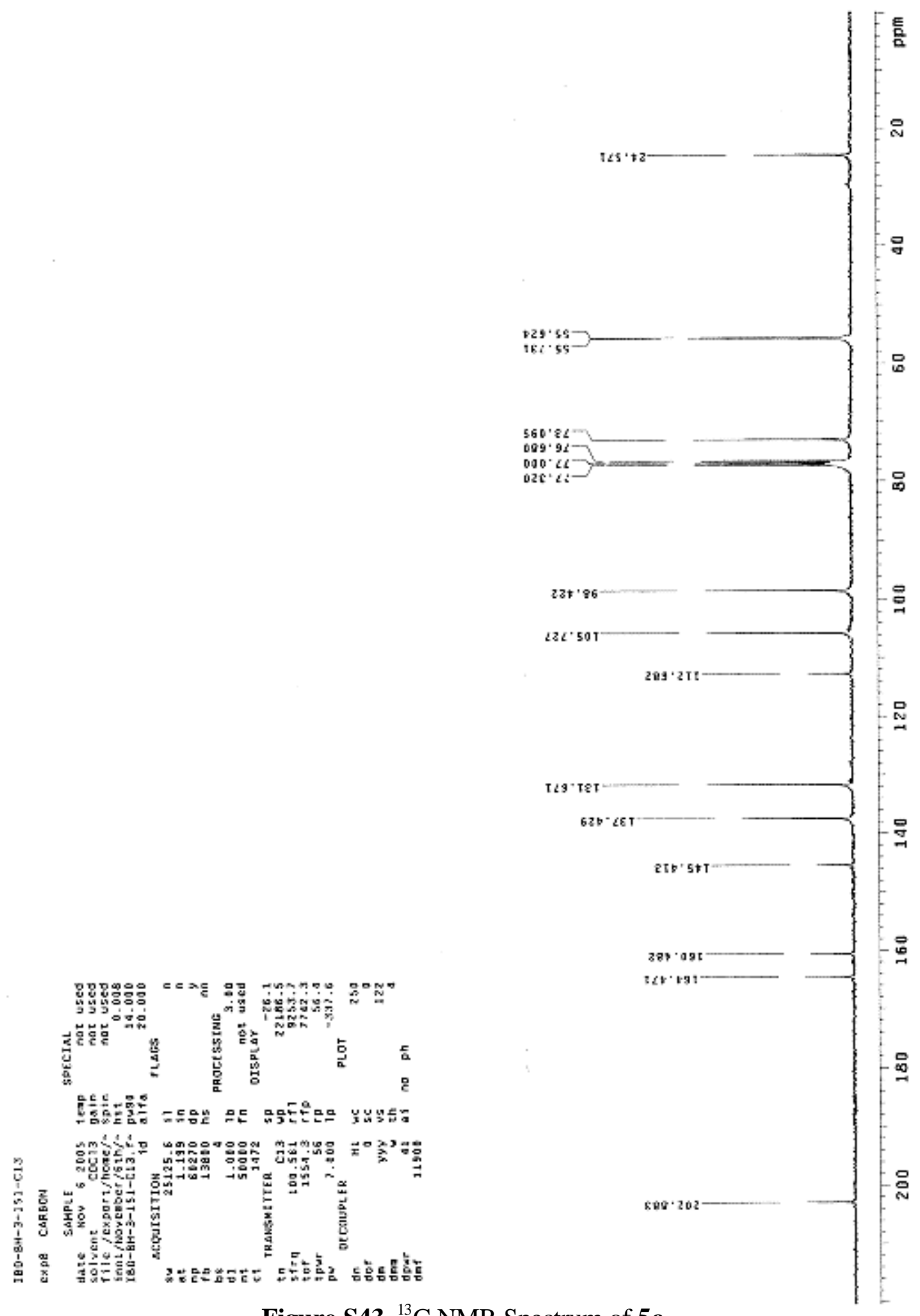

Figure S43. ${ }^{13} \mathrm{C}$ NMR Spectrum of $\mathbf{5 c}$ 


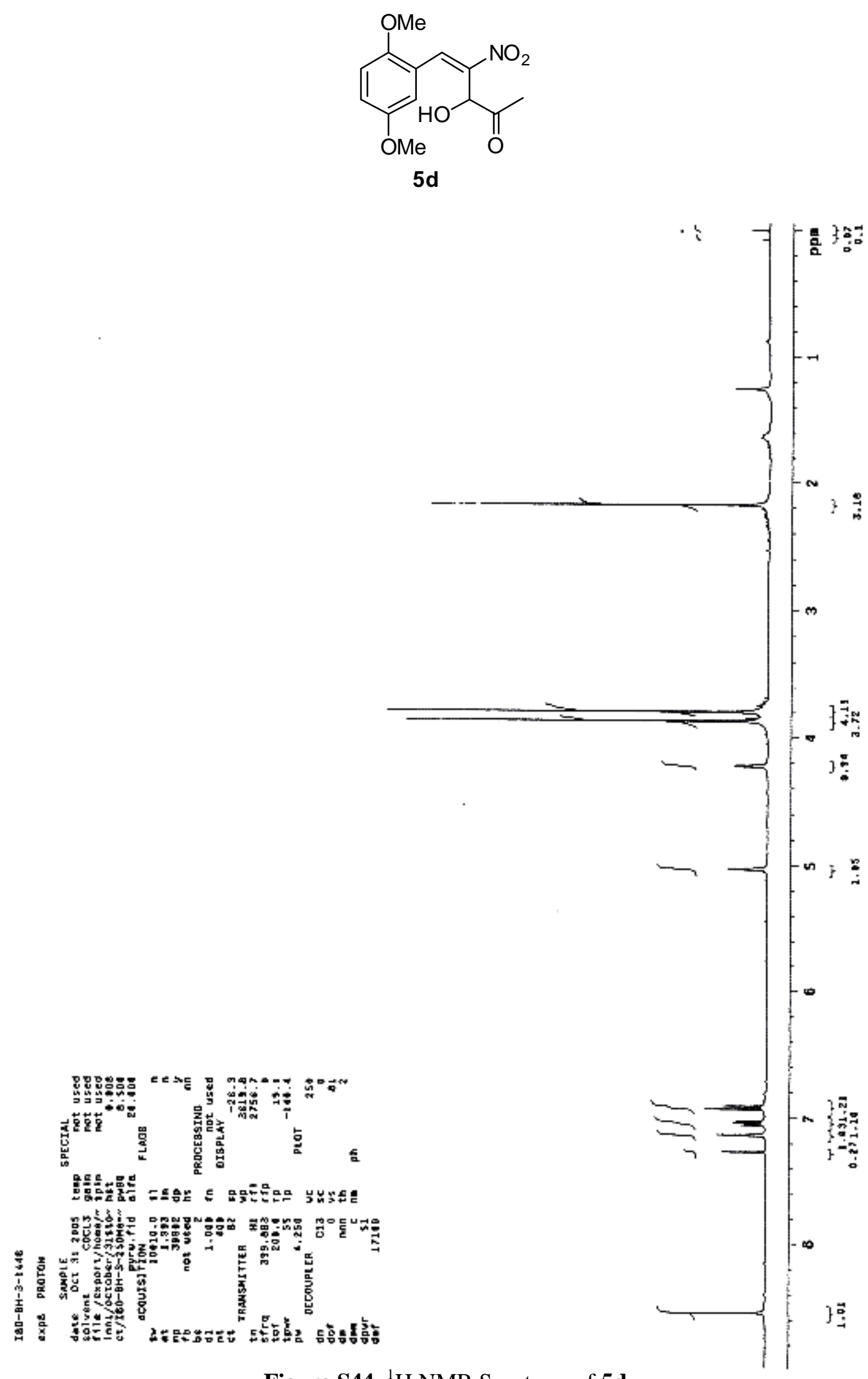

Figure S44. ${ }^{1} \mathrm{H}$ NMR Spectrum of $\mathbf{5 d}$ 


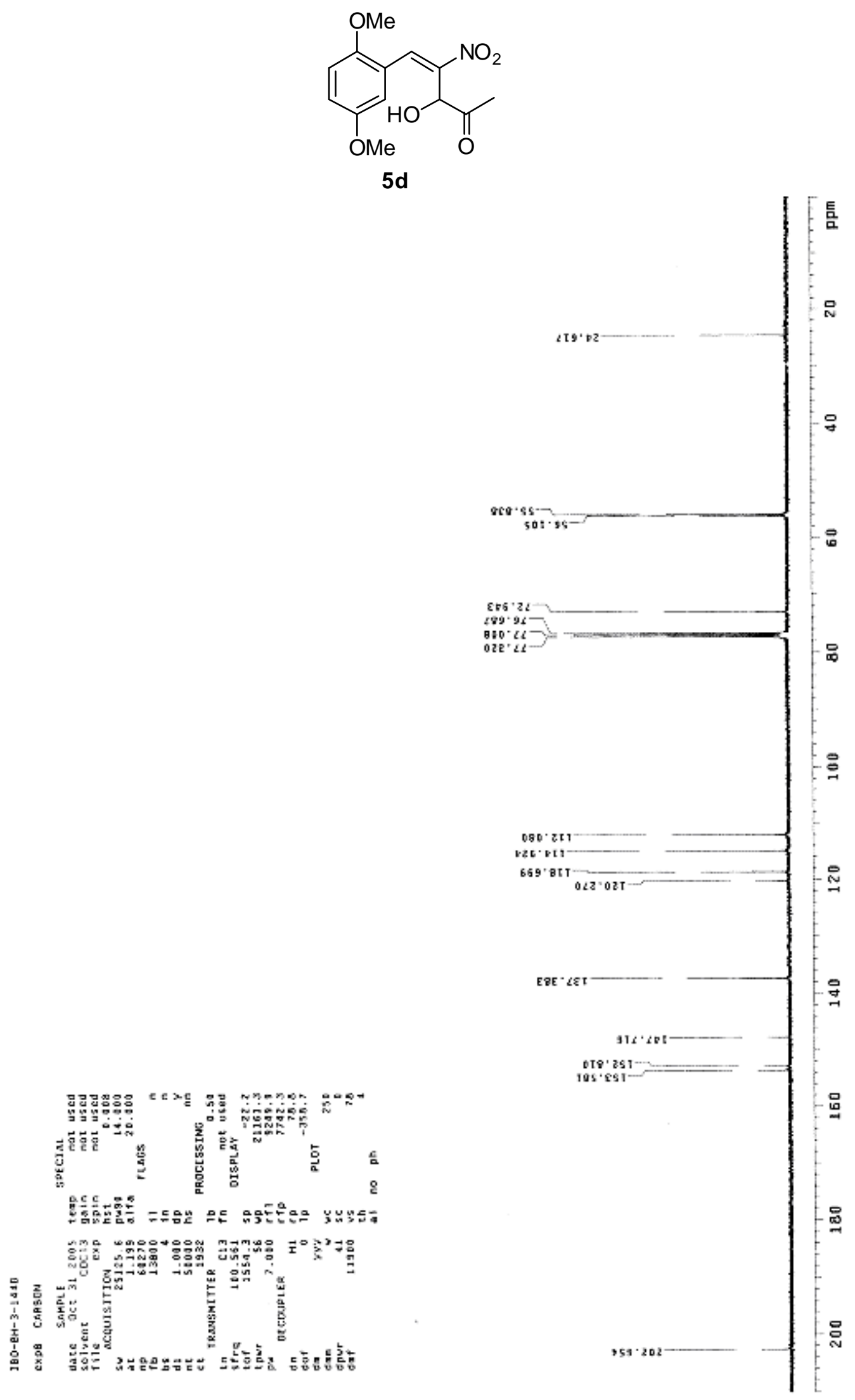

Figure $\mathbf{S 4 5} .{ }^{13} \mathrm{C}$ NMR Spectrum of $\mathbf{5 d}$ 


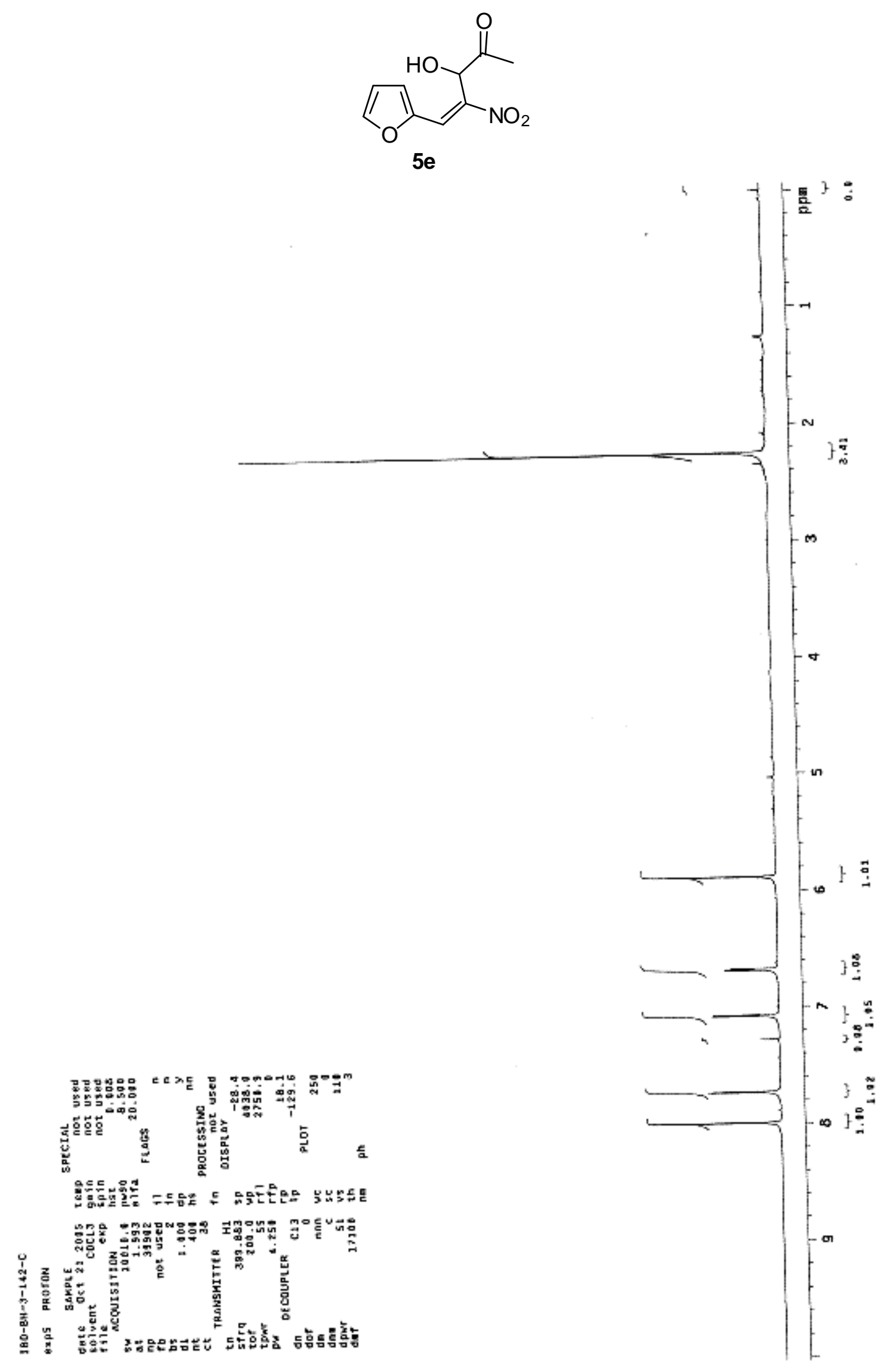

Figure S46. ${ }^{1}$ H NMR Spectrum of $\mathbf{5 e}$ 

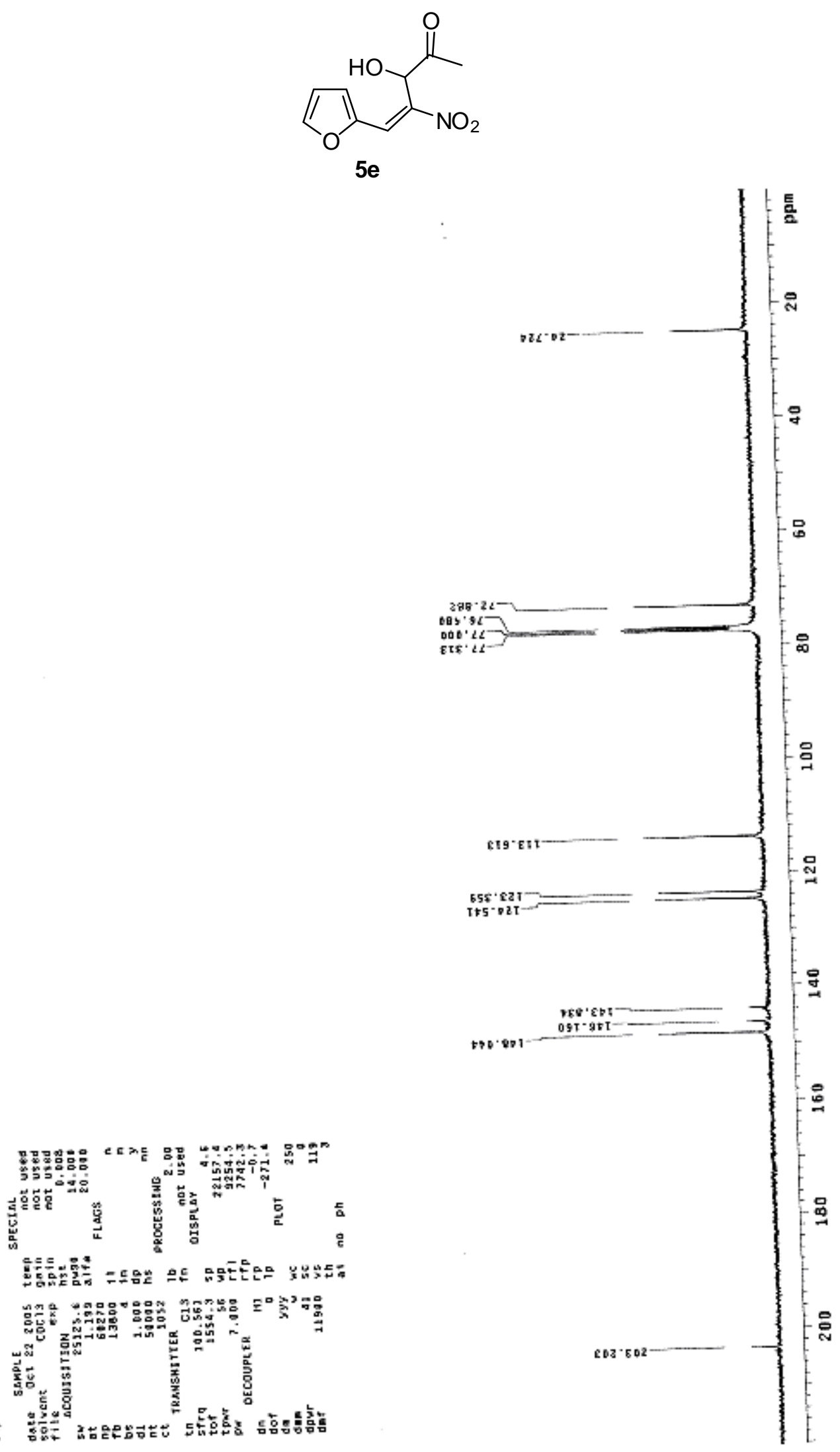

Figure S47. ${ }^{13} \mathrm{C}$ NMR Spectrum of $\mathbf{5 e}$ 


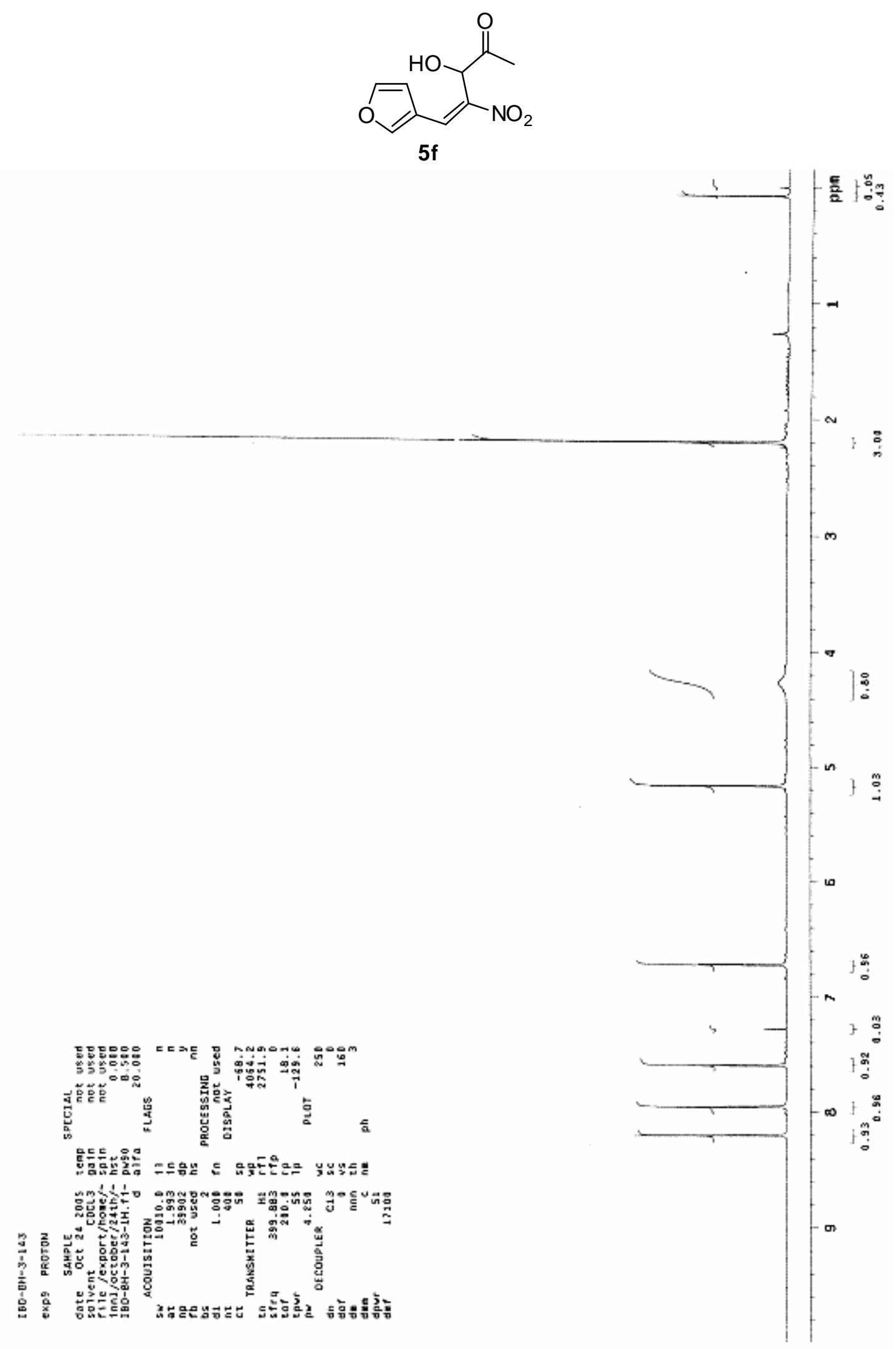

Figure S48. ${ }^{1} \mathrm{H}$ NMR Spectrum of $\mathbf{5 f}$ 


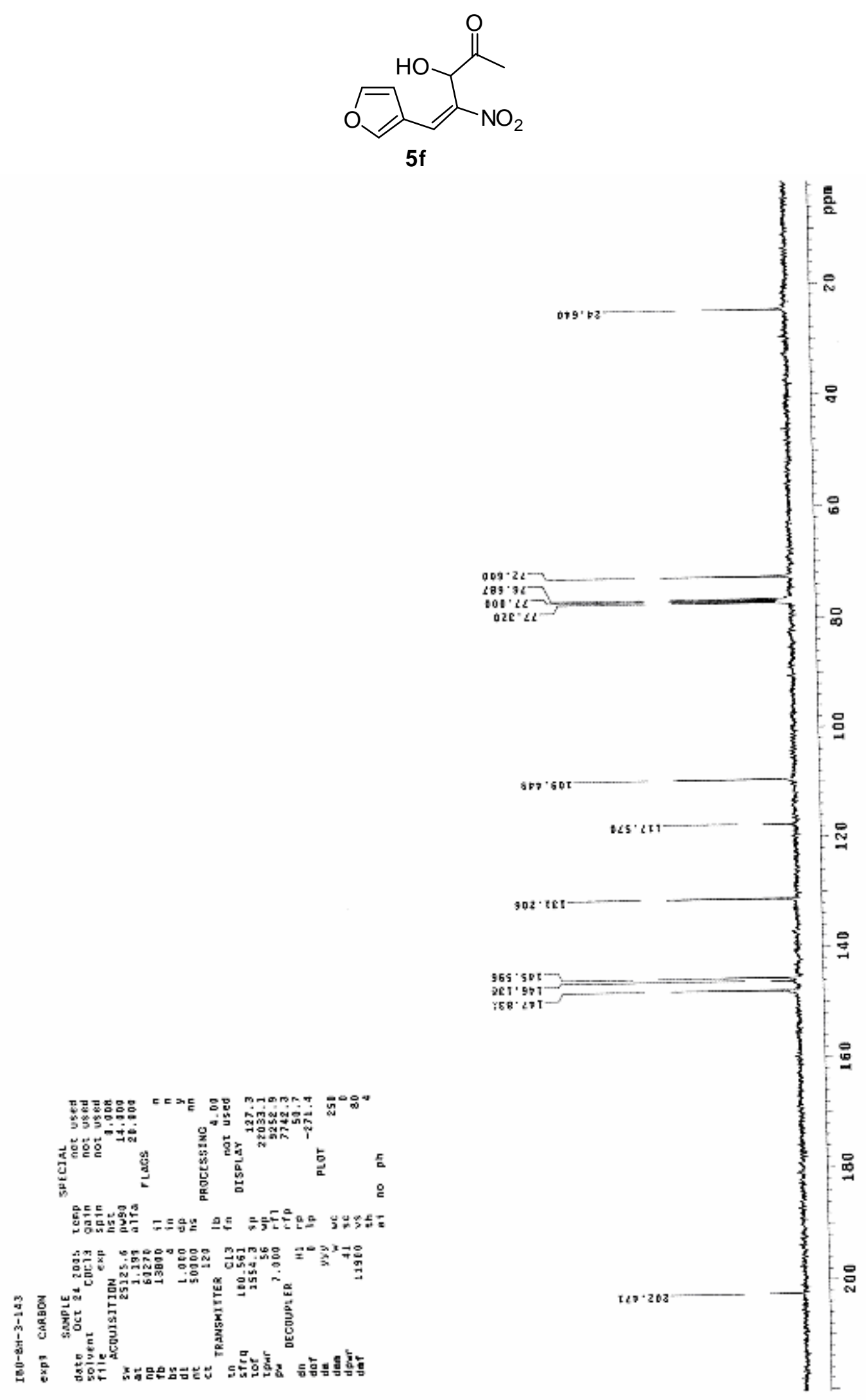

Figure S49. ${ }^{13} \mathrm{C}$ NMR Spectrum of $\mathbf{5 f}$ 


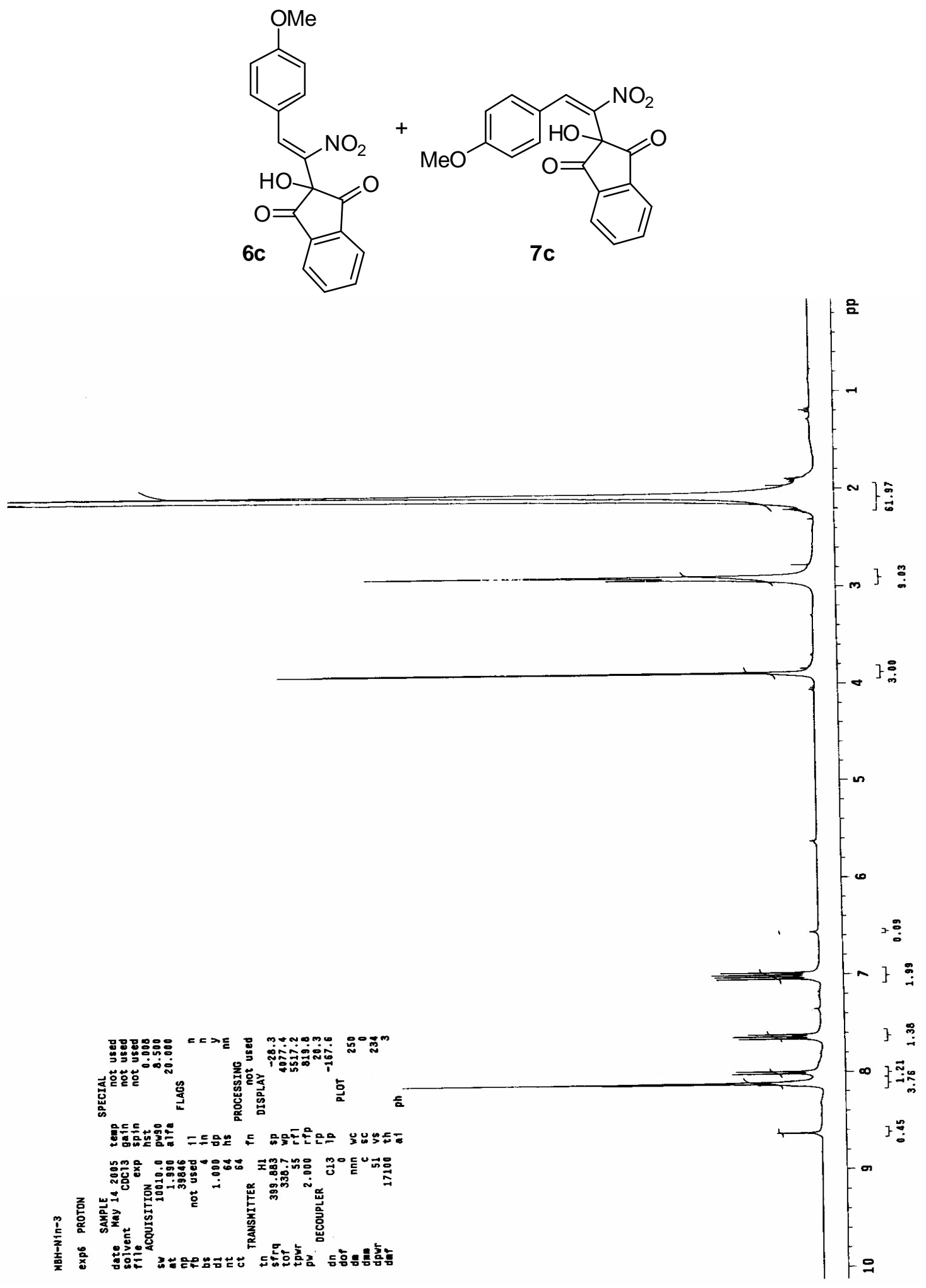

Figure S50. ${ }^{1} \mathrm{H}$ NMR Spectrum of $\mathbf{6 c}+\mathbf{7 c}$ 


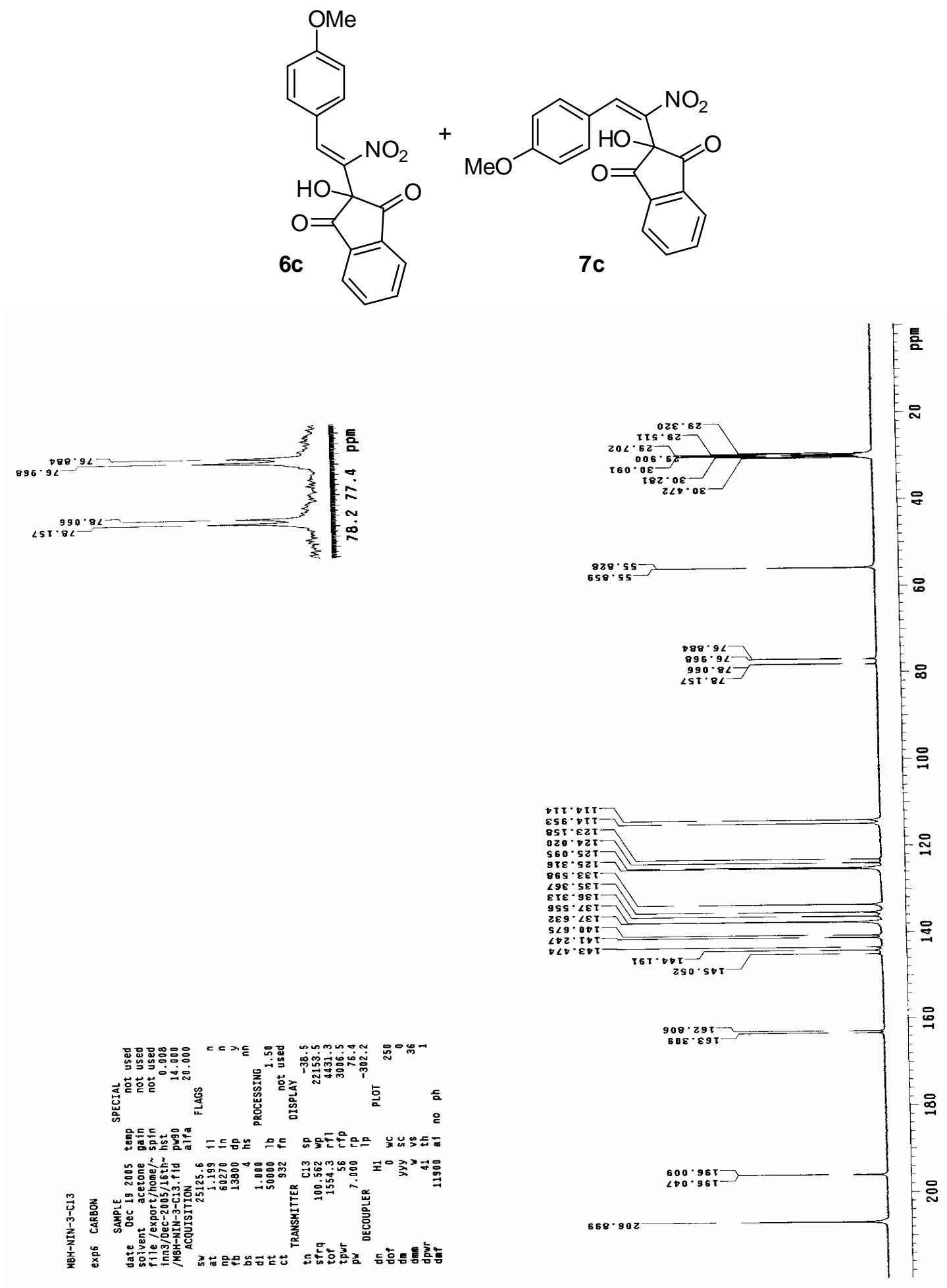

Figure S51. ${ }^{13} \mathrm{C}$ NMR Spectrum of $6 c+7 c$ 


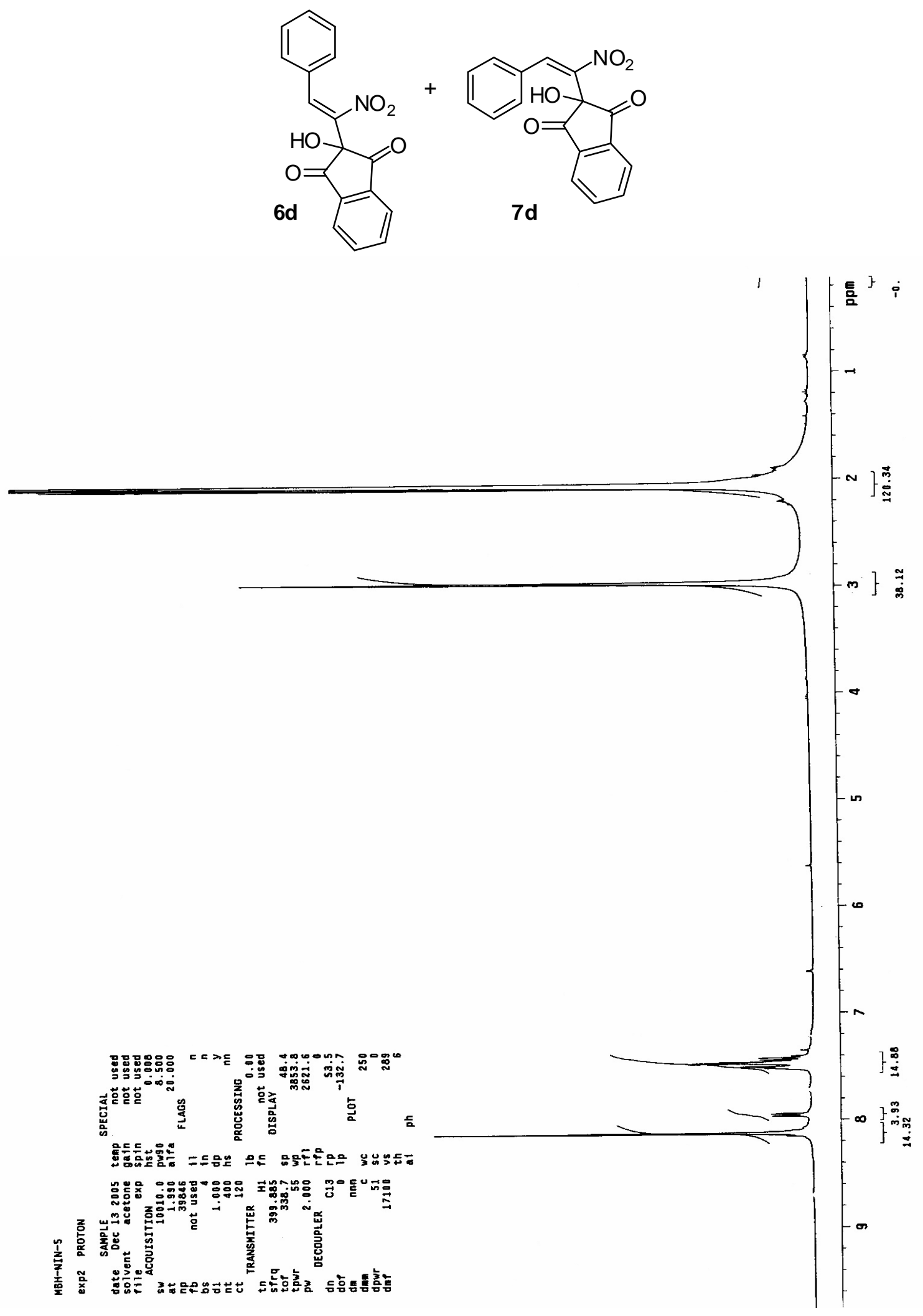

Figure S52. ${ }^{1}$ H NMR Spectrum of $6 \mathbf{d}+\mathbf{7 d}$ 

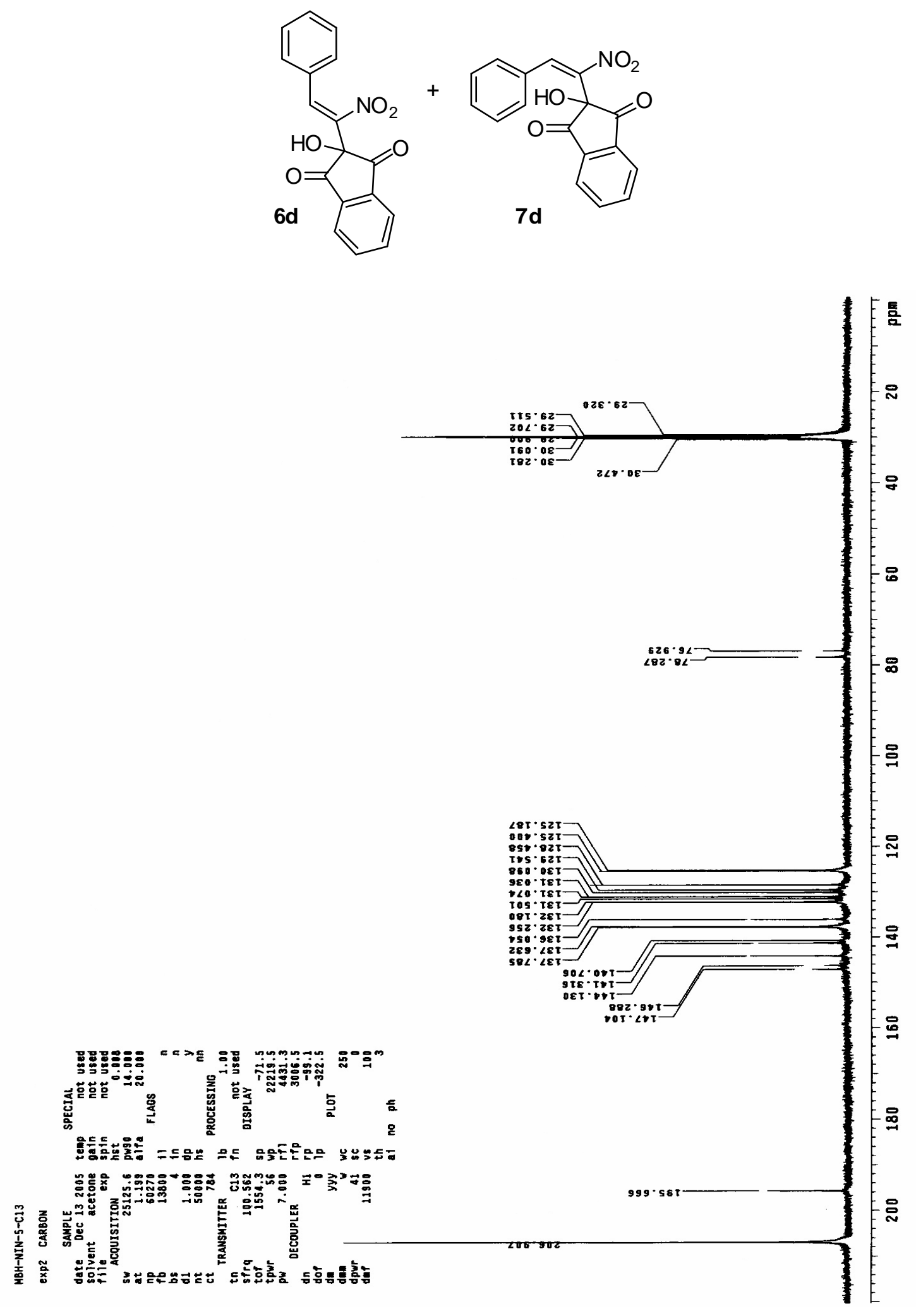

Figure S53. ${ }^{13} \mathrm{C}$ NMR Spectrum of $\mathbf{6 d}+\mathbf{7 d}$ 


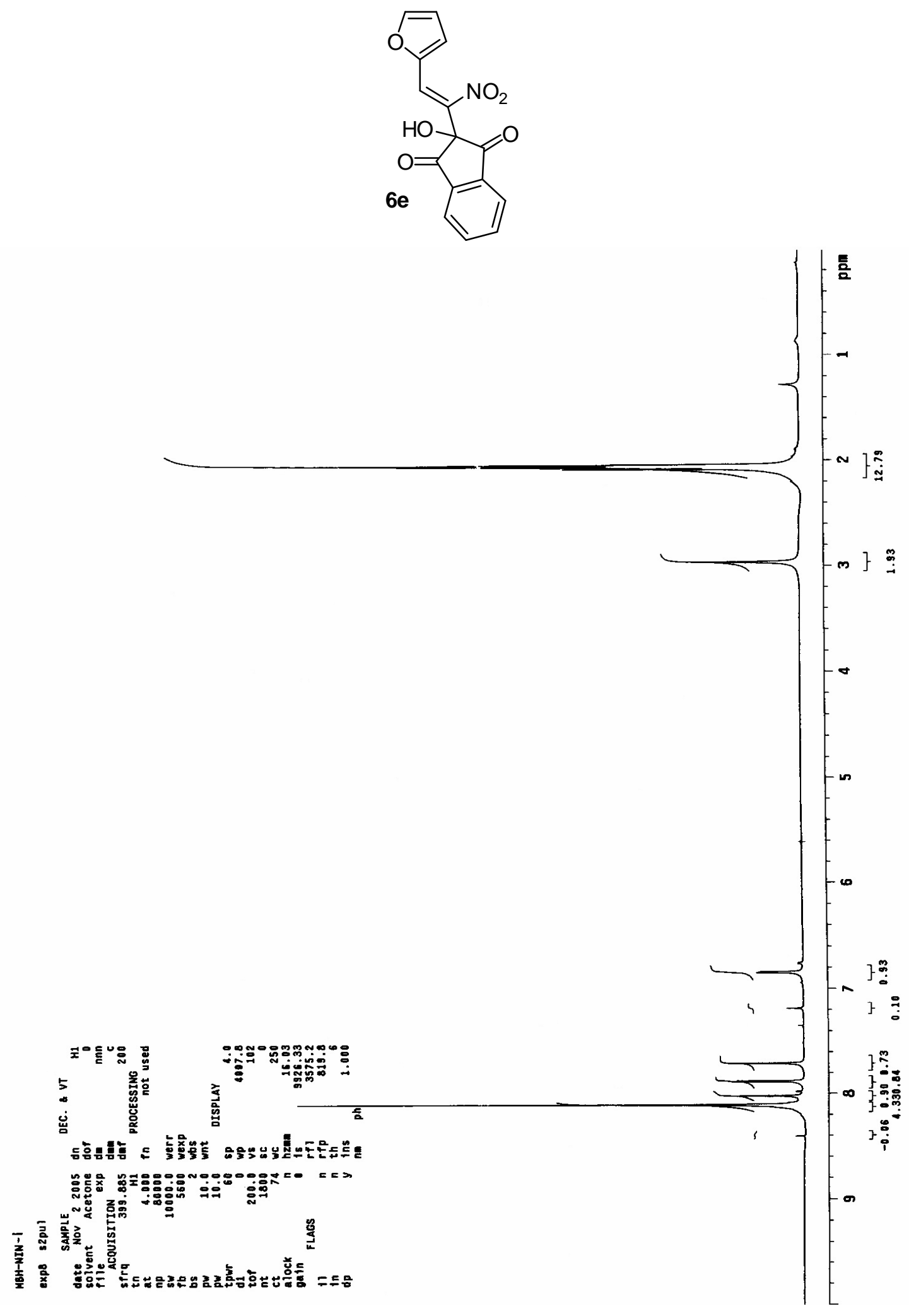

Figure S54. ${ }^{1}$ H NMR Spectrum of $\mathbf{6 e}$ 


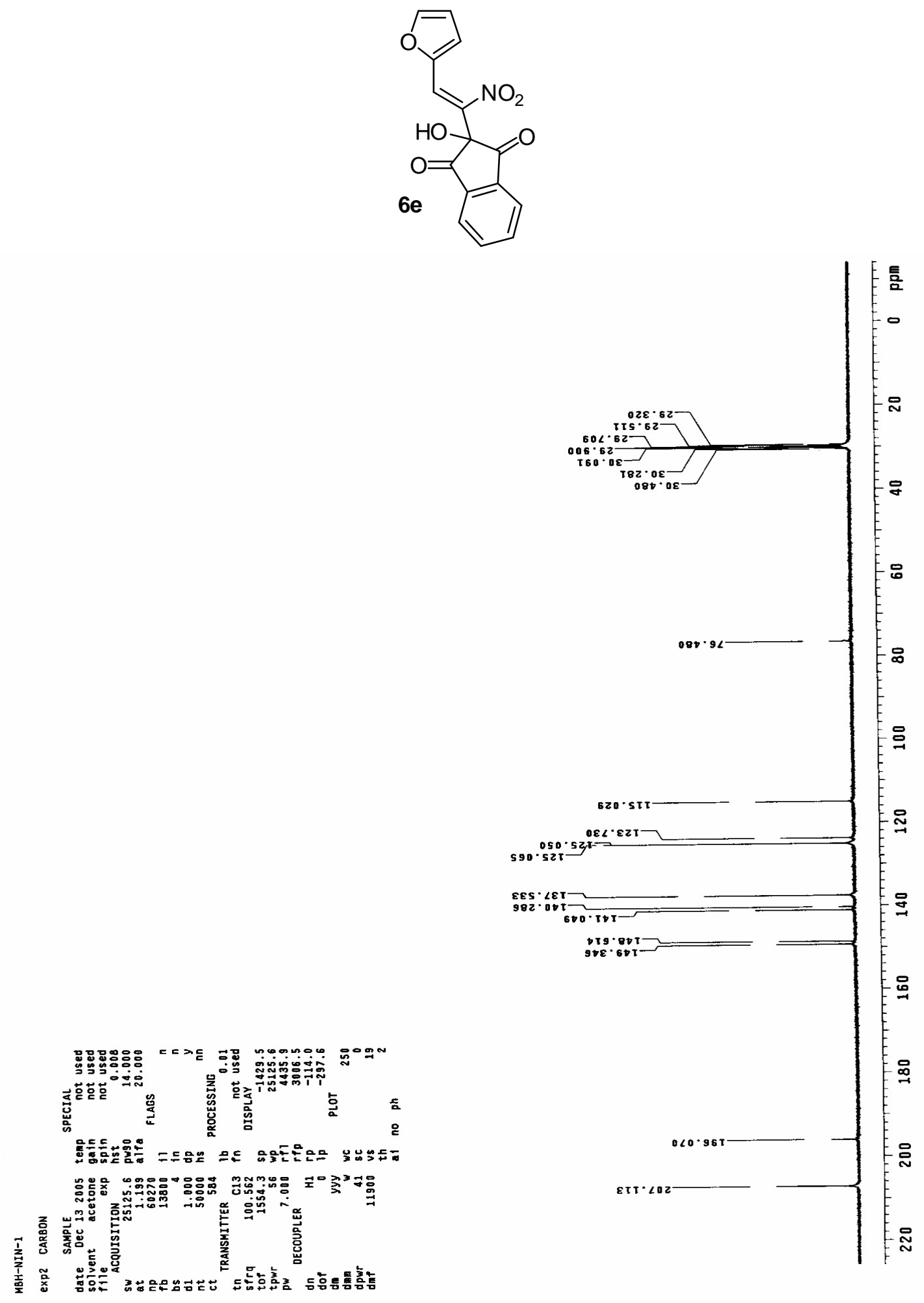

Figure S55. ${ }^{13} \mathrm{C}$ NMR Spectrum of $\mathbf{6 e}$ 


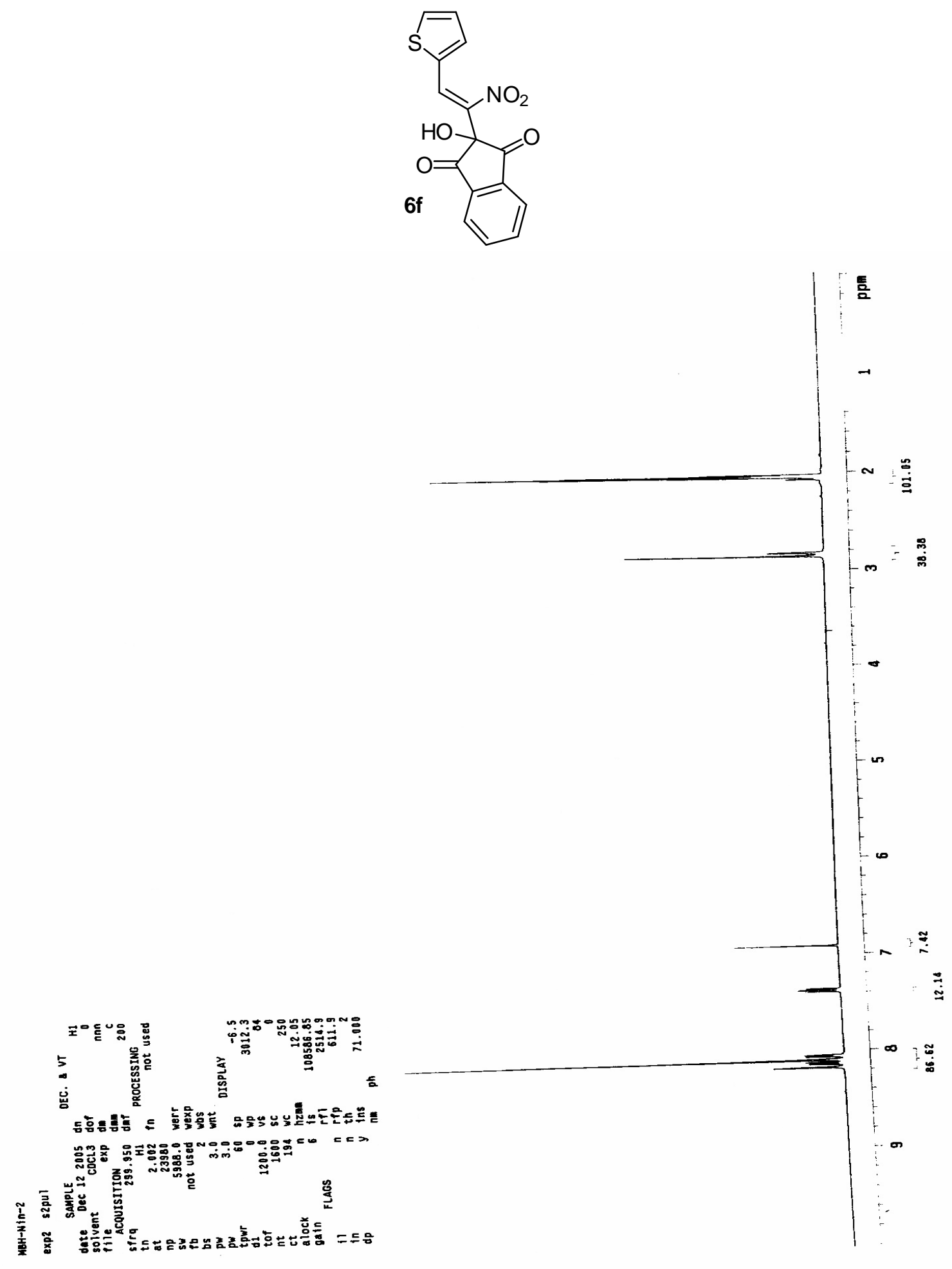

Figure S56. ${ }^{1} \mathrm{H}$ NMR Spectrum of $\mathbf{6 f}$ 


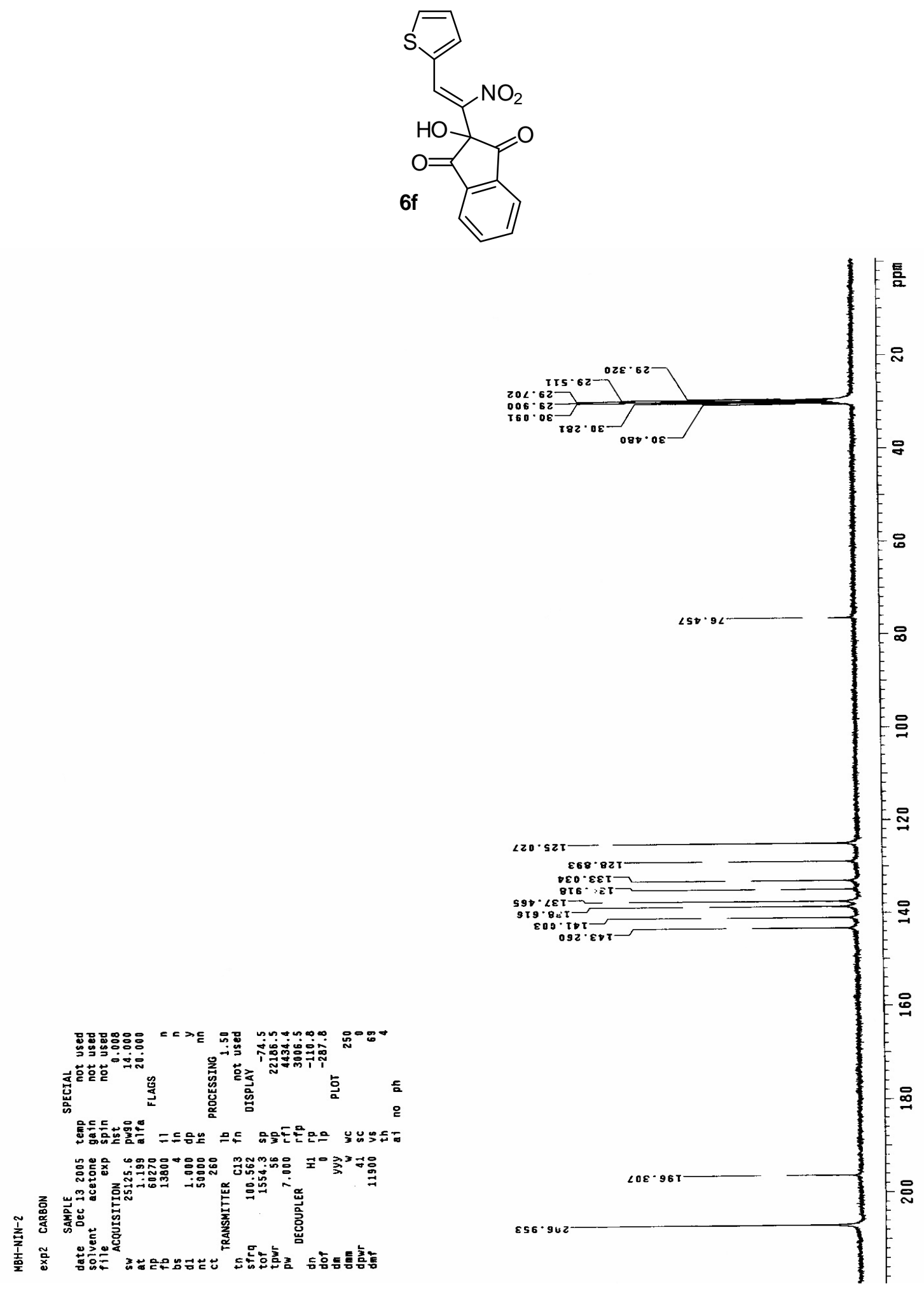

Figure S57. ${ }^{13} \mathrm{C}$ NMR Spectrum of $\mathbf{6 f}$ 


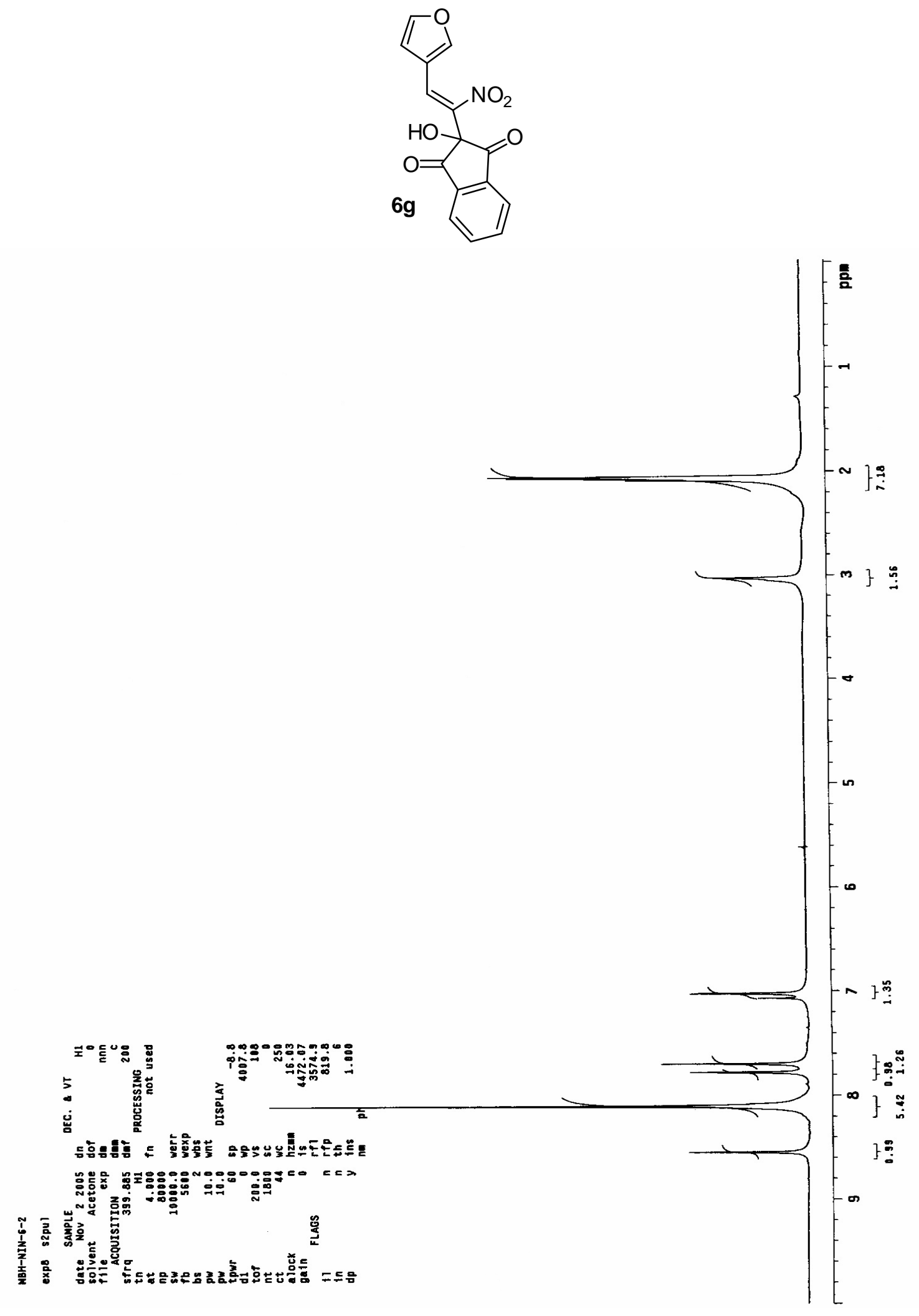

Figure S58. ${ }^{1} \mathrm{H}$ NMR Spectrum of $\mathbf{6 g}$ 


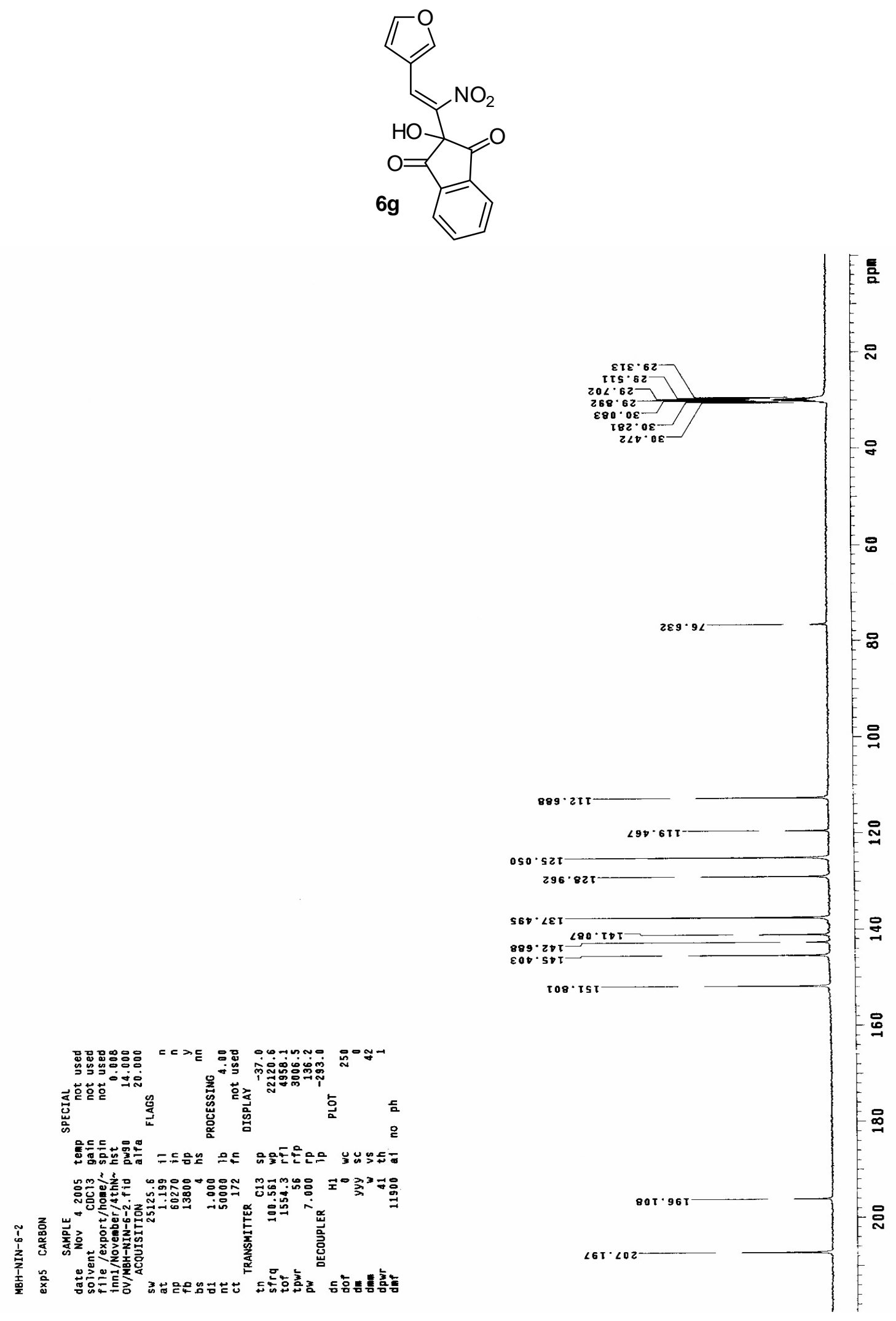

Figure S59. ${ }^{13} \mathrm{C}$ NMR Spectrum of $\mathbf{6 g}$ 


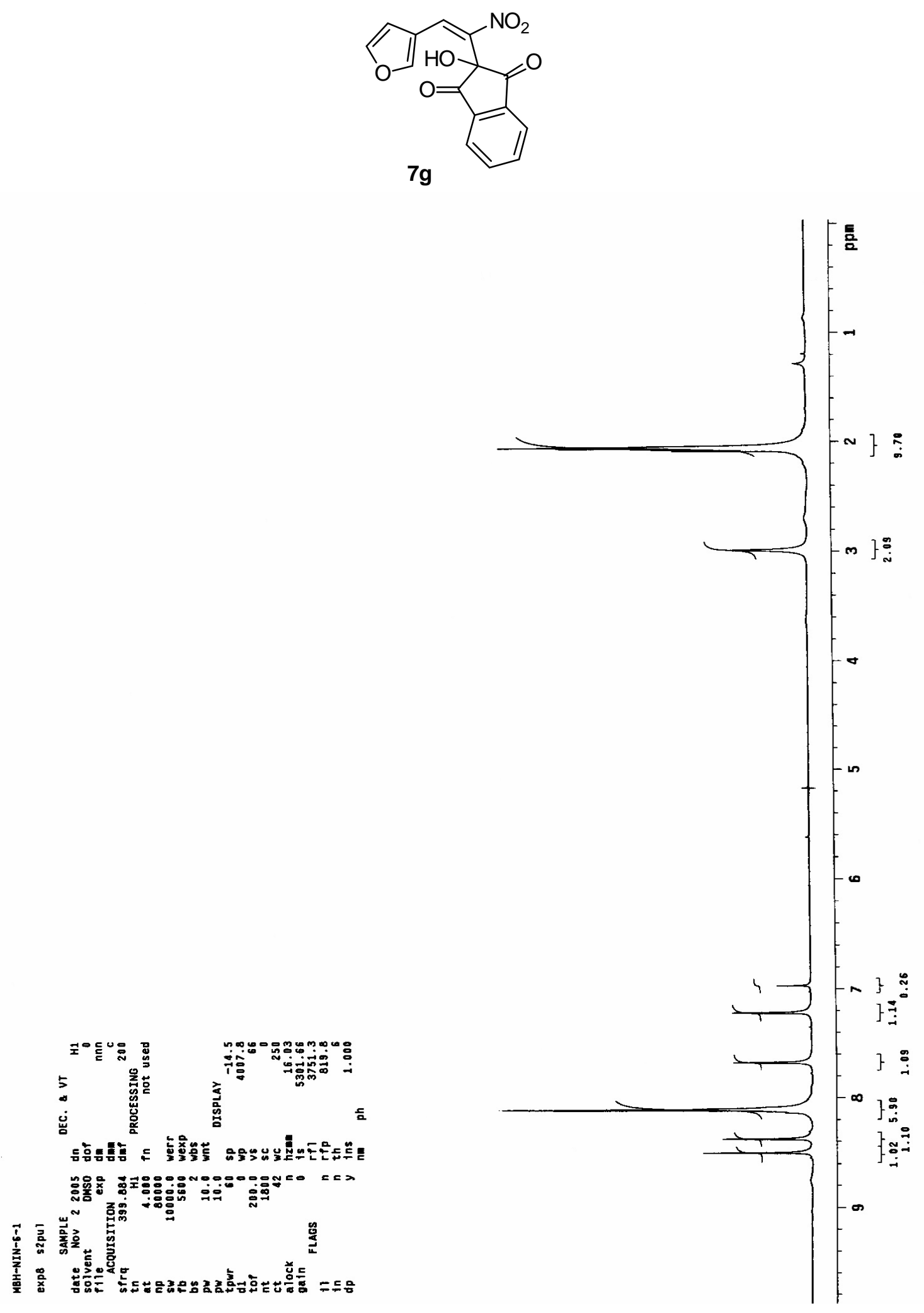

Figure S60. ${ }^{1} \mathrm{H}$ NMR Spectrum of $\mathbf{7 g}$ 

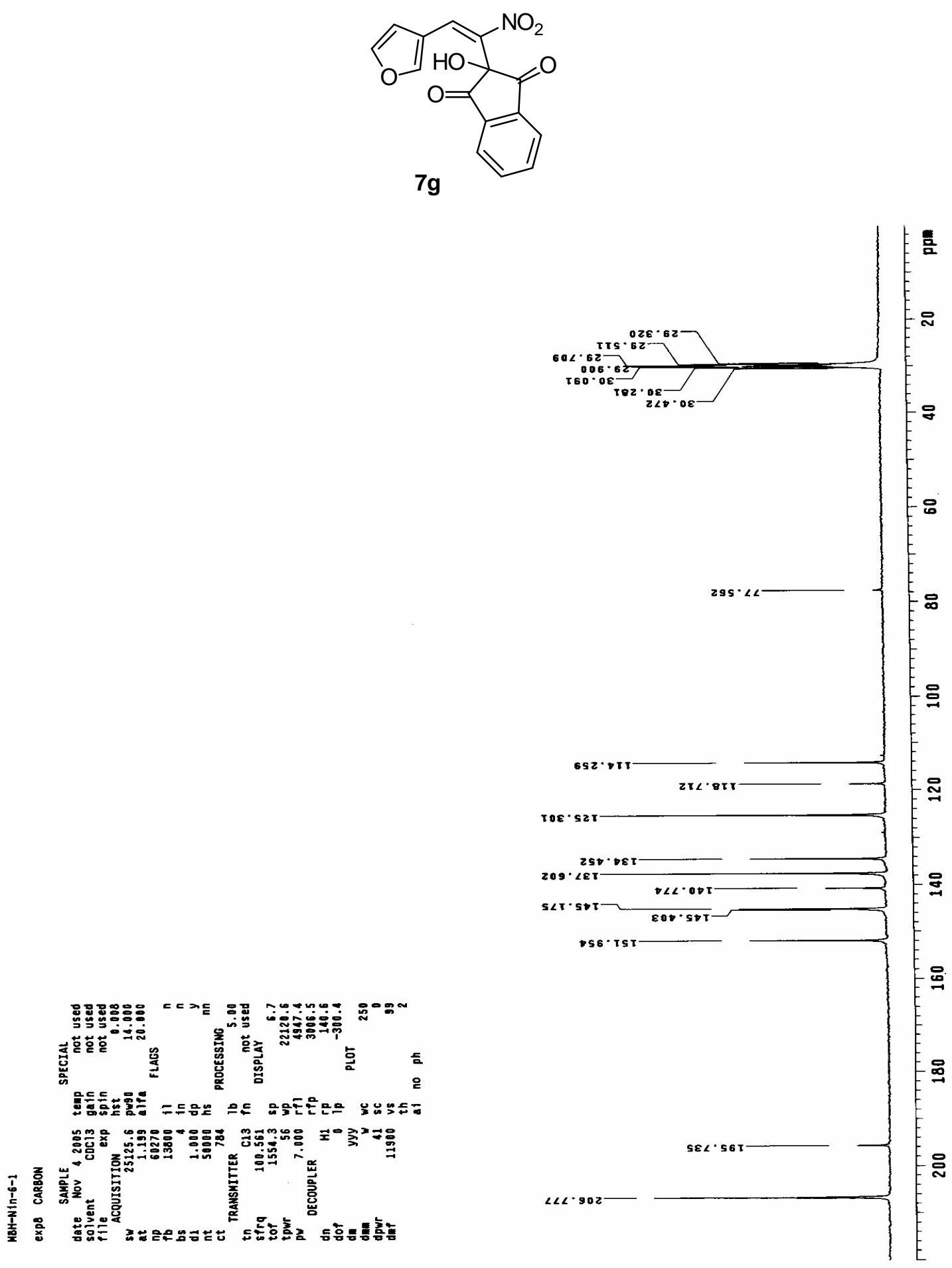

Figure S61. ${ }^{13} \mathrm{C}$ NMR Spectrum of $\mathbf{7 g}$ 